THE STEPS IN THE DEVELOPMENT OF AN ATMOSPHERIC VORTICITY METER

by

Thomas W. Singleton

B. S., United States Naval Academy (1993)

Submitted to the

\begin{tabular}{|c|}
\hline $\begin{array}{c}\text { MARINE } \\
\text { BIOLOGICAL } \\
\text { LABORATORY }\end{array}$ \\
\hline LIBRARY \\
\hline $\begin{array}{c}\text { WOOOS MOLE, KASSS. } \\
\text { W. H. O. I. }\end{array}$ \\
\hline
\end{tabular}

Massachusetts Institute of Technology/ Woods Hole Oceanographic.Inst
Joint Program in Oceanography and Oceanographic Engineering in partial fulfillment of the requirements for the degree of

Master of Science in Oceanographic Engineering at the

Massachusetts Institute of Technology and the

Woods Hole Oceanographic Institution

September 1995

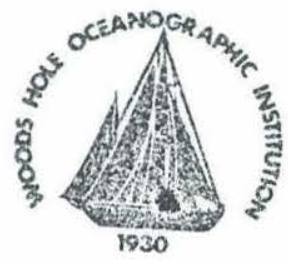

(c)1995 Thomas W. Singleton. All rights reserved.

The author hereby grants to MIT, WHOI and the U. S. Government permission to reproduce and to distribute copies of this thesis document in whole or jy part.

Signature of Author

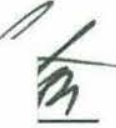

Joint Program in Oceanographi£ Engineering, Massachusetts Institute of Technology / Woods Hole Oceanographic Institution

Certified by

Albert J. Williams, III

Senior Scientist, Woods Hole Oceanographic Institution $\wedge$ A Thesis Supervisor

Certified by James B. Edson Certified by $\sim 2$ Thesis Supervisor ArthurB. Baggeroer Ford Professor of Engineering, Massachusetts Institute of Technology Accepted by SThesis Supervisor

Arthur B. Baggeroer Chairman, Joint Committee for Oceanographic Engineering, Massachusetts Institute of Technology / Woods Hole Oceanographic Institution 


\title{
THE STEPS IN THE DEVELOPMENT OF AN ATMOSPHERIC VORTICITY METER
}

by

\author{
Thomas Wade Singleton
}

Submitted to the Department of Ocean Engineering at MIT and the Department of Applied Ocean Physics and Engineering at WHOI in partial fulfillment of the requirements for the degree of Master of Science in Oceanographic Engineering.

\section{ABSTRACT}

This thesis describes the steps necessary to develop an acoustic vorticity meter for the atmosphere. The analysis is based on Benthic Acoustic Stress Sensor (BASS) technology that is currently used for similar acoustic measurements in the ocean. Compared to sonic anemometer measurements, the BASS measurements of velocity are not only made in a different fluid but in a different way. Due to these differences, the physical make up of BASS needed to be altered, and the validity of the measurement technique had to be explored.

The alterations to the BASS hardware occurred for several reasons. Because attenuation of sound is much higher in air than in water for the same frequencies, it was necessary to change the transducers. The generally faster and unidirectional mean flows that are present in the air encourage open measurement volumes which the BASS vorticity meters do not have. The difference in group speed of sound is different for water and air, and this forced a change to the timing and burst generation board of the BASS vorticity meter.

The measurement technique used by the BASS instrumentation is validated by the error analysis in the text. Because the BASS instrumentation actually provides a time difference, the equation used by the BASS instrumentation to compute velocity was assumed throughout the error analysis. The error analysis shows that the combination of BASS measurement techniques with a temperature sensor will provide errors that are less than $2 \%$ of the velocity.

The types of measurements that an atmospheric vorticity meter would provide to a researcher are described in the text to show the meter's potential. If deployed on a buoy, a vorticity meter could measure shearing of the wind close to the surface of the waves. If deployed at heights much greater than its path lengths, an atmospheric vorticity meter could provide three-dimensional vorticity measurements which would provide a unique measurement of a fundamental characteristic of turbulent flows.

Thesis Supervisor: Albert J. Williams, III

Title: Senior Scientist, Woods Hole Oceanographic Institution

Thesis Supervisor: James B. Edson

Title: Associate Scientist, Woods Hole Oceanographic Institution

Thesis Supervisor: Arthur B. Baggeroer

Title: Ford Professor of Engineering, Massachusetts Institute of Technology 


\section{ACKNOWLEDGMENTS}

The author would like to thank many people for their assistance in making this thesis possible. First, I would like to thank Dr. James Edson for his diligent efforts to convert my thesis into a worthy scientific document. I would like to thank Alan Hinton for the hours (and hours) that he has spent to make this project fruitful. I would like to thank Dr. A.J. 'Sandy' Williams for his efforts to help me understand the BASS instrumentation. I would like to thank Dr. Arthur Baggeroer for his efforts to keep my education at MIT and WHOI on the right path. I would like to thank Dick Payne for the use of his calibrations and instrumentation for the windtunnel. I would like to thank Robin Singer for her assistance in developing a work-around of the C Library/ Basic communication difficulties. I would like to thank Dr. Eugene Terray and Don Peters for their assistance in determining useful designs for atmospheric measurements of vorticity. I would like to thank Karlen Wannop for allowing me to have almost continuous use of her available instrumentation. I would like to thank Fred Thwaites for making a copy of his doctoral thesis on the BASS vorticity meter available to me. Finally, I would like to thank the Keck Grant that made all of the research possible. 


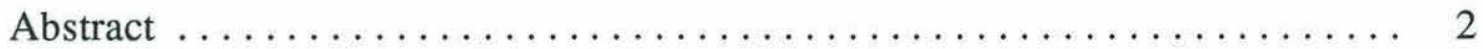

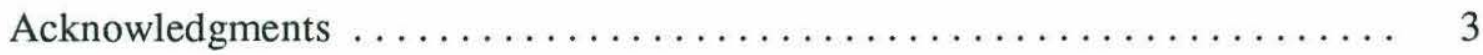

List of Figures and Tables $\ldots \ldots \ldots \ldots \ldots \ldots \ldots \ldots \ldots \ldots \ldots \ldots \ldots \ldots \ldots \ldots \ldots \ldots \ldots \ldots$

$\begin{array}{ll}\text { Chapter 1. Introduction } & 8\end{array}$

Chapter 2. Atmospheric Vorticity and Circulation 11

Chapter 3. Modification of Bass 14

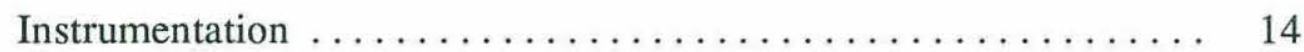

Transducer Design . . . . . . . . . . . . . 21

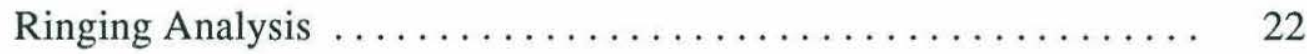

Timing and Burst Generation $\ldots \ldots \ldots \ldots \ldots \ldots \ldots \ldots \ldots \ldots \ldots \ldots$

Chapter 4. Error Analysis

Errors from Higher Order Terms $\ldots \ldots \ldots \ldots \ldots \ldots \ldots \ldots \ldots \ldots$

Errors due to Virtual Temperature Changes . . . . . . . . . 37

Errors due to Fluctuating Temperature $\ldots \ldots \ldots \ldots \ldots \ldots \ldots \ldots$

Errors in the Measured Time Difference .............. 40

$\begin{array}{ll}\text { Chapter 5. Windtunnel } & 41\end{array}$

Chapter 6. Results and Conclusions $\quad 44$

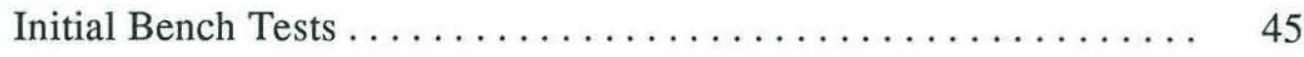

Future Tunnel and Field Tests $\ldots \ldots \ldots \ldots \ldots \ldots \ldots \ldots \ldots \ldots$

Bibliography $\quad 50$

Appendix A $\quad 52$

$\begin{array}{ll}\text { Appendix B } & 64\end{array}$ 
$\begin{array}{ll}\text { Appendix C } & 67\end{array}$

$\begin{array}{ll}\text { Appendix D } & 83\end{array}$

$\begin{array}{lr}\text { Appendix E } & 92\end{array}$ 
Page Number

Fig. 3-1. Picture of open measurement volume of an anemometer $\ldots \ldots \ldots \ldots \ldots \ldots$

Fig. 3-2. BASS instrument and close view of four transducers per pod $\ldots \ldots \ldots \ldots \ldots .16$

Fig. 3-3. A possible atmospheric design .......................... 17

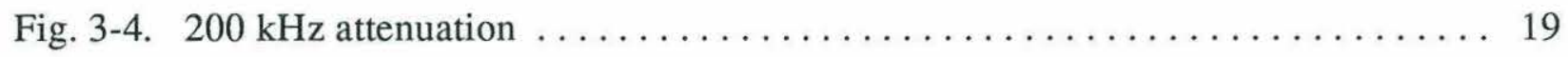

Fig. 3-5. $1.75 \mathrm{MHz}$ attenuation ................................ 19

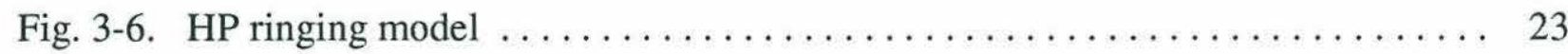

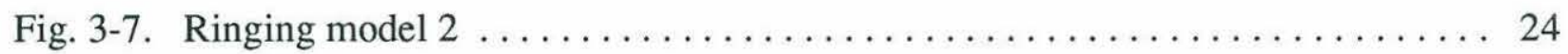

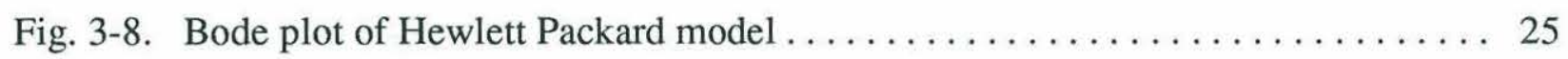

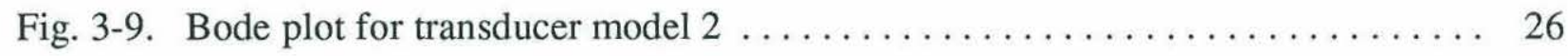

Fig. 3-10. Assumed input to an E-188/220 transducer $\ldots \ldots \ldots \ldots \ldots \ldots \ldots \ldots \ldots \ldots \ldots \ldots$

Fig. 3-11. Hypothetical output of transducer using assumed input . . . . . . . . . . 27

Fig. 3-12. Circuit used to generate a short burst of $220 \mathrm{kHz}$ waves $\ldots \ldots \ldots \ldots \ldots \ldots .29$

Fig. 3-13. Transmitted signal through an E-188/220 .................... 30

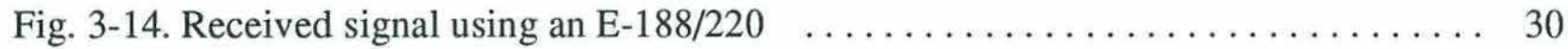

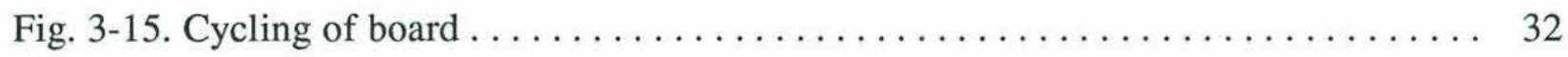

Fig. 3-16. Alterations of timing and burst generation counters $\ldots \ldots \ldots \ldots \ldots \ldots \ldots \ldots$

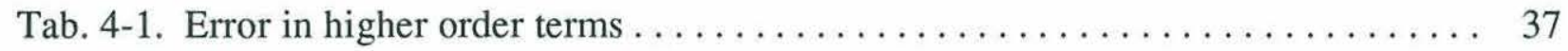

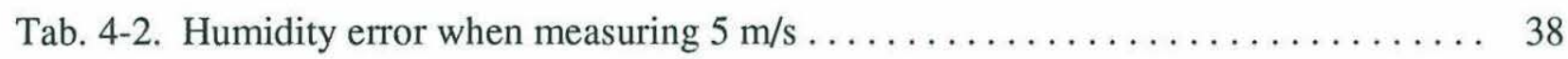

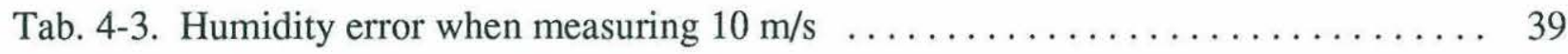

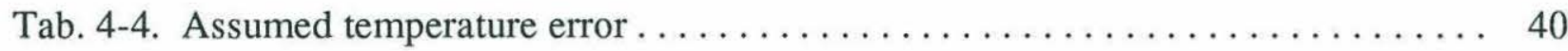

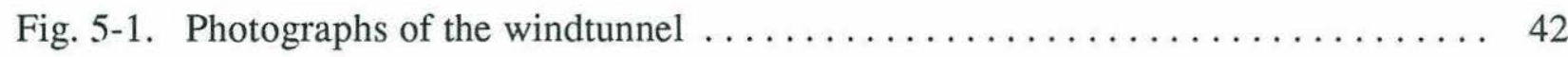

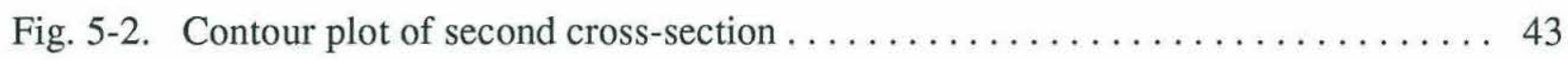

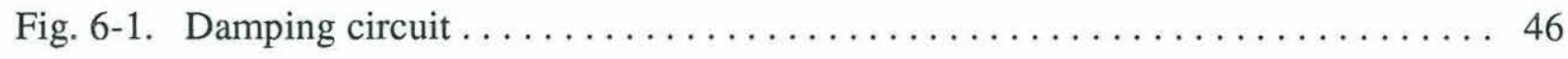

Fig. A-1. Model using Thevinin equivalent circuit for receiving transducer $\ldots \ldots \ldots \ldots \ldots 53$ 
Fig. A-2. Direct measurements of transducer frequency response from HP4195A $\ldots \ldots \ldots .56$

Fig. A-3. Response of the transducer to an input signal using the direct measurements in A-2 56

Fig. B-1. Left half of timing and burst generator schematic $\ldots \ldots \ldots \ldots \ldots \ldots \ldots \ldots, 65$

Fig. B-2. Right half of timing and burst generator schematic ................ 66

Fig. E-1. Massa Products' specifications for E-188/220 .................. 93 


\section{CHAPTER 1}

\section{INTRODUCTION}

The turbulent motions in the oceanic and atmospheric boundary layers are primarily responsible for the transport of momentum, heat, gases, and mass toward or away from the interface. If one wishes to study the turbulent processes that occur on either side of these interfaces, fast response instrumentation is required. Over the past several decades, sonic anemometry has advanced to the point that sonic anemometers are routinely used to measure turbulent fluctuations in the atmosphere. Several types of sonic anemometers determine the instantaneous wind velocity by measuring the time of flight of acoustic pulses in air (Schotanus et al, 1983). Sonic anemometers record the times of flight of separate acoustic pulses in air in opposite directions along each acoustic path. These measurements are made consecutively. The high frequency of measurement allows the use of sonic anemometers for measurements of turbulent motions in the atmosphere. When these measurements are taken near the air-sea interface, we can gain insight into the exchange between the two fluids.

The BASS, Benthic Acoustic Stress Sensor, velocity meter is frequently used to fulfill a similar role in the oceans to that of sonic anemometers in the air. The BASS was originally designed to operate in water near a fluid-solid interface while sonic anemometers operate in air near a fluid-fluid or fluid-solid interface. The BASS instrumentation and structure have recently been modified to create a family of three axis acoustic vorticity meters for use in water. These vorticity meters have been deployed to measure the shear in the upper ocean boundary layer, internal waves in the thermocline, and turbulence in the bottom boundary layer (Thwaites et al., 1995).

The measurement of vorticity as a variable would greatly assist atmospheric turbulence research. Therefore, a group of air-sea interaction researchers at Woods Hole Oceanographic Institution (WHOI) decided that it would be extremely useful to transfer this acoustic vorticity technology to the atmosphere. An atmospheric vorticity meter could be used to make vorticity measurements at the bottom of the atmosphere that are similar in nature to those made by its aquatic counterpart. It could also be used to 
measure the shear near the surface over ocean waves or over land.

The BASS measurements are different from the sonic measurements in several important ways. The BASS uses transducers that are designed to make measurements in the ocean and not in the atmosphere. The BASS timing circuitry produces acoustic pulses that travel in opposite directions along an acoustic path and occur concurrently rather than consecutively. Therefore, the BASS measurements along each path are time differences rather than two recorded times of flight per path. Due to these differences in the measurement technique, the transfer of a three axis acoustic vorticity measurement to the atmosphere will require some modifications and additions.

In order to operate in the marine boundary layer, an atmospheric vorticity meter must be rugged and reliable enough to withstand the harsh conditions encountered over the sea. Another objective in the development of the atmospheric vorticity meter is to give it a large dynamic range. With a large dynamic range, it will be possible to use the vorticity meter in a wide spectrum of conditions, which would lead to broader use of the instrument. It must also be portable with path lengths of about 0.15 meters in length. With these built in characteristics, the atmospheric vorticity meter should be adequate for shipboard or buoy use. At sea use is the main target for the final stages of development because less is known about boundary layers over the oceans than over land. This is particularly true in the layer very close to the sea surface where wave induced motions complicate the flow field.

The motivation for measuring vorticity is that in many ways it is the superior estimate of the turbulent kinetic energy in comparison to an anemometer's covariance measurements. For example, on days with strong winds, shear is the largest contributor to turbulent kinetic energy near interfaces. An acoustic vorticity meter is able to give a direct measurement of the instantaneous shear. An acoustic anemometer is not capable of providing this measurement.

The sections which follow contain a description of the efforts to modify the BASS vorticity meters for atmospheric measurements. Chapter 2 describes aspects of vorticity and gives examples of vorticity's relevance in turbulent studies. Chapter 3 describes the physical modifications to which the BASS instrumentation was subjected during its 
conversion for atmospheric applications. Chapter 4 describes some of the errors that will be inherent in the initial atmospheric design. Chapter 5 describes the calibrated windtunnel that will be used to determine the accuracy of BASS instrumentation in air. Chapter 6 contains the conclusion. In the next chapter, I begin my discussion with a description of the quantity being measured, i.e., vorticity. 


\section{CHAPTER 2}

\section{ATMOSPHERIC VORTICITY AND CIRCULATION}

Atmospheric vorticity can be described in several ways, but it can be visualized as a vector field which provides microscopic measurements of rotation at every point in the atmosphere (Holton, 1979). A vortex can be thought of as a three-dimensional eddy with a principal axis. These eddies are the irregular, or turbulent, motion responsible for the turbulent transport of momentum, heat, gases, and mass. As an example of the generation of eddies, a shearing of the mean wind will tend to produce a vortex with a principal axis that is aligned with the mean strain rate (Tennekes and Lumley, 1980). These eddies produce effects that are visible to the human eye, such as catspaws on the water. The wavelike motions in wheat fields also mark the passing of eddies. These examples describe eddies that are associated with forced convection. Forced convection is a situation in which shear production of turbulent kinetic energy exceeds buoyant production. Forced convection typically dominates on windy days with little surface heating.

The scintillation that is visible over deserts is another example of eddy generation. However, this form of eddy generation is associated with free convection. Free convection means that buoyant production of turbulent kinetic energy exceeds the shear production. For example, free convection occurs when there are light winds with strong surface heating. Free convection results in the production of buoyant plumes of air and associated vertical, turbulent motion.

Formally, vorticity is defined as the curl of the velocity vector, which is a measure of angular rotation about a local position. This leads to the concept of length scales that affect the local position. The maximum length scales that effect the vorticity relate to the largest eddies that are important to the local position. For example, in the atmospheric surface layer the largest eddies logically scale with the height above the surface layer.

Mathematically, the local position collapses to a point as the spatial interval lengths of velocity measurements approach zero; i.e., the formal definition of vorticity relates it to the microscopic rotation about a point in space. In practice, velocity measurements are 
separated by some distance, and an average vorticity is measured. This area averaged vorticity is closely related to the concept of circulation, which is the measure of the macroscopic circulation over some area (Holton, 1979). The circulation over a macroscopic path is represented by Stokes Theorem:

$$
C=\oint V \cdot d \boldsymbol{l}=\iint(\nabla \times V) \cdot d A
$$

where $C$ is the calculated circulation, $V$ is the measured velocity, $d l$ is the acoustic path, and $d A$ is the area enclosed by the acoustic path. This circulation information is used to estimate the area average vorticity over the macroscopic area by using the following relationships:

$$
\begin{gathered}
\xi=\lim _{A \rightarrow 0} \frac{C}{A}=\nabla \times V \\
\bar{\xi}=\frac{C}{A}
\end{gathered}
$$

where $\xi$ is the vorticity, $\bar{\xi}$ is the area average vorticity, and $A$ is the area enclosed by the sonic paths of the vorticity meter.

Since time-averaged, area-averaged, horizontal vorticity equals time-averaged, areaaveraged, vertical shear (Thwaites, 1995), it is useful to determine an expected vertical shear to determine the accuracy requirements of a vorticity meter. If a neutral boundary layer is assumed, the shearing of the mean wind can be modeled by:

$$
\frac{\partial u}{\partial z}=\frac{u_{\star}}{\kappa z}
$$

where $u_{\star}$ is the friction velocity, $\kappa$ is von Karman's constant, and $\mathrm{z}$ is the height above 
the ground. If a reasonable friction velocity of $0.20 \mathrm{~m} / \mathrm{s}$ were assumed at a measurement height of $1.00 \mathrm{~m}$, a $0.15 \mathrm{~m}$ path length would require a velocity measurement error that is at least an order of magnitude less than the $7.5 \mathrm{~cm} / \mathrm{s}$ velocity shear for the measurements to be useful. If this condition could be met, it would be possible to recover the shearing of the wind in the vertical from the vorticity measurements. 


\section{CHAPTER 3}

\section{MODIFICATION OF BASS}

The Benthic Acoustic Stress Sensor, BASS, was designed for use in the water, such that the BASS instrumentation is not precisely compatible with use in the atmosphere. Basic modifications to transducer design, timing and burst generation, and physical shape of the sensor are necessary to convert a BASS vorticity sensor to atmospheric use. These modifications are necessary because of the difference in how air responds to high frequency sound waves. Additionally, the effects of flow distortion by the vorticity meter are expected to be different in air versus water.

\section{INSTRUMENTATION}

A common instrument used for atmospheric boundary layer research is the acoustic anemometer. A singular velocity measurement along one acoustic path is similar in nature for an acoustic anemometer or vorticity meter, such that an acoustic anemometer suffers from the same problems associated with high signal loss through air as a vorticity meter. Therefore, it was useful to look at an anemometer during the development of our vorticity meter. The advantages that are found in the anemometer should be incorporated into the design of the final atmospheric vorticity meter.

It is common for acoustic anemometers to use open measurement volumes, fifteen to thirty centimeter path lengths, and piezoceramic transducers. An open measurement volume refers to a configuration that excludes any obstructions on the upwind side of the transducers of an anemometer. This aspect of anemometer design is evident in the photograph in Figure (3-1). The open measurement volume concept was not so important in the BASS design because the mean flow in the ocean rarely exceeds one meter per second. Additionally, the BASS vorticity meter is often used in oscillating flows where it is not possible to define a preferred direction. Therefore, the BASS used a center post to support its vortical paths. This aspect of the BASS design is evident in Figure (3-2).

Due to the large mean flows that occur in the atmosphere, it may be necessary to create an open measurement volume for the final design of the atmospheric vorticity 


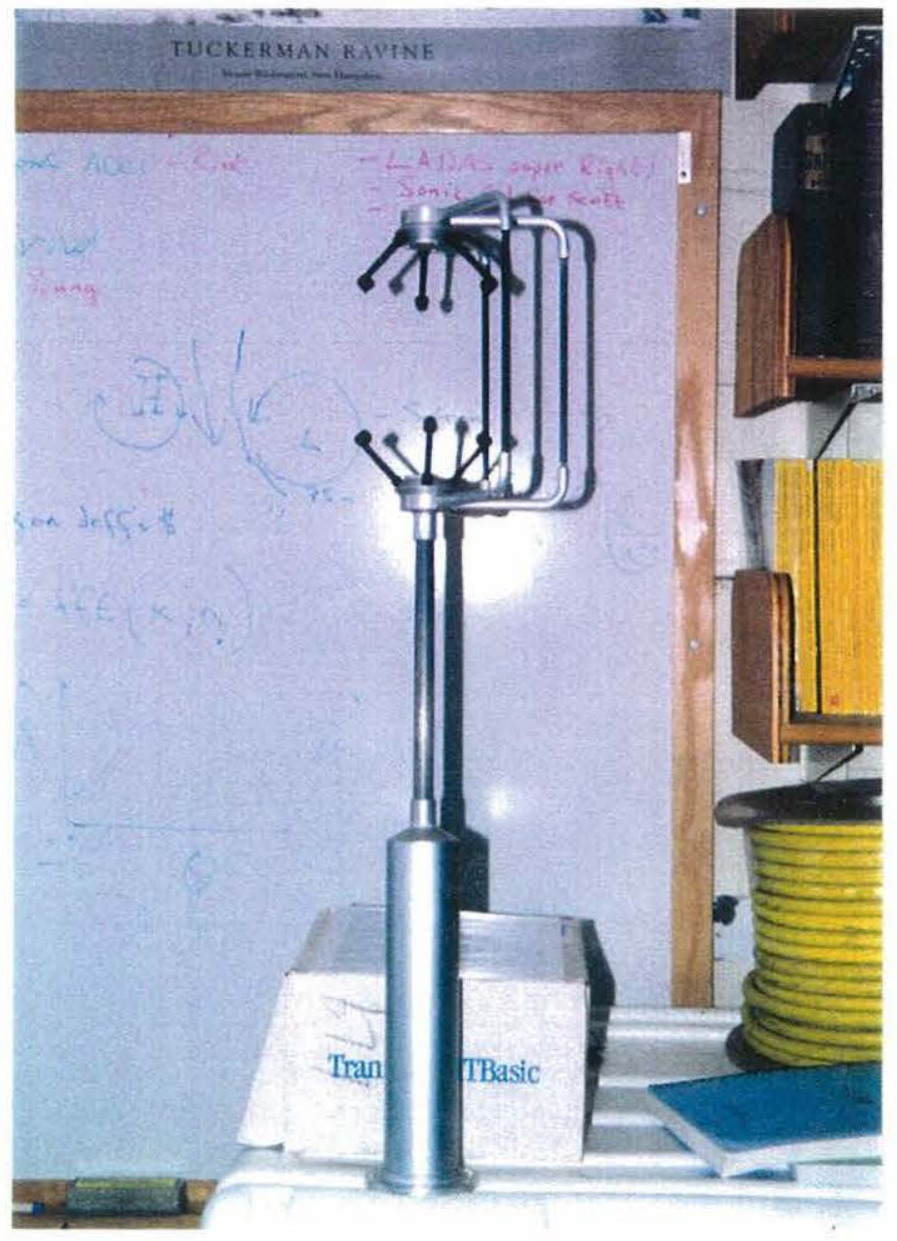

Figure 3-1. Picture of open measurement volume of an anemometer 

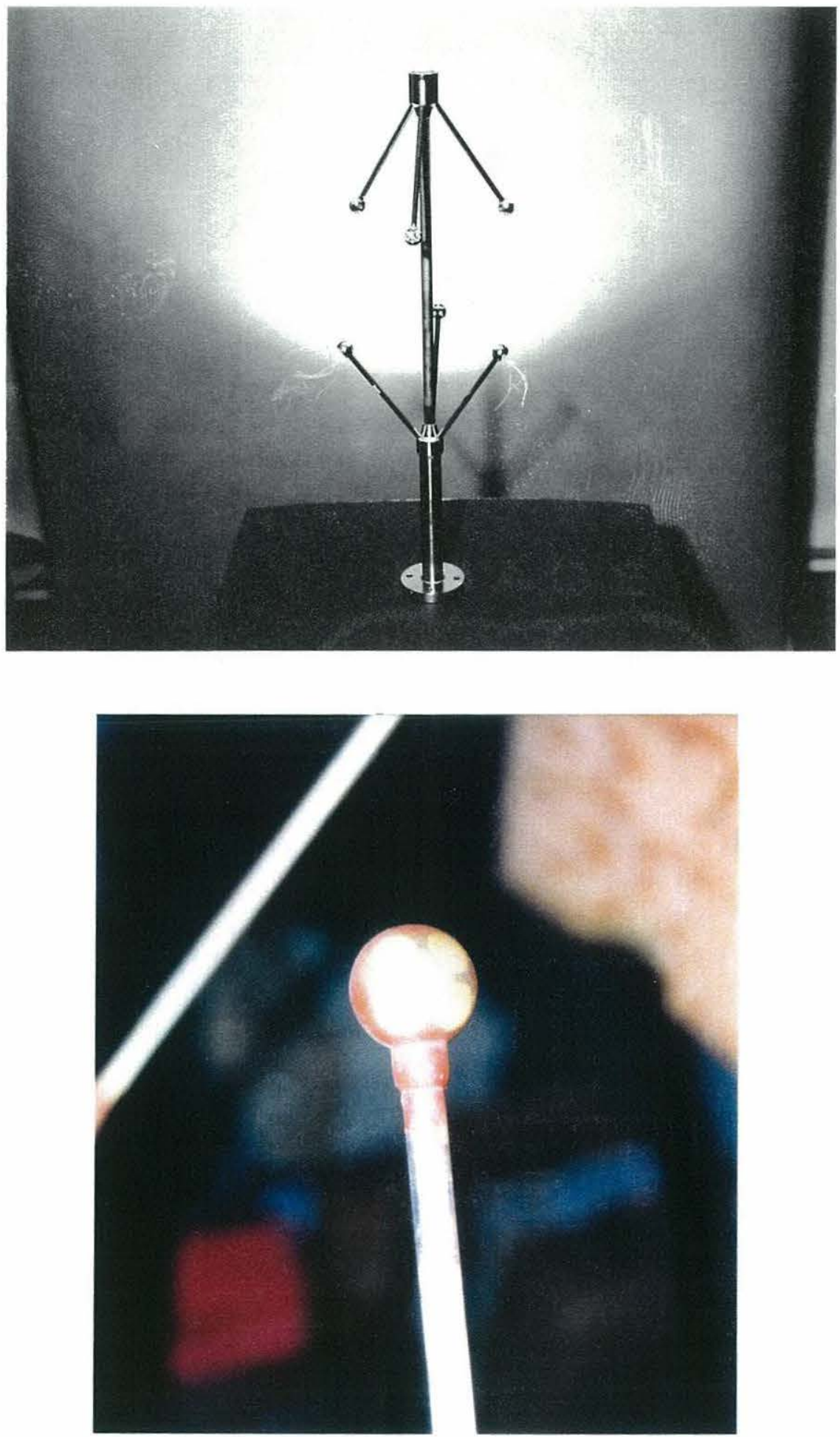

Figure 3-2. BASS instrument and close view of four transducers per pod 
meter. The open measurement volume design should provide air that is minimally affected by instrument generated wakes for angles of attack that are less than $\pm 90^{\circ}$. A possible configuration that would permit the open measurement volume to exist in the atmospheric

Side View

$13.0 \mathrm{~cm}$

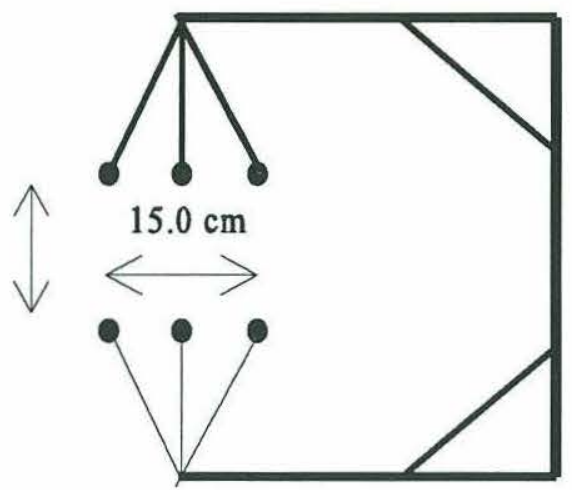

The Top Struts are thicker in the drawing only. This makes the top look different from the bottom.

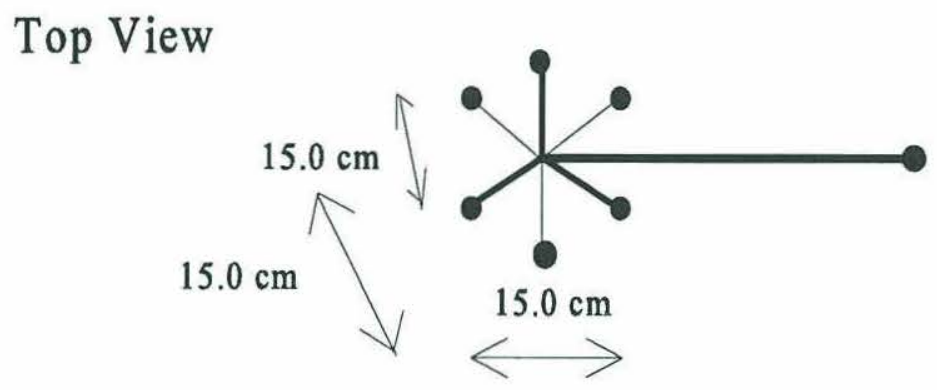

Figure 3-3. A possible atmospheric design

vorticity meter is presented in Figure (3-3). Figure (3-3) represents the basic requirements for atmospheric use, but the issues of weight and vibration will probably force changes to be made. As noted in the top view from Figure (3-3) all acoustic path lengths are $15 \mathrm{~cm}$ in length.

There are many advantages to longer path lengths through air from an accuracy point of view. However, there are advantages to shorter path lengths from analysis and 
feasibility points of view. From a feasibility point of view, the received signal strength becomes closer to the noise level as path lengths and frequency increase. Once a planewave sound pulse is in the air, its amplitude is governed by the following equation:

$$
A=A_{0} \exp ^{(-\alpha x)}
$$

where $A$ is the amplitude of the sound wave, $\alpha$ is the attenuation coefficient in units of per centimeter, and $x$ is the distance in centimeters. In fluids, the attenuation coefficient increases as the square of the frequency of a sound wave. For dry, $\mathrm{CO}_{2}$-free air at $20^{\circ} \mathrm{C}$, $\alpha$ has a value determined by the following equation:

$$
\alpha=1.37 \cdot 10^{-13} f_{s}^{2}
$$

where $f_{s}$ is the frequency of the sound wave in Hertz (Beyer and Letcher, 1969). A value for $\alpha$ in moist air at $30^{\circ} \mathrm{C}$ is given by:

$$
\alpha=1.68 \cdot 10^{-13} f_{s}^{2}
$$

(Herzfeld, 1959). Equations (3-2) and (3-3) are based on the frequency squared relationship of Stokes-Kirchhoff classical absorption theory. There are factors that cause deviations from these curves-of-best-fit to the frequency squared relationship. However, the deviant response of absorption due to relative humidity and temperature occurs at frequencies that are below our frequencies of interest (Kneser, 1935). In fact, almost all of the difference between equations (3-2) and (3-3) at frequencies near $200 \mathrm{kHz}$ could be accounted for by the deviant $\mathrm{CO}_{2}$ absorption in air as measured by Grossman (Wood, 1948). The absorption of sound by $\mathrm{CO}_{2}$ is maximum at $100 \mathrm{kHz}$, and it is an order of magnitude smaller than the classical absorption at $200 \mathrm{kHz}$. Although there are measurements of absorption coefficients for frequencies near $200 \mathrm{kHz}$ and $1.75 \mathrm{MHz}$ that 
are higher than equation (3-3), these small factors are unimportant to the analysis that follows. Using the more conservative estimate of attenuation given by (3-3), the necessity of short path lengths for high frequency sounds in air can be established. Figures (3-4) and (3-5) show the attenuation of the amplitude of a plane-wave using equation (3-3) for frequencies of $200 \mathrm{kHz}$ and $1.75 \mathrm{MHz}$.

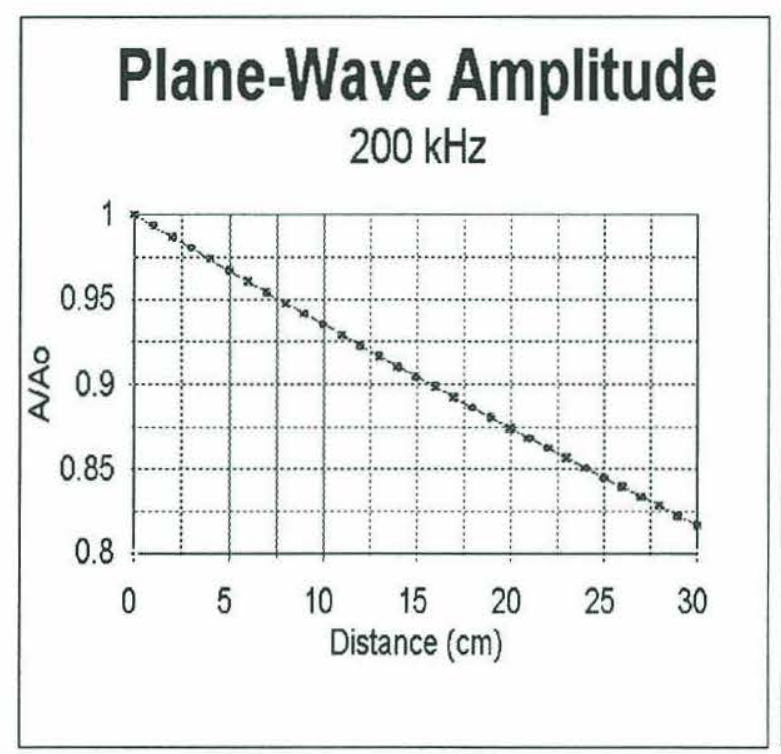

Figure 3-4. $200 \mathrm{kHz}$ attenuation

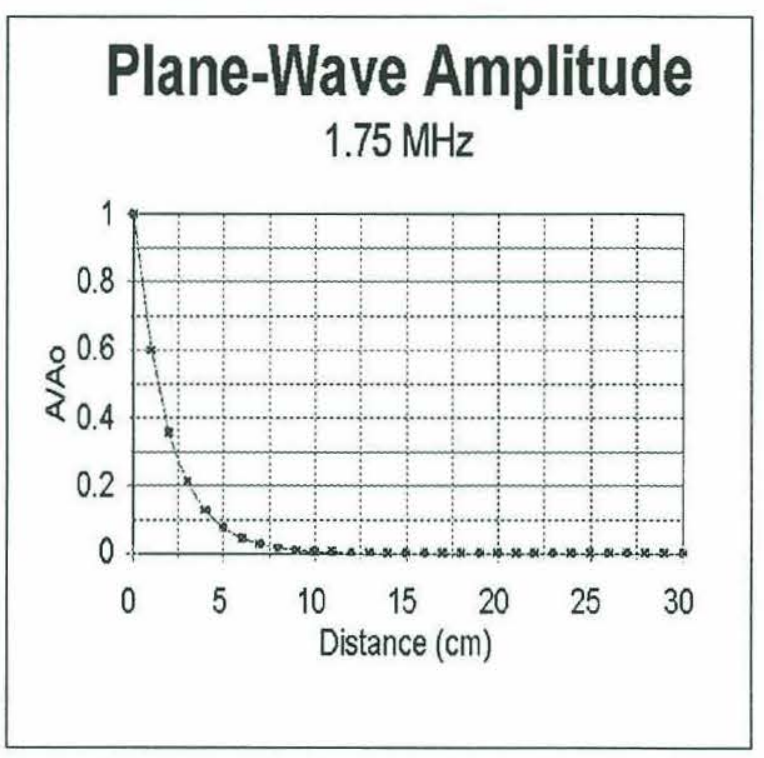

Figure 3-5. $1.75 \mathrm{MHz}$ attenuation

A straightforward way to examine the attenuation of the signal is to discuss it in terms of the extinction distance. The extinction distance is given by the inverse of the attenuation coefficient, and it represents the distance at which the amplitude has been reduced by $1 / \mathrm{e}$, or a $63 \%$ reduction, by absorption. The BASS instrumentation requires high frequencies to take advantage of its accuracy. The BASS transducers use $1.75 \mathrm{MHz}$ as their transmit frequency. The extinction distance of this frequency in fresh water can be more than $3800 \mathrm{~cm}$. (Bergmann, 1938). Using (3-3), the extinction distance for this frequency in air is $1.94 \mathrm{~cm}$, as shown in Figure (3-5). Over a $15.0 \mathrm{~cm}$ path through moist air, a $1.75 \mathrm{MHz}$ sound wave could be expected to lose $99.96 \%$ of its amplitude. It is 
important to note that this expected loss doesn't include the coupling problem of a transducer to air or the spreading losses.

Acoustic anemometers commonly use frequencies near $200 \mathrm{kHz}$. Using (3-3), the extinction distance for $200 \mathrm{kHz}$ in air is $148.8 \mathrm{~cm}$. Over a $15.0 \mathrm{~cm}$ path through moist air, a $200 \mathrm{kHz}$ sound wave could be expected to lose $9.59 \%$ of its amplitude, as shown in Figure (3-4). Clearly, the $200 \mathrm{kHz}$ attenuation is acceptable, but the $1.75 \mathrm{MHz}$ attenuation is not acceptable over a $15.0 \mathrm{~cm}$ path length. Therefore, it is necessary to compromise between acoustic frequency and acoustic path length in air. Assuming the signal frequency maintains a value near $200 \mathrm{kHz}$, the above mentioned $15.0 \mathrm{~cm}$ path length could be expanded to even greater lengths.

From an analysis point of view there can be increased difficulties generated by longer path lengths. One of the more obvious concerns is vibration of the struts and the frame. As the path lengths increase, the strut lengths and frame height would require more length if the model shown in Figure (3-3) were used. As the lengths increase, the effective stiffness of the members would probably be decreased. This decrease in stiffness would eventually lead to vibration that would alter the path lengths. Because the vibrational modes would be generated by random forcing functions, it would be extremely difficult to remove all of the vibrational-mode errors in the raw data.

Secondly, if the points raised in the introduction are revisited, another difficulty with longer path lengths comes to light. A major objective of this vorticity meter is to analyze boundary layers close to the sea surface. For this purpose, a small measurement distance between horizontal paths is optimal. If the path lengths were made large enough in the vorticity meter, considerably less expensive cup anemometers would provide a more accurate measurement of the shear in the boundary layer. The purpose of going to acoustic measurements would be lost.

Assuming that the measurement volume is open (as described above), the percentage of an acoustic path that would be affected by transducer wakes would be reduced by longer path lengths. In an open measurement volume, the acceleration of flow around the transducers is interpreted as a faster or slower velocity in the two portions of the acoustic paths that are affected. These local increases in velocity cause a small change in the 
averaged acoustic velocity over the path. The simplest and best way to correct for this acceleration problem is to perform wind tunnel tests and correct the results empirically (e.g., Grelle and Lindroth, 1994). Of course, path lengths that are long enough would make the empirical corrections negligible. In addition, the small errors in the timing circuitry would represent a smaller portion of the total time that an acoustic signal would require to transit the acoustic path length. Despite these advantages, the acoustic path length requirements and limitations prevent a lengthening of acoustic path lengths in the initial instrument design. Therefore, a signal of approximately $200 \mathrm{kHz}$ over a $15.0 \mathrm{~cm}$ path length is an adequate compromise. However, it is unlikely that the acoustic vorticity meter will be used in only one acoustic path length as it evolves.

The empirical corrections to velocity measurements from a wind tunnel test are most useful if the instrument is as symmetric as possible. If the wake generation effects on velocity paths were not symmetric, the instrument would require calibrations at various angles to the mean wind. This would require that an estimated mean wind be backed out of the measurements before corrections could be applied. This is the reason that the six transducer pods in Figure (3-3) have a spherical shape. Each of the six transducer pods shown in Figure (3-3) would contain four transducers in a configuration that would be similar to the pod configuration in BASS.

\section{TRANSDUCER DESIGN}

The first difficulty that occurs when attempting to insonify air is an impedance mismatch between the transducer and the air. This difficulty occurs because the density of piezoelectric ceramics and crystals is much higher than that of air. The effective impedance mismatch can be substantially reduced by the use of piezopolymers or the use

of multiple matching layers covering a ceramic or crystal (Wallace, 1992). Other methods use piezoceramic embedded in epoxy to decrease the impedance mismatch between air and a transducer (Hayward et al., 1992).

Our group attempted to use the experience of atmospheric transducer design by searching for off-the-shelf transducers that would work with the BASS electronics. The first two transducers tested were simple piezoelectric discs that resonated at $1.75 \mathrm{MHZ}$ 
and $875 \mathrm{kHz}$. These discs were tested because they were already available at WHOI, such that these discs would have represented substantial savings if they showed any promise. These discs were tested using a storage oscilloscope with 10x probes. Not surprisingly, given the above discussion, the results for these discs were negative. However, it should be noted that no amplification or layer matching was used.

The next attempt used piezoceramic cylinders that were designed for a resonance of approximately $200 \mathrm{kHz}$. The resonance frequencies of the ten cylinders that were ordered were found to vary between $240 \mathrm{kHz}$ and $310 \mathrm{kHz}$. In an attempt to decrease the impedance mismatch between the cylinders and air, RTV was used as a filling material for the cylinders. Once the cylinders were filled with RTV, the resonance frequencies were found to vary from $250 \mathrm{kHz}$ to $330 \mathrm{kHz}$. Any two cylinders were separated by a distance of $0.15 \mathrm{~m}$, and one transmitted under a square wave voltage with an amplitude of 20 volts while the other received. Once an amplifier with a gain of 480 was developed, a signal of approximately $30 \mathrm{mV}$ was visible on the storage oscilloscope. However, these transducers were found to be unacceptable because of their large variance in resonance frequency and because of their poor coupling with the air.

The final transducer design tested was the E-188/220 by Massa Products. It has an estimated $220 \mathrm{kHz}$ resonance frequency, and it takes advantage of impedance matching materials. The E-188 consists of a piezoceramic disc with a quarter wavelength silicon matching layer. This transducer design was much more dependable in its proximity to the expected resonance frequency, and the E-188 was found to work well in air. Without amplification, an E-188 transmitting under a square wave of frequency $220 \mathrm{kHz}$ and amplitude one volt can generate up to a $1.5 \mathrm{mV}$ signal in another E-188 that is 0.15 meters away. These results clearly indicate that the design of the E-188 allows a coupling to air that is orders of magnitude more efficient than the coupling of the piezoceramic cylinders.

\section{RINGING ANALYSIS}

Because the estimated length of separation of the transducers was expected to be 0.15 $\mathrm{m}$ in the test design, the continued oscillation, or ringing, of the transducers after the 15 - 
cycle sine wave pulse was a concern. In order to test the ringing of the E-188, the transducers were modeled as a transfer function and were separately tested against an oscilloscope. The initial modeling of the transfer function was performed on the E-188's with a Hewlett Packard 4195A Network Analyzer. In our tests, the E-188's were subjected to a multi-cycle sine wave, and the results were recorded on a storage oscilloscope.

The Hewlett Packard Network Analyzer is capable of modeling crystal oscillators using the following equivalent circuit:

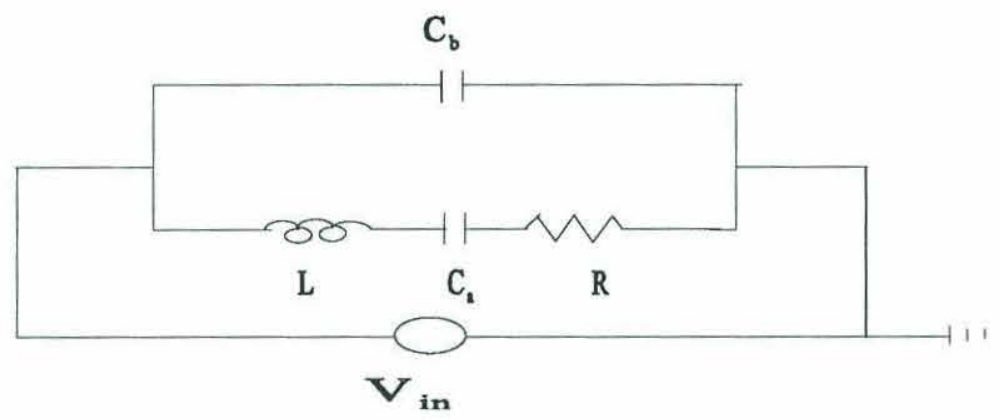

Figure $3-6$. IIP ringing model

where $\mathrm{L}$ is an inductor, $\mathrm{R}$ is a resistor, and $\mathrm{C}$ is a capacitor with subscripts denoting different values. This equivalent circuit is capable of generating the following Laplace transfer function:

$$
\frac{\frac{L}{C_{b}} S^{2}+\frac{R}{C_{b}} S+\frac{1}{C_{a} C_{b}}}{L S^{3}+R S^{2}+S\left(\frac{1}{C_{a}}+\frac{1}{C_{b}}\right)}
$$

However, the addition of a quarter wavelength silicon layer to the piezoceramic disk creates a situation where two separate systems interact. This overlapping of systems can be modeled by the following parallel equivalent circuit: 


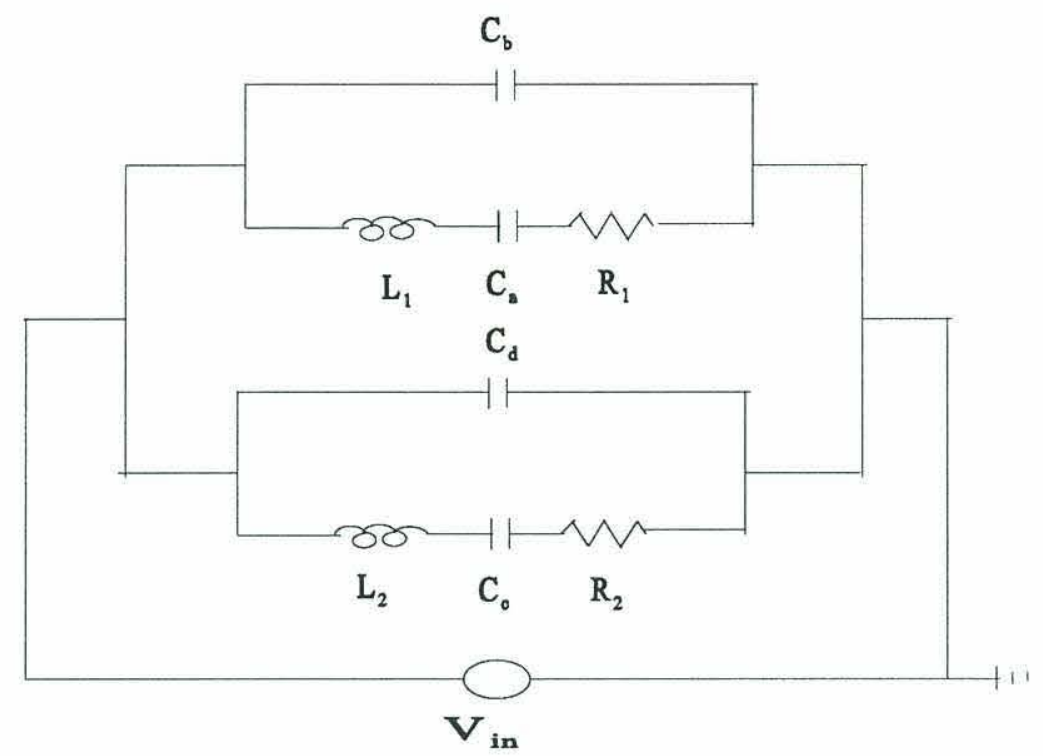

Figure 3-7. Ringing model 2

where $\mathrm{C}_{\mathrm{x}}$ 's are capacitors, $\mathrm{L}_{\#}$ 's are inductors, and $\mathrm{R}_{\#}$ 's are resistors. The overlapping of two crystal oscillators generates the following Laplace transfer function:

$$
\begin{aligned}
& \frac{\frac{L_{1}}{C_{b}} S^{2}+\frac{R_{1}}{C_{b}} S+\frac{1}{C_{a} C_{b}}}{L_{1} S^{3}+R_{1} S^{2}+S\left(\frac{1}{C_{a}}+\frac{1}{C_{b}}\right)} \cdot \frac{\frac{L_{2}}{C_{d}} S^{2}+\frac{R_{2}}{C_{d}} S+\frac{1}{C_{c} C_{d}}}{L_{2} S^{3}+R_{2} S^{2}+S\left(\frac{1}{C_{c}}+\frac{1}{C_{d}}\right)} \\
& \frac{\frac{L_{1}}{C_{b}} S^{2}+\frac{R_{1}}{C_{b}} S+\frac{1}{C_{a} C_{b}}}{L_{1} S^{3}+R_{1} S^{2}+S\left(\frac{1}{C_{a}}+\frac{1}{C_{b}}\right)}+\frac{\frac{L_{2}}{C_{d}} S^{2}+\frac{R_{2}}{C_{d}} S+\frac{1}{C_{c} C_{d}}}{L_{2} S^{3}+R_{2} S^{2}+S\left(\frac{1}{C_{c}}+\frac{1}{C_{d}}\right)}
\end{aligned}
$$

This result can be rewritten by creating like denominators and removing them from the function. This yields the following Laplace transfer function: 


$$
\begin{aligned}
& {\left[\frac{1}{C_{b}+C_{d}}\right]\left[L_{1} L_{2} S^{4}+\left(L_{1} R_{2}+L_{2} R_{1}\right) S^{3}+\left(\frac{L_{1}}{C_{c}}+R_{1} R_{2}+\frac{L_{2}}{C_{a}}\right) S^{2}+\left(\frac{R_{1}}{C_{c}}+\frac{R_{2}}{C_{a}}\right) S+\frac{1}{C_{a} C_{c}}\right]} \\
& L_{1} L_{2} S^{5}+\left(L_{1} R_{2}+L_{2} R_{1}\right) S^{4}+\left(\frac{L_{1}}{C_{c}}+R_{1} R_{2}+\frac{L_{2}}{C_{a}}+\frac{L_{1}+L_{2}}{C_{b}+C_{d}}\right) S^{3}+\left(\frac{R_{1}}{C_{c}}+\frac{R_{2}}{C_{a}}+\frac{R_{1}+R_{2}}{C_{b}+C_{d}}\right) S^{2}+\left(\frac{1}{C_{a} C_{c}}+\frac{\frac{1}{C_{a}}}{C_{b}}+\frac{1}{C_{c}}\right) S
\end{aligned}
$$

This form of the transfer function allows the power of the numerator and denominator to be easily seen. Since the power of the denominator is larger than the power of the numerator, a first approximation suggests that the system should be stable.

The Hewlett Packard Network Analyzer was able to produce the following values with its equivalent circuit analysis option for crystal oscillators like Figure (3-6):

$$
\begin{aligned}
& \mathrm{R}=45.5342 \Omega \\
& \mathrm{L}=0.980964 \mathrm{mH} \\
& \mathrm{C}_{\mathrm{a}}=597.691 \mathrm{pF} \\
& \mathrm{C}_{\mathrm{b}}=1.23217 \mathrm{nF}
\end{aligned}
$$

Using these results in equation (3-4) produces the following bode plot:
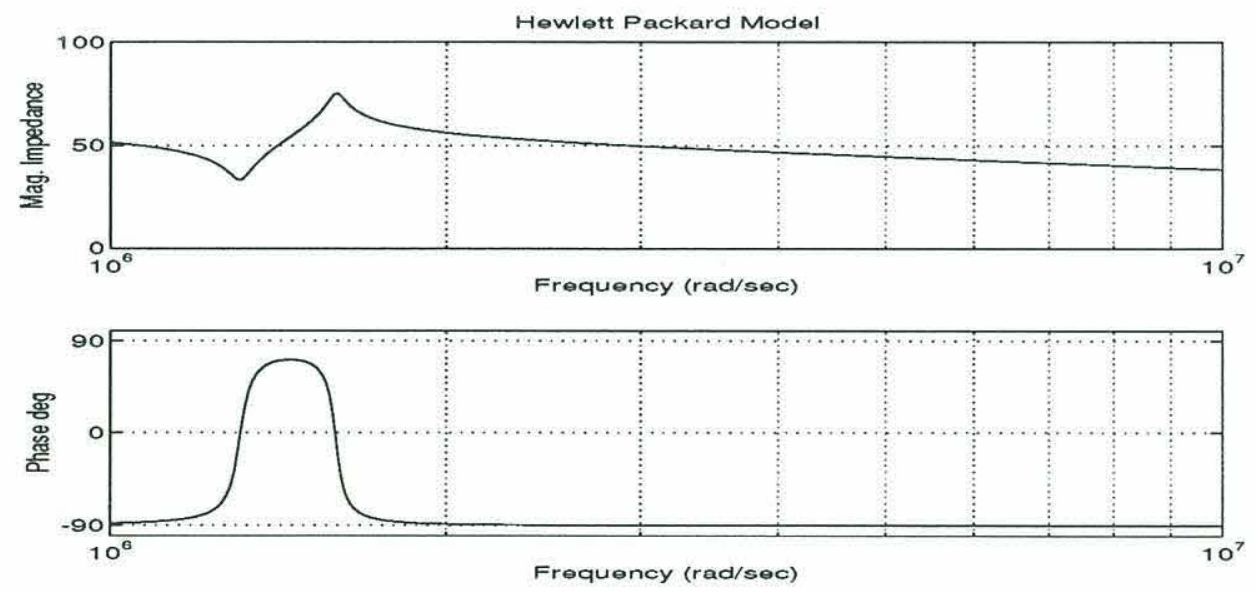

Figure 3-8. Bode plot of Hewlett Packard model 
The 'Hewlett Packard Model' plot has some similarity to the manufacture's specifications and the measurements displayed by the network analyzer, but it is missing a second peak near $220 \mathrm{kHz}$. By modifying the values provided by the network analyzer, it is possible to produce a bode plot that resembles the manufacturer's specifications and the actual measurements displayed by the network analyzer. The modified values for use in equation (3-6) are as follows:

$$
\begin{aligned}
& \mathrm{R}=45.5342 \Omega \\
& \mathrm{L}=0.980964 \mathrm{mH} \\
& \mathrm{C}_{\mathrm{a}}=597.691 \mathrm{pF} \\
& \mathrm{C}_{\mathrm{b}}=1.23217 \mathrm{nF} \\
& \mathrm{R}_{2}=\quad 35 \Omega \\
& \mathrm{L}_{2}=0.84 \mathrm{mH} \\
& \mathrm{C}_{\mathrm{c}}=575 \mathrm{pF} \\
& \mathrm{C}_{\mathrm{d}}=\quad 2 \mathrm{nF}
\end{aligned}
$$

The first four values are identical to the four measured values generated by the network analyzer for a crystal oscillator. However, the use of these eight values in the transform function of the overlapping system produces the bode plot shown in the following figures:
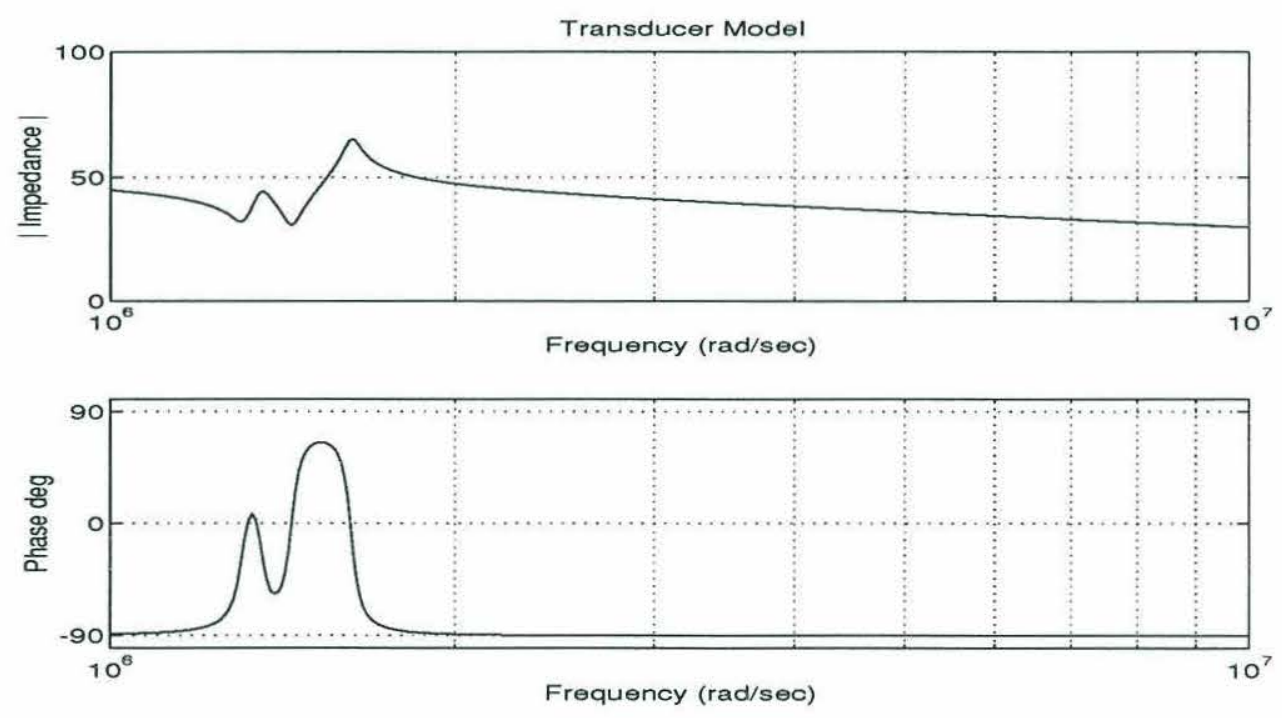

Figure 3-9. Bode plot for transducer model 2 
This 'Transducer Model' bode plot closely resembles the manufacture's specifications for the E-188/220. By placing the equivalent circuit in Figure (3-7) under a 14.2449-cycle, $220 \mathrm{kHz}$ sine wave of amplitude one volt, the following plots of the transducer input and transducer response were generated:

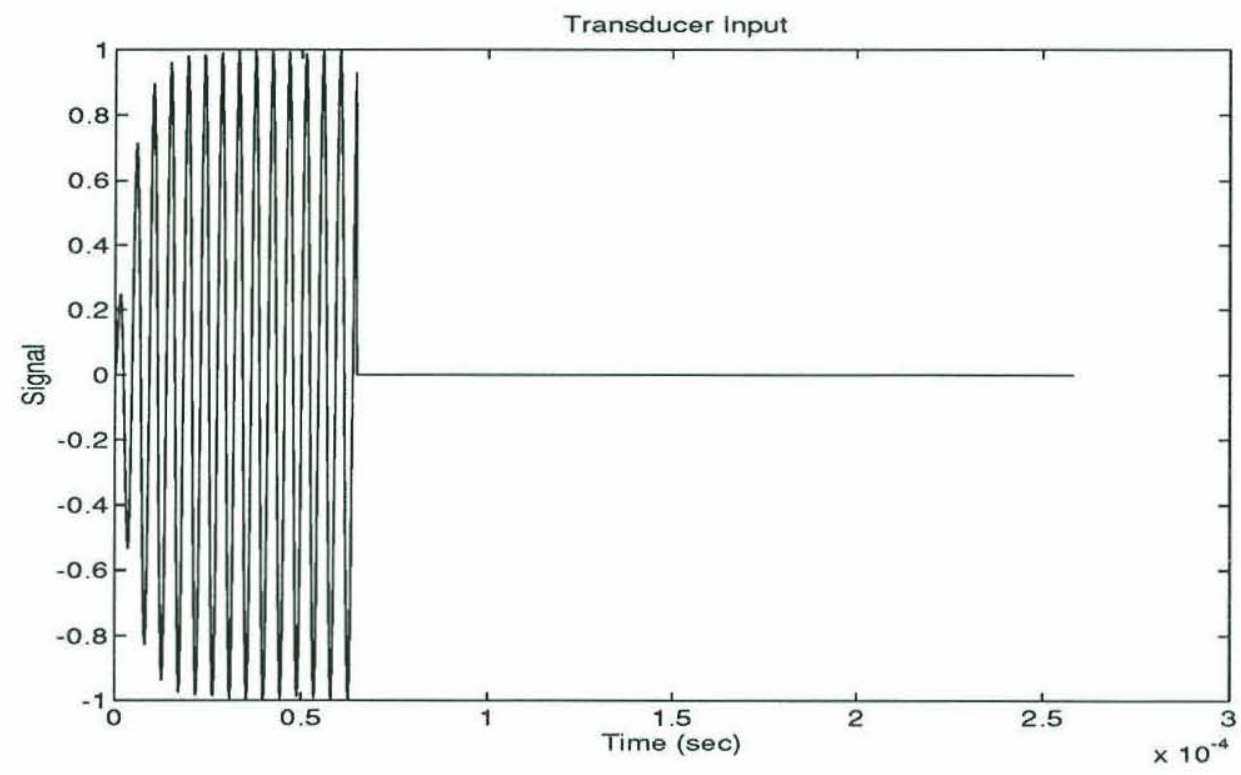

Figure 3-10. Assumed input to an E-188/220 transducer

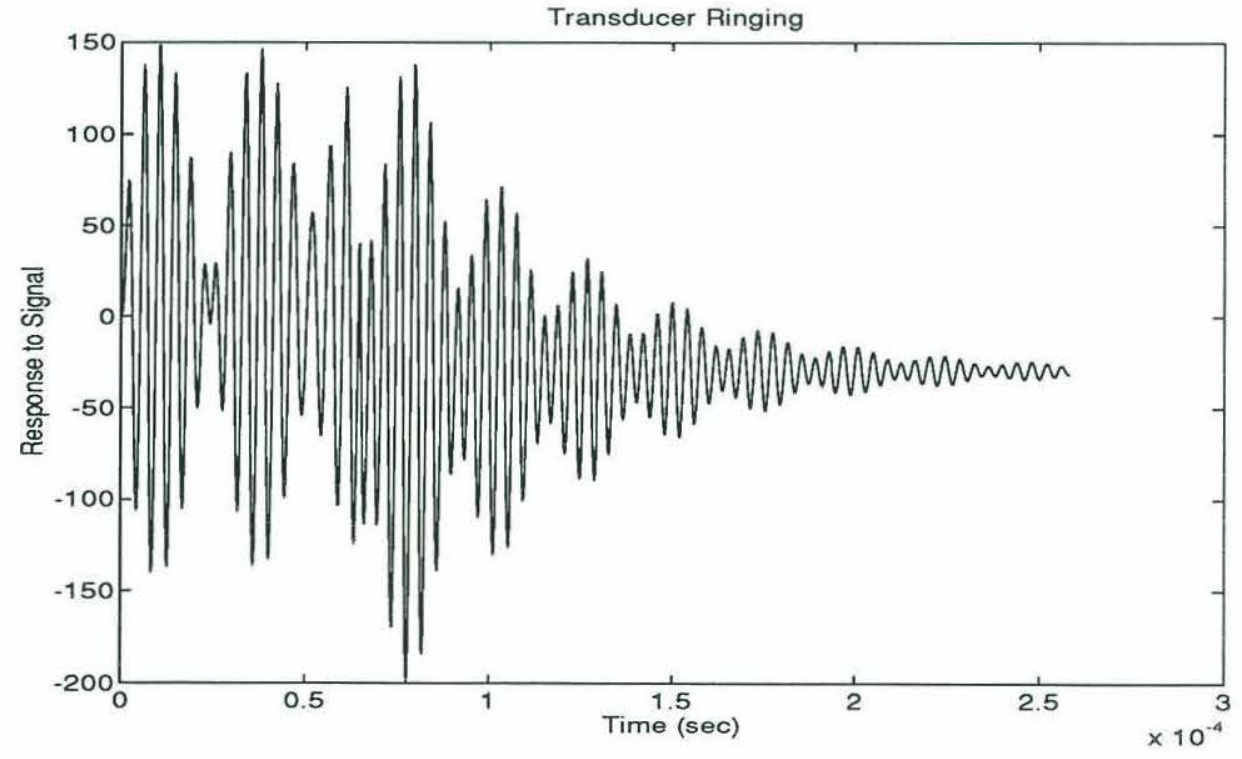

Figure 3-11. Hypothetical output of transducer using assumed input 
These analytical results show a transducer response that stabilizes at some voltage offset. The voltage offset changes as the number of frequency cycles changes. For example, the use of a 14-cycle, $220 \mathrm{kHz}$ sine wave would show a more negative voltage offset in Figure (3-11). The use of a 14.5 -cycle, $220 \mathrm{kHz}$ sine wave would show a small positive offset that would be almost equal in magnitude to the offset shown in Figure (3-11).

These results do not make physical sense. However, the ringing response about the stabilization voltage looks the same in all of the cycle lengths used in our tests. Therefore, there may be some value in the analysis. The analytical results are dubious by any standard because the conditioning number for the values used in equation (3-6) to generate the transducer response was almost $4 \times 10^{35}$. Therefore, it was necessary to look at the physical characteristics of the transducer ringing after a multi-cycle input. More information on the analytical portion of this analysis is presented in Appendix A.

Because the ringing of the transducers was still a concern for measurements using modified BASS instrumentation, a physical ringing test was set up in such a manner that it would determine whether ringing was a concern or not a concern. Two transducers were set up at a separation distance of approximately $15 \mathrm{~cm}$. The transmitting transducer was connected to a circuit with the effect of a one shot, i.e., the length of time between transmissions was substantially longer than the length of transmission. This 'one shot' was tuned for a multi-cycle sine wave of approximately $220 \mathrm{kHz}$, and a schematic of its design is shown in Figure (3-12).

The output of the circuit was tuned for a multi-cycle sine wave at $220 \mathrm{kHz}$ every $1 / 1000^{\text {th }}$ of a second. The length of the multi-cycle sine wave was almost ten times shorter than the length of time between pulses, which provided an effective one shot to the signaling transducer. The output of the receiving transducer was measured on a LeCroy Digital Oscilloscope. The Lecroy Digital Oscilloscope was connected to 10X probes that provided the only amplification of the transmitted and received signals. These signals are displayed in Figure (3-13) and Figure (3-14), respectively. The transmitting signal had a duration of $75 \mu s$, and although there is some physical ringing, it rapidly falls near the 
noise level. In air, a sound wave will take about $440 \mu \mathrm{s}$ to traverse a $15.0 \mathrm{~cm}$ pathlength. Therefore, the ringing of the transducers did not appear to be a concern.

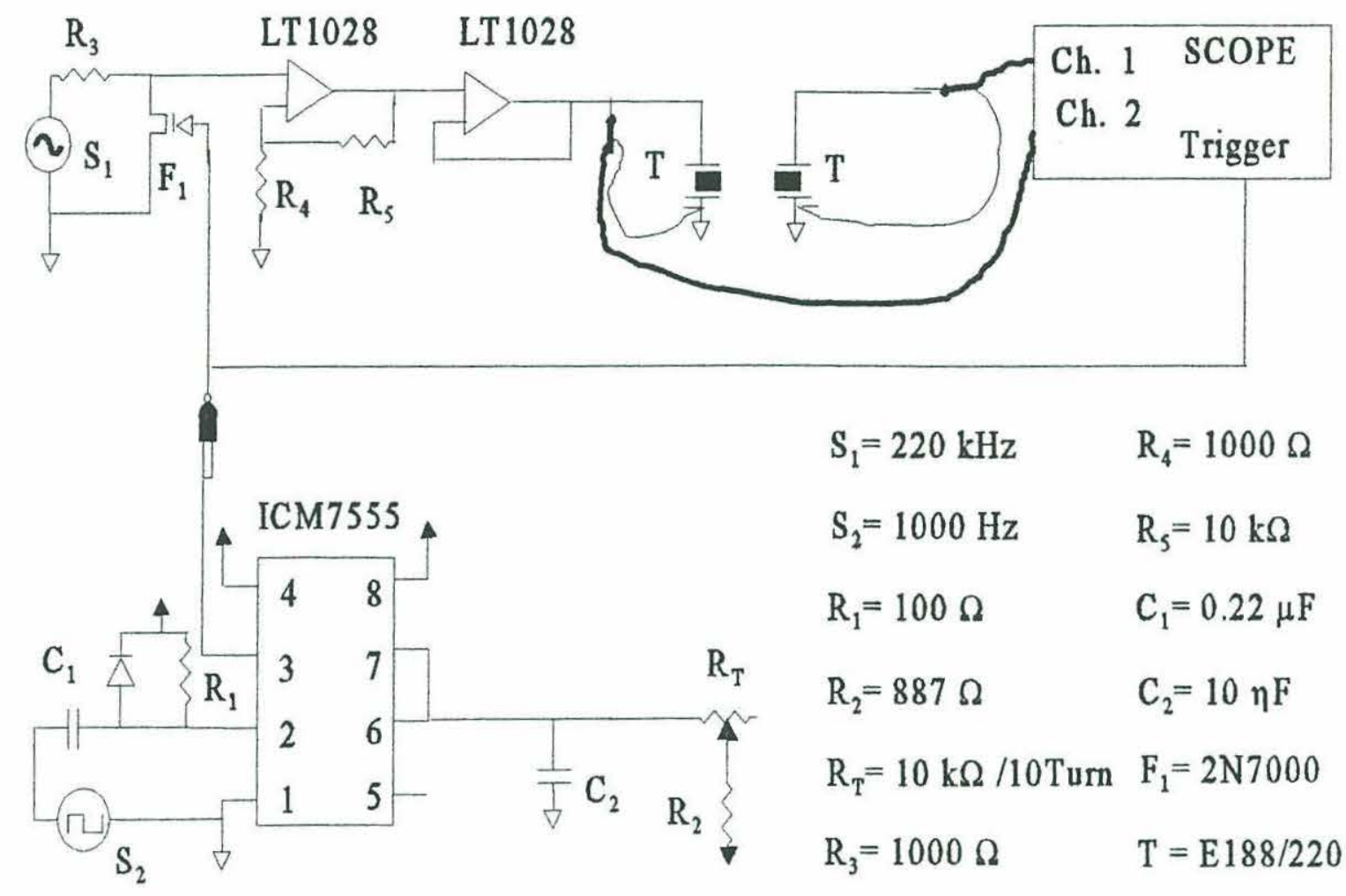

Figure 3-12. Circuit used to generate a short burst of $220 \mathrm{kHz}$ waves 


\section{Transmit Signal}

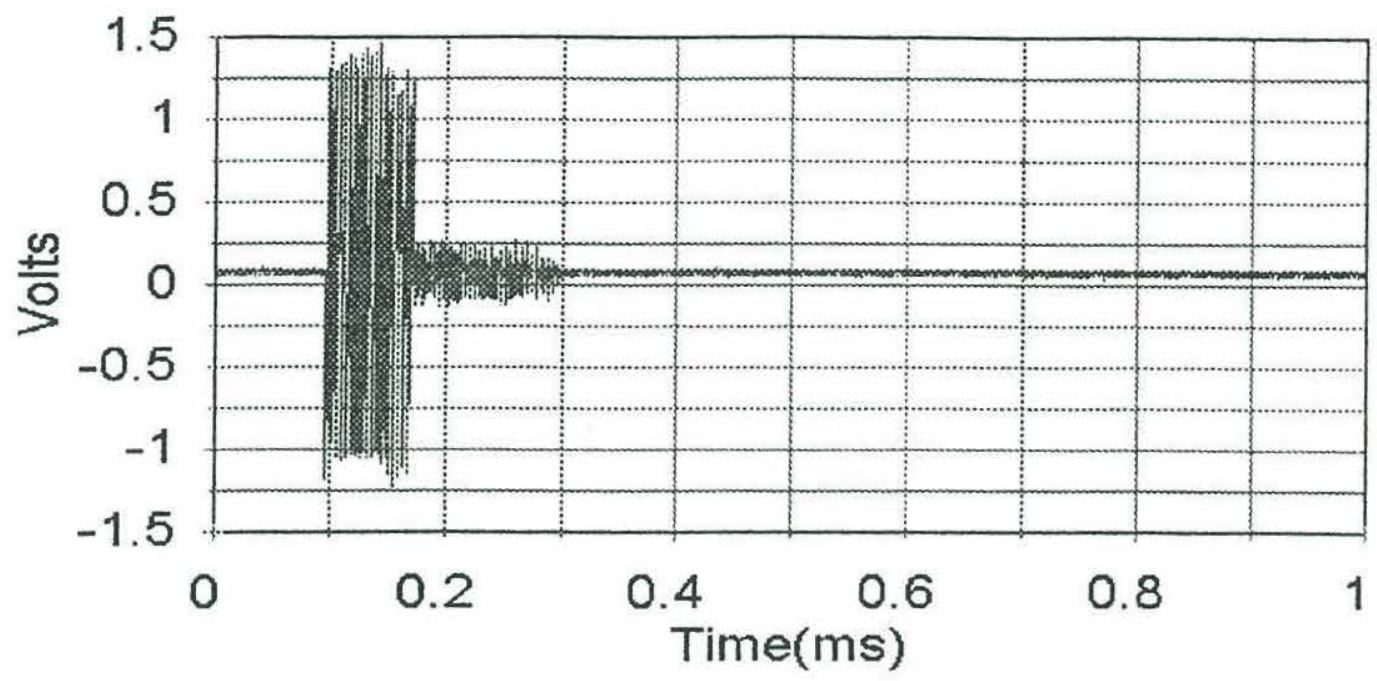

Figure 3-13. Transmitted Signal through an E-188/220

\section{Receive Side Transducer}

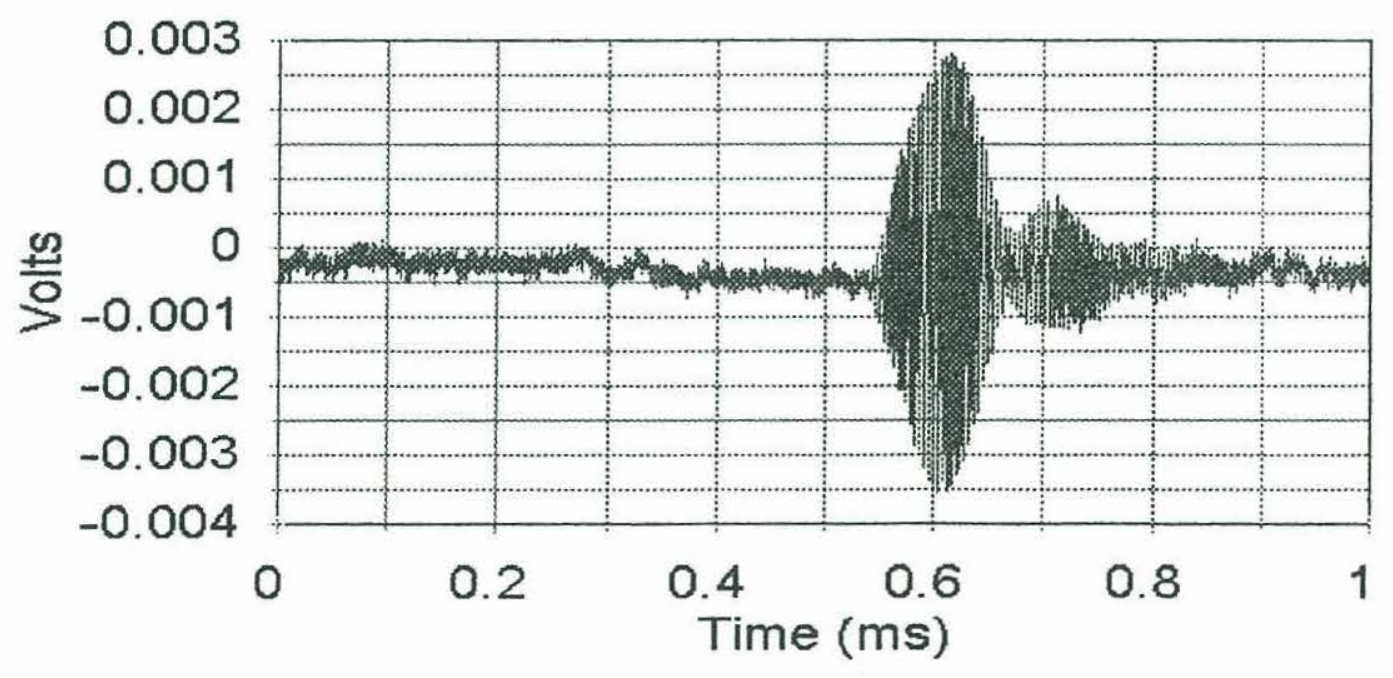

Figure 3-14. Received Signal using an E-188/220 


\section{TIMING AND BURST GENERATION}

Due to the different group velocities of sound waves in air and water, the timing for a pulse in air over a $15.0 \mathrm{~cm}$ path length must be different from the timing of a pulse in water over a $15.0 \mathrm{~cm}$ path length. In addition to the timing changes, the resonant frequency had to be changed from $1.75 \mathrm{MHz}$ to $220 \mathrm{kHz}$. In the BASS instrumentation, the timing and resonant frequency generation is performed within the circuitry of the timing and burst generation board, and its original form is displayed in Appendix B. Although the alterations to the board required several iterations, only the final changes are detailed in this section.

In order to change the resonance of the board, a resonant $\mathrm{LC}$ circuit had to be changed to meet the requirements of $220 \mathrm{kHz}$ transducers. This $\mathrm{LC}$ circuit is represented in Appendix $\mathrm{B}$ by capacitor $\mathrm{C}_{1}$ and inductor $\mathrm{L}_{1}$. Resonance in the $\mathrm{LC}$ circuit follows the following equation:

$$
f=\frac{1}{2 \pi \sqrt{L_{1} C_{1}}}
$$

where $f$ is the frequency in Hertz. The divide by two behavior of the circuit creates an additional factor of approximately 2.26 . Therefore, the new LC circuit should combine an $\mathrm{L}_{1}$ and $\mathrm{C}_{1}$ that are resonant near $495 \mathrm{kHz}$. Because the availability of capacitors exceeds that of inductors, $\mathrm{C}_{1}$ was replaced with a $3600 \mathrm{pF}$ capacitor. This produces a resonant frequency of slightly more than $218 \mathrm{kHz}$ going to the E-188/220 transducers.

The timing of the circuitry also had to be changed. During these modifications, we were able to take advantage of a previously unused clock that was available on the board (represented by U9B on the schematic in Appendix B). In the air-side circuitry, that clock was used to double the length of each clock step: i.e., one clock cycle was changed from $6.5 \mu s$ to $13 \mu s$ in length. This change allowed the new timing board to compensate for the generally higher velocities found in wind measurements as compared to current measurements in water. The counters $\mathrm{U}_{2}$ and $\mathrm{U}_{3}$ on the timing and burst generation board were used to alter the settings for oscillator control, start transmit time, transmit disable, start $A / D$, and reset. 
The oscillator control is turned on first so that any capacitance is charged in the resonant part of the circuit before a signal is sent to a pair of transducers. Next, the start transmit goes high to set the circuitry such that it will transmit the resonant pulse when the clock resets are turned off. When transmit disable goes low immediately after start transmit goes high, the clock resets are turned off, and pulse transmission begins. This pulse is generated by the resonant part of the circuit, and it is transmitted to a pair of transducers as long as start transmit is high. Start transmit eventually goes low, and the transducers are no longer excited by the circuitry. After a short time, the unclamp receiver goes low, which allows the same transducers to act as receivers and to communicate their received signals to a set of counters. When fourteen zero-crossings have occurred at one counter due to the cycling of its transducer at the resonant frequency, the counter switches a constant current source to an integrating capacitor. Assuming there is some flow along the acoustic path, the other counter will count fourteen zero-crossings from its transducer at a slightly later time, and that counter will switch a constant current source to another integrating capacitor. After some voltage has built on the two integrating capacitors, the difference between the values is recorded on the A/D board when start $A / D$ goes high. The system is then reset, and another path is measured. The cycling of these settings is represented in the following figure:

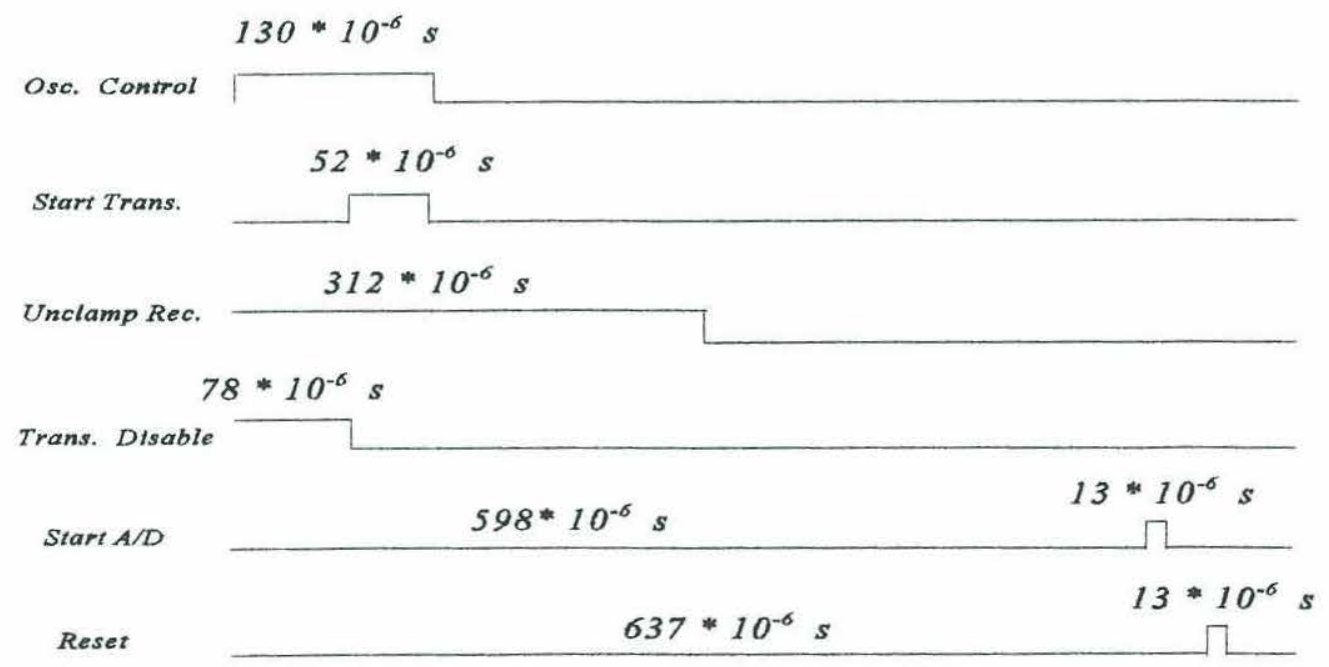

Figure 3-15. Cycling of board 
The cycles in Figure (3-15) were created by using the following $U_{2}$ and $U_{3}$ connections:

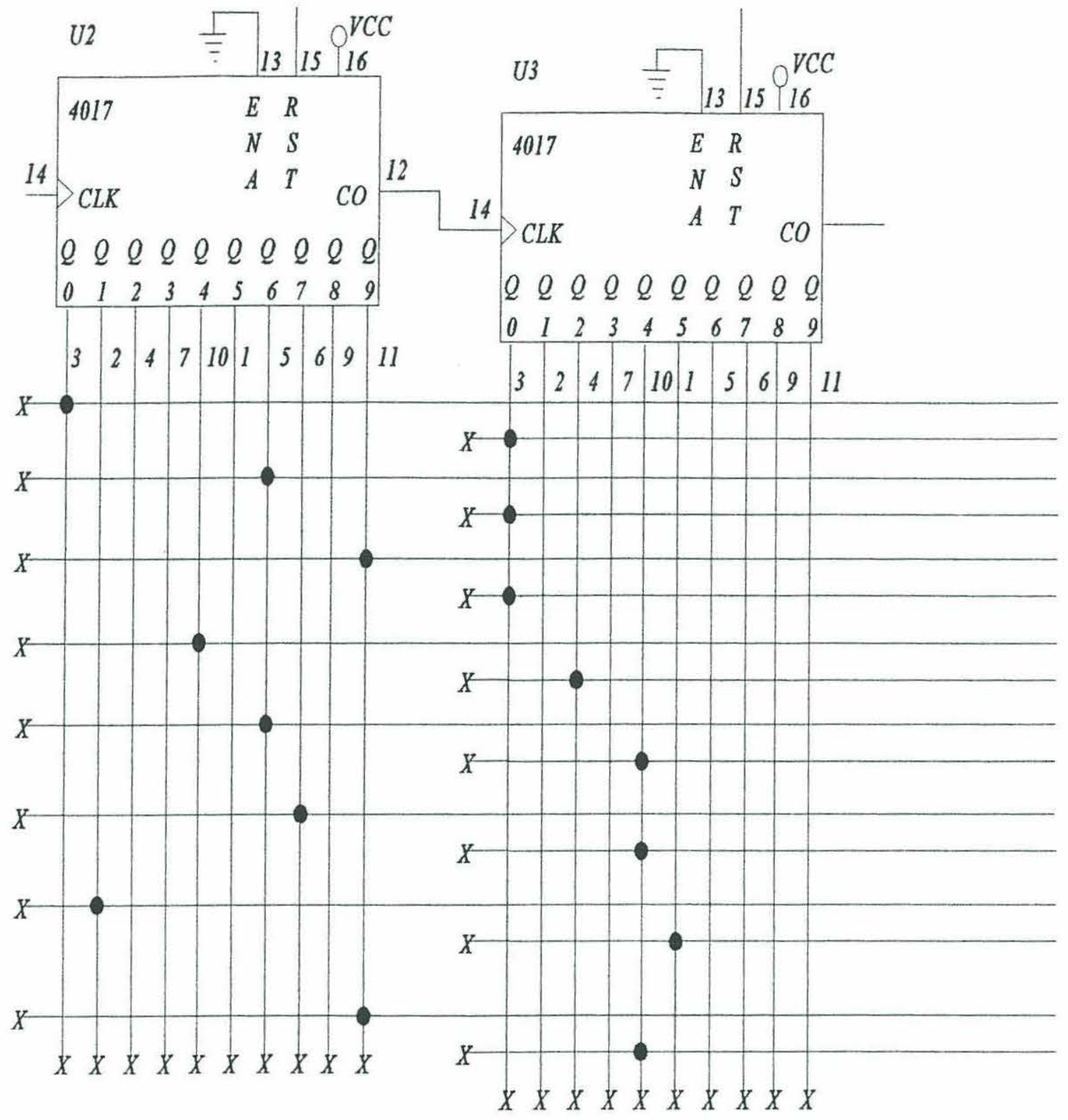

Figure 3-16. Alterations to timing and burst generation counters

The BASS instrumentation contains a Tattletale which is used to make an equivalent 
time difference based on the voltage difference that is recorded on the A/D board. The Tattletale is programmed through a language called TTBasic, and a program similar to the ones used by BASS instrumentation is provided in Appendix D. Once an equivalent time difference is calculated, it is used to calculate a velocity difference. The measurement of the velocity difference can be improved by iterative processes. If these iterations were done by the TTBasic program, the Tattletale would be in non-sleep modes for longer periods, and this could cause power requirement problems for longer, battery powered deployments. If a long deployment only returned voltage difference or time difference data, the processing of twelve paths sampled at $10 \mathrm{~Hz}$ for 100 days could require more processing time that a researcher would like to spend. The error analysis in Chapter 4 assumes the use of the simple equation for velocity that does not require iteration and is already used by BASS. 


\section{CHAPTER 4}

\section{ERROR ANALYSIS}

Typical commercially available sonic anemometers compute the time it takes for a sonic pulse to travel between two transducers. The time of flight for the pulse is altered if the wind has a velocity component along the path between the transducers. For two pulses traveling in opposite directions, the times of flight are given by:

$$
\begin{aligned}
& t_{1}=\frac{d}{c-v} \\
& t_{2}=\frac{d}{c+v}
\end{aligned}
$$

where $t_{1}$ and $t_{2}$ are travel times in opposite directions, $d$ is the acoustic path length, $c$ is the local speed of sound in the medium, and $v$ is the spatially averaged velocity component along the acoustic path. The wind velocity can then be determined from the difference of the reciprocal times by :

$$
v=\frac{d}{2}\left(\frac{1}{t_{2}}-\frac{1}{t_{1}}\right)
$$

The advantage of this method is the removal of the speed of sound from the equation.

BASS does not record the travel times separately, it uses the difference between travel times to determine the flow component along an acoustic path. The time difference can be used in the following equation to calculate velocity:

$$
v=-\frac{d}{\Delta t} \pm \sqrt{\frac{d^{2}}{(\Delta t)^{2}}+c^{2}}
$$


where the correct root is easy to determine since one gives a velocity greater than the speed of sound. However, the accuracy of this equation obviously rest with an accurate measurement of the speed of sound. Equations (4-1a) and (4-1b) can be combined to yield an expression for the difference in travel times as:

$$
\Delta t=2 d v \frac{\left[1+\frac{v^{2}}{c^{2}}+\frac{v^{4}}{c^{4}}+\ldots\right]}{c^{2}}
$$

Some BASS TTBasic programs use only the first term in equation (4-4), such that the velocity is derived from:

$$
v=\frac{c^{2} \Delta t}{2 d}
$$

The error caused by the exclusion of the higher order terms for measurements performed in water is approximately $1 \mathrm{ppm}$ (Williams et al., 1987). Because the ratio of air velocity to speed of sound is generally larger in air, we expect this error to be substantially larger as well. The purpose of the following sections is to demonstrate where the more important errors will or can exist so that they may be eliminated if necessary.

\section{ERRORS FROM HIGHER ORDER TERMS}

The errors from higher order terms in equation (4-4) are more substantial in air than in water for two reasons. First, the average velocities seen in air are higher than those seen in the water. Second, the speed of sound in air is slower than the speed of sound in water by a factor of almost five. Therefore, the errors generated by the exclusion of the higher order terms in equation (4-4) require evaluation in order to determine whether (4-5) is a valid approximation in the atmosphere. The results of a comparison made at a virtual temperature of $273 \mathrm{~K}$ with an acoustic path length of $0.15 \mathrm{~m}$ are presented below: 


\begin{tabular}{|c|c|c|c|}
\hline Velocity & Time Diff & Time Diff. & $\%$ Error \\
\hline & 3 Terms & 1 Term & \\
\hline$(\mathrm{m} / \mathrm{sec})$ & (msec) & (msec) & \\
\hline 1.00000 & 0.00273 & 0.00273 & 0.00091 \\
\hline 5.00000 & 0.01364 & 0.01363 & 0.02272 \\
\hline 10.00000 & 0.02729 & 0.02727 & 0.09089 \\
\hline 15.00000 & 0.04099 & 0.04090 & 0.20451 \\
\hline 20.00000 & 0.05474 & 0.05454 & 0.36357 \\
\hline 25.00000 & 0.06856 & 0.06817 & 0.56807 \\
\hline 30.00000 & 0.08248 & 0.08180 & 0.81799 \\
\hline
\end{tabular}

Table 4-1. Error in higher order terms

It is an obvious result from the table that errors due to the omission of the higher order terms should not exceed one percent of the true value of the time difference. Since the time difference and velocity are linearly related, the same can be said for our velocity estimates. Thus, the higher order terms in equation (4-4) will be neglected during this first stage in the development of the atmospheric vorticity meter. If more accuracy than that provided by equation (4-5) is required, a combination of temperature and/or hygrometer measurements could be used to deliver an accurate speed of sound for use in equation (43). Equation (4-5) is used in the error analysis because it is used by BASS, and it provides more computational efficiency than equations (4-3) or (4-4).

\section{ERRORS DUE TO VIRTUAL TEMPERATURE CHANGES}

The speed of sound in air is a function of both temperature and humidity. These effects are most easily related to the speed of sound using the sonic virtual temperature in the following equations:

$$
c=\sqrt{403 T_{v_{s}}}
$$




$$
T_{v_{s}}=T(1+0.51 q)
$$

where $\mathrm{c}$ is the group speed of sound waves, $T_{v_{s}}$ is the sonic virtual temperature, $\mathrm{T}$ is temperature and $q$ is specific humidity (Schotanus, 1983). This quantity differs slightly from the classically derived virtual temperature given by:

$$
T_{v}=T(1+0.61 q)
$$

where $T_{v}$ is the virtual temperature. Virtual temperature is the temperature that dry air would need to have a density equal to moist air at the same pressure (Stull, 1988). Because water vapor is less dense than diatomic oxygen and nitrogen, a packet of moist air would be less dense than a packet of dry air at the same temperature and pressure.

Although the ability to neglected the higher order terms in equation (4-4) has been shown, the calculations that were involved assumed perfect measurements of virtual temperature. Accurate measurement of humidity is often difficult in the marine environment. Therefore, it is of interest to see what the exclusion of this correction would do to our measurements. Assuming that a proper measurement of temperature is provided at $300 \mathrm{~K}$, the following tables show the errors that might occur in equation (4-5) for

\begin{tabular}{|c|c|c|c|}
\hline Relative & Velocity & Velocity & $\%$ Error \\
\hline Humidity & Temp & Temp \& & \\
\hline$(\%)$ & & Humidity & \\
\hline 30.00 & 5.00 & 5.02 & 0.33 \\
\hline 40.00 & 5.00 & 5.02 & 0.45 \\
\hline 50.00 & 5.00 & 5.03 & 0.56 \\
\hline 60.00 & 5.00 & 5.03 & 0.67 \\
\hline 70.00 & 5.00 & 5.04 & 0.78 \\
\hline 80.00 & 5.00 & 5.04 & 0.89 \\
\hline 90.00 & 5.00 & 5.05 & 1.00 \\
\hline 100.00 & 5.00 & 5.06 & 1.11 \\
\hline
\end{tabular}
relative humidities between $30 \%$ and $100 \%$ :

Table 4-2. Humidity error when measuring $5 \mathrm{~m} / \mathrm{s}$ 


\begin{tabular}{|r|r|r|r|r|}
\hline Relative & Velocity & Velocity & & \% Error \\
\hline Humidity & Temp & Temp \& & & \\
\hline$(\%)$ & & Humidity & & \\
\hline 30.00 & 10.00 & 10.03 & & 0.33 \\
\hline 40.00 & 10.00 & 10.04 & & 0.45 \\
\hline 50.00 & 10.00 & 10.06 & & 0.56 \\
\hline 60.00 & 10.00 & 10.07 & & 0.67 \\
\hline 70.00 & 10.00 & 10.08 & & 0.78 \\
\hline 80.00 & 10.00 & 10.09 & & 0.89 \\
\hline 90.00 & 10.00 & 10.10 & & 1.00 \\
\hline 100.00 & 10.00 & 10.11 & & 1.11 \\
\hline
\end{tabular}

Table 4-3. Humidity error when measuring $10 \mathrm{~m} / \mathrm{s}$

Once again, the errors produced are much less than $2 \%$, even for extreme cases.

Therefore, the use of a separate hygrometer is not necessary for reasonable accuracy in the acoustic velocity measurements. In fact, it is worth noting that the errors resulting from the exclusion of higher order terms in (4-5) and specific humidity in (4-6) tend to offset each other.

\section{ERRORS DUE TO FLUCTUATING TEMPERATURE}

Since the need for a separate hygrometer and the use of higher order terms in equation (4-4) have been eliminated, the next step is a test for the need of an atmospheric temperature sensor. The vorticity meter should be capable of operating in a broad range of temperatures. Therefore, an operating range of $273-310 \mathrm{~K}$ will be assumed. If a user were trying to pick a temperature that would minimize errors throughout this range, an fixed temperature of $293 \mathrm{~K}$ might be used. The following table compares the errors generated by this temperature assumption when a $0.15 \mathrm{~m}$ acoustic path is subjected to the extreme temperatures of its range.

In Table (4-4), the time differences are first computed by inverting equation (4-5) (as if the modified BASS instrument was operating in air) and using the velocity that is shown in the table to calculate the speed of sound at a temperature of $273 \mathrm{~K}$ through equation (46). The following column shows the velocity calculated using the same time difference with an assumed temperature of $292 \mathrm{~K}$. The percent error is presented in the next column. 


\begin{tabular}{|r|r|r|r|r|r|r|r|}
\hline Velocity & Measured & Velocity & $\%$ Error & & Measured & Velocity & $\%$ Error \\
\hline (m/s) & Time Diff & w/ $292 \mathrm{~K}$ & in $292 \mathrm{~K}$ & & Time Diff & w/ $292 \mathrm{~K}$ & in $292 \mathrm{~K}$ \\
\hline & $273 \mathrm{~K}(\mathrm{~ms}$ & Assumed & w/ T=273 & & $310 \mathrm{~K}(\mathrm{~ms}$ & Assumed & w/ T=310 \\
\hline 1.00000 & 0.00273 & 1.06960 & 6.95971 & & 0.00240 & 0.94193 & 5.80658 \\
\hline 5.00000 & 0.01363 & 5.34798 & 6.95971 & & 0.01201 & 4.70968 & 5.80634 \\
\hline 10.00000 & 0.02727 & 10.69598 & 6.95971 & & 0.02401 & 9.41936 & 5.80649 \\
\hline 15.00000 & 0.04090 & 16.04396 & 6.95971 & & 0.03602 & 14.12903 & 5.80646 \\
\hline 20.00000 & 0.05454 & 21.39194 & 6.95971 & & 0.04803 & 18.83871 & 5.80643 \\
\hline 25.00000 & 0.06817 & 26.73993 & 6.95971 & & 0.06003 & 23.54838 & 5.80647 \\
\hline 30.00000 & 0.08180 & 32.08791 & 6.95971 & & 0.07204 & 28.25807 & 5.80644 \\
\hline
\end{tabular}

Table 4-4 Assumed temperature error

The next three columns repeat the process for a measurement taken at a temperature of $310 \mathrm{~K}$. For the acoustic paths to meet the accuracy requirement, it is evident that a temperature sensor of some form will be necessary. This temperature sensor would be used to adjust the speed of sound estimate generated by equation (4-6).

\section{ERRORS IN THE MEASURED TIME DIFFERENCE}

Throughout the error analysis, it was assumed that the time difference as measured by the BASS instrumentation was without substantial error. For BASS time difference measurements, the accuracy is approximately $40 \mathrm{ps}$ (Trivett, 1991). The extreme accuracy of this measurement is generated by the cancellation of noise generated errors within the BASS instrument when the voltages from the integrating capacitors are subtracted. The $40 \mathrm{ps}$ error in time differences is several orders of magnitude smaller than the time difference generated by a $1 \mathrm{~m} / \mathrm{s}$ mean wind. Therefore, this error is not considered.

BASS instrumentation has shown an accuracy of $7 \mathrm{~ns}$ for time of flight measurements (Trivett, 1991). As shown by equation (4-2), the use of times of flight instead of time differences would alleviate the need for additional temperature and/or humidity sensors when taking velocity measurements. A $7 \mathrm{~ns}$ time error would equate to a velocity error of less than $0.6 \mathrm{~cm} / \mathrm{sec}$, i.e., it would provide a much better estimate than the errors shown in the rest of this chapter. However, the time of flight technology is being put into BASS instruments at the time that this thesis is being written, and it is not immediately available. 


\section{CHAPTER 5}

\section{WINDTUNNEL}

A windtunnel was used to calibrate and test the velocity measurements of one axis of the atmospheric vorticity meter. In order to test one axis of the vorticity meter properly, it was necessary to understand the characteristics of the windtunnel that was used. The velocities at three cross-sections, with twenty-eight experimental samples per crosssection per wind speed, were measured with a new pitot tube. The cross-sections were taken at distances of $2.5 \mathrm{~cm}, 71.8 \mathrm{~cm}$, and $98.4 \mathrm{~cm}$ behind the front, leftmost, window of the windtunnel shown in the photographs. The photographs in Figure (5-1) display the experimental section and shape of the windtunnel. The fan is used to pull air, rather than push air, through the tunnel in order to generate a more laminar flow field inside the experimental section. The experimental section has a height of $61.0 \mathrm{~cm}$ and a width of $91.4 \mathrm{~cm}$. The air intake at the front of the tunnel has a height of $1.05 \mathrm{~m}$ and a width of $1.89 \mathrm{~m}$.

The wind-speeds at the center of the second cross-section were used as the normalizing velocity for each of the three velocities used in the calibration. The three, normalized velocities were $2.35 \mathrm{~m} / \mathrm{s}, 4.37 \mathrm{~m} / \mathrm{s}$, and $8.81 \mathrm{~m} / \mathrm{s}$. Using the pitot tube, an experimental sample was taken approximately every $10.2 \mathrm{~cm}$ in the horizontal and every $7.6 \mathrm{~cm}$ in the vertical for each cross-section. The experimental samples avoided the top and bottom 7.6 $\mathrm{cm}$ as well as the first $10.2 \mathrm{~cm}$ on each side of the windtunnel.

The windtunnel had no record of calibrations except the one that occurred when the windtunnel was first built. That calibration was thirty years old. Therefore, there was some concern that the characteristics of the windtunnel had changed. When the new calibration experiments were performed, the windtunnel displayed the same characteristics that it had displayed thirty years ago. Based on this thirty-year stability, it was assumed that the windtunnel results were stable for the few weeks of its use during this experiment. A contour plot of the windtunnel's second experimental cross-section at a normalized velocity of $2.35 \mathrm{~m} / \mathrm{s}$ is provided in the Figure (5-2). 


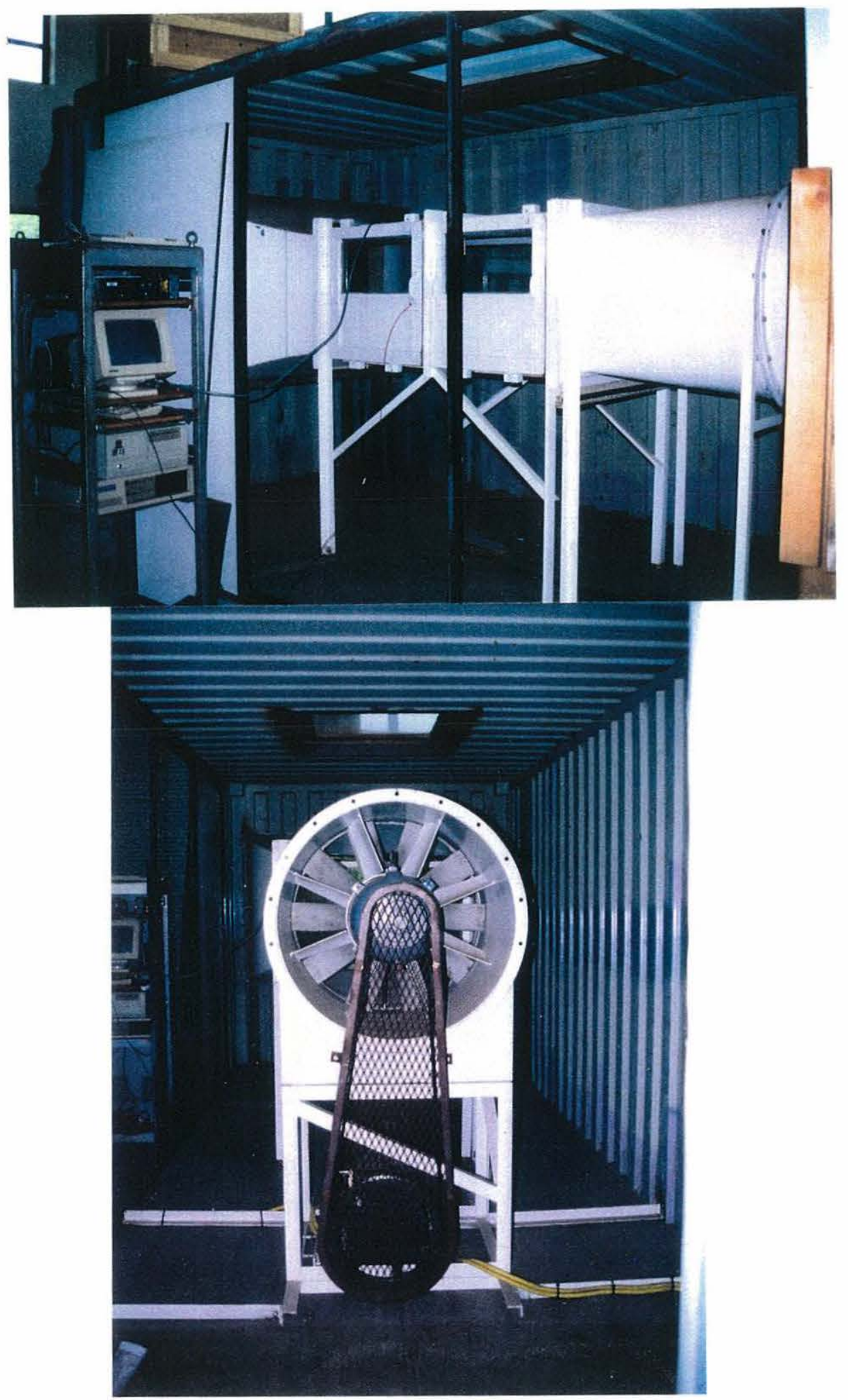

Figure 5-1. Photographs of the windtunnel 
Test Section Contour for $2.35 \mathrm{~m} / \mathrm{sec}$ at Center

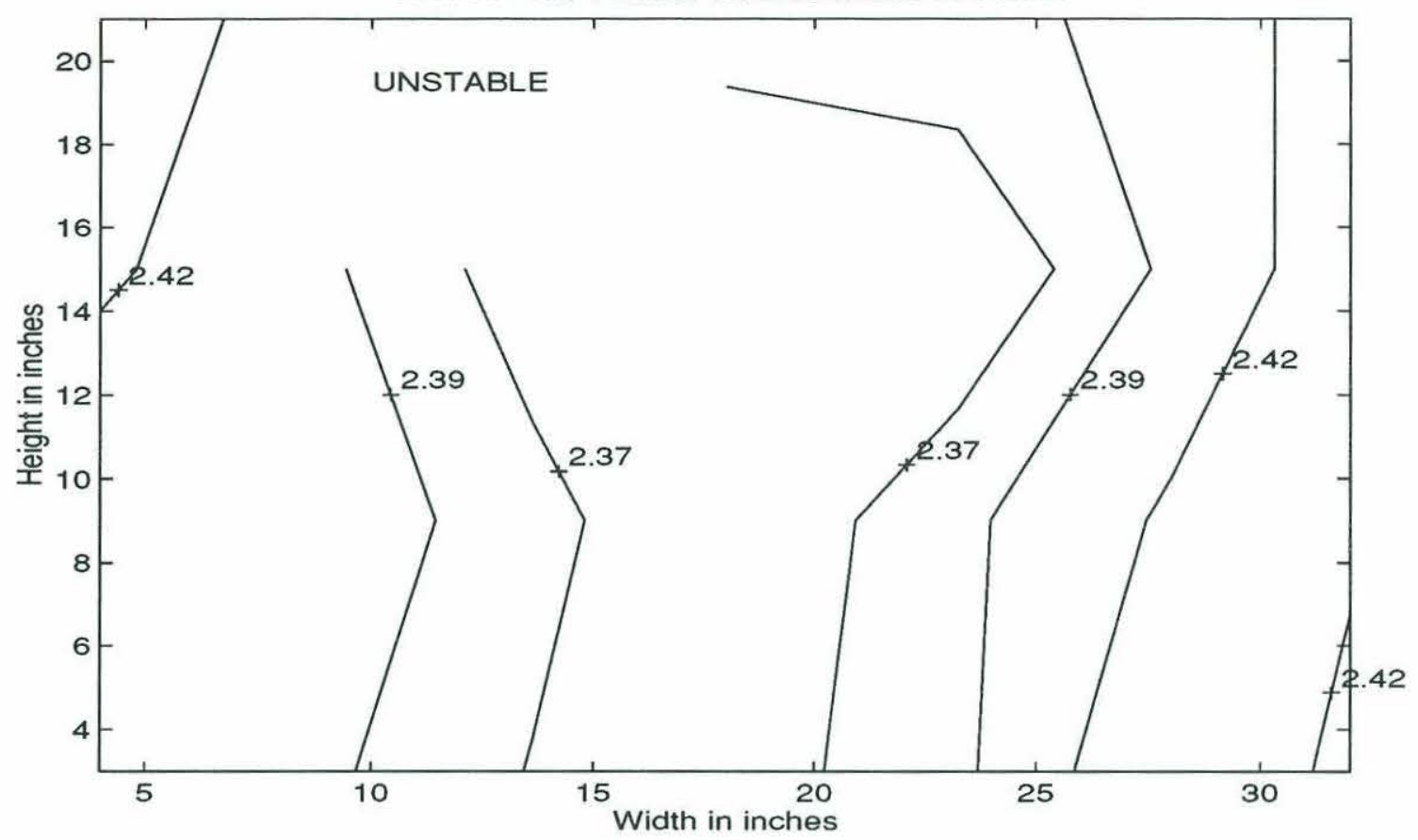

Figure 5-2. Contour plot of second cross-section

Appendix $\mathrm{C}$ contains the Basic and $\mathrm{C}$ programming files that were written for use with the windtunnel. The parts of the programs which refer to CIO8 are referring to files for the A/D board. The A/D board files came with the A/D board, and they are not included for this reason. In addition, a portion of the CPU's RAM was defined as the D drive when Windram.bas was running. This was done in the config.sys file using ramdrive.sys. The use of RAM as a dummy drive allowed more rapid input and output of data to and from the file Diff.tmp. 


\section{CHAPTER 6}

\section{RESULTS AND CONCLUSIONS}

This thesis was a test of the feasibility of converting BASS instrumentation for the ocean into atmospheric instrumentation. There were several changes to the circuitry that were expected for the transfer of technology to be successful. First, the resonant frequency of the transducers needed to be reduced because the absorption of high frequency sound in air is greater than that for water. Second, the timing of the circuitry needed to be adjusted in order to account for the slower group speed of sound waves in air in comparison to water. Third, the resonant frequency of the LC circuit used to excite the transducers had to be lowered to the resonant frequency of the new transducers. Using these few changes, it was assumed that a working instrument for atmospheric use could be developed.

After an extensive search for a set of transducers that were resonant at a frequency near $200 \mathrm{kHz}$, the E-188/220's by Massa Products were selected. These transducers provided adequate coupling to air due to their $1 / 4$ wavelength silicon matching layer. The optimal signal frequency of these transducers occurred near $220 \mathrm{kHz}$, and the four transducers of the initial order compared nicely in their response to an HP4195A Spectrum Analyzer. The E-188/220's were then subjected to a ringing analysis. The results shown in Figures (3-13) and (3-14) show that the ringing of the transducers for path lengths of $15.0 \mathrm{~cm}$ would not be a concern.

An error analysis concerning the use of the current BASS equation for velocity and the accuracy of the time difference measurement was also conducted. This analysis showed that the equation used for analyzing BASS velocity data would be of sufficient accuracy for some tests. However, the use of more terms in equation (4-4) or equation (4-3) in the TTBasic program could prove to be a quick way to increase accuracy for air measurements. The error in time difference measurements for BASS instrumentation is so small that it is not worth consideration at this point.

Finally, a windtunnel was prepared to test the accuracy of the velocity measurements against the measurements made by a calibrated pitot tube. A QBasic code which recorded 
the time of a measurement and the temperature in ${ }^{\circ} \mathrm{C}$, barometric pressure in mbars, and velocity in $\mathrm{m} / \mathrm{s}$ of that measurement was developed. Additionally, the windtunnel showed very long term stability in its calibration measurements. The measurements of velocity (or simply a voltage difference) at a particular time for BASS instrumentation are recorded on its internal Tattletale using TTBasic.

\section{INITIAL BENCH TESTS}

When the modified timing and burst generation board was inserted into the remaining BASS circuitry, there were two problems. First, the almost $60 \mathrm{~dB}$ losses of the E$188 / 220$ 's over a 15.0 centimeter path length were higher than those of the BASS transducers through water. In this case, the loss was mainly due to the impedance mismatch and spreading loss that resulted in a low received signal (rather than plane-wave attenuation of the signal). Secondly, there was noise in the receiver that interfered with the received signal. This noise was occurring in the same frequency band as the received signal. These problems had to be fixed before a working device could be constructed.

The problem that could be solved was that of signal loss. The signal in the BASS instrumentation limited the input to a transducer to four volts. The signal was increased to twelve volts and a step-up transformer was used to achieve a twenty-nine volt transmit signal. The use of a twenty-nine volt signal allowed the receiving transducer to receive a signal near $300 \mathrm{mV}$. This signal was large enough to be detected in the zero-crossing counting circuitry. Therefore, simply generating a larger signal solved the first problem.

The second problem was more complex. The circuitry ringing was unexpected because the ringing analysis had shown rapid reduction in signal strength after the transducers were removed from the signal. Therefore, we suspected that this problem was due to ringing inside the BASS instrumentation. In order to be sure, we double checked the ringing analysis for the transducers and obtained results that were very similar to the previous set of data. Therefore, there was some other problem.

Because the LeCroy analyzer was having no problem detecting a signal, the BASS circuitry had to have a different nature that allowed the ringing to occur. The first attempts to solve the problem involved matching the impedance for both the transmit and 
receive sides of the circuit at a lower impedance. The impedances needed to be matched to avoid phase shifts, i.e., when voltages are zero, the phase shifts between voltages and currents are zero (Brown and Lawson). The impedance was reduced in order to get a larger signal into the air. This produced slight improvements, but they were not enough to detect a received signal. Another attempt involved adding circuitry between the transducers and the existing BASS circuitry that was designed to damp the receiver noise. The circuit and its relationship to a transducer are shown in Figure (6-1). This circuit

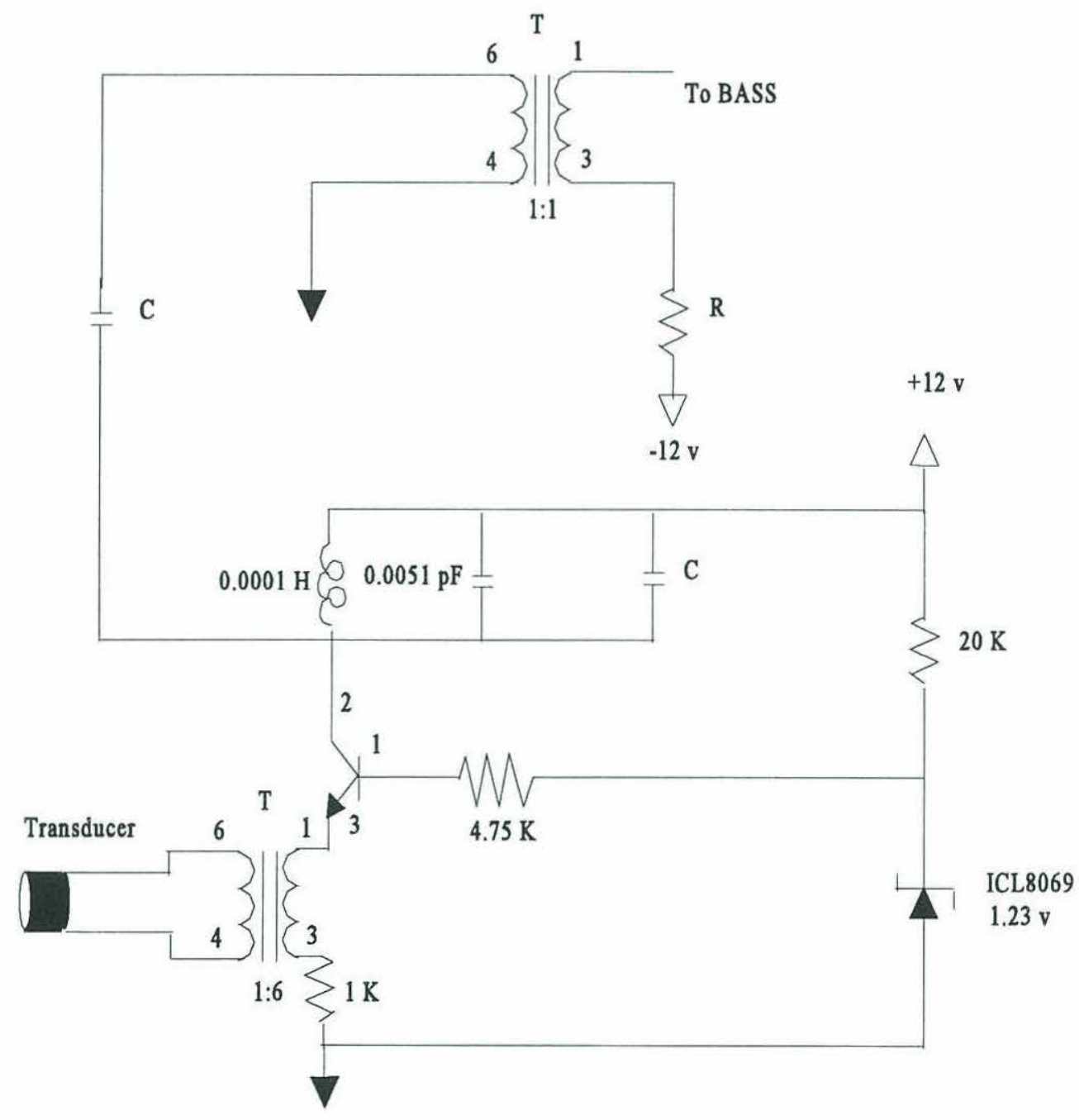

Figure 6-1. Damping circuit 
worked nicely on a temporary (bread) board, but when it was incorporated in the BASS instrumentation, a received signal could not be detected above the circuit noise. Due to the time constraints involved, it was proving to be unlikely that an actual measurement would be made.

The next possible solution is to increase the impedance going into the transducer in order to create more damping in the circuitry. Of course, this introduces the possibility of phase shifts between voltage and current which would introduce errors into measurements of the time difference. These errors could be calibrated out of the measurement. Since the transducers were not tested for fluctuations due to temperature shifts, the calibration might need to be conditioned on temperature (Brown and Lawson).

\section{FUTURE TUNNEL AND FIELD TESTS}

The first test that will need to be performed with BASS instrumentation is a one path velocity measurement in the windtunnel. When the noise in the circuitry is small enough that a received signal can be detected, the rest of the equipment for these tests will be waiting. The first result to look for will be voltage outputs (as recorded in the Tattletale) that are proportional to the different wind speeds. These windtunnel tests should not exceed $2.4 \mathrm{~m} / \mathrm{s}$ until corrections are made to linearize the constant current source response with faster transistors (Williams, 1995). If the changes in velocity prove to be proportional to the changes in voltage recorded by BASS, the next step will be to determine the cosine response of the acoustic path axis to the direction of velocity. When the cosine response measurements are made, the effects of flow distortion by the transducers should be apparent.

Errors in the velocity measurements due to flow distortion should show proportionality to the following equations (Thwaites, 1995):

$$
\frac{U_{\infty} d}{2 l} \operatorname{Cos} \theta \quad \text { Potential Flow }
$$




$$
U_{\infty}\left(\frac{d}{L}\right)^{\frac{4}{3}} \quad 3-D \text { Sphere Wake }
$$

where $\mathrm{d}$ is the diameter of the object in the flow, $l$ is the acoustic path length, and $\mathrm{L}$ is the distance downstream of the object. However, it has been noted that it is better to calibrate structures in a windtunnel than to attempt calibration using theory (Wyngaard, 1981). If left uncalibrated, these flow distortion errors would make accurate shear measurements impossible. Even calibrated acoustic instruments can have errors as large as $45 \mathrm{~cm} / \mathrm{sec}$ for ten second averages of wind speed (Solent Research, 4.1). However, these errors are generated by instruments that do not have the accuracy of time measurements that BASS does. Additionally, Thwaites (1995) has shown that wake generated errors tend to cancel using a four-path design. Ultimately, the accuracy of a four-path axis calibration will determine if a velocity shear measurement can be made with $15.0 \mathrm{~cm}$ acoustic paths.

If $15.0 \mathrm{~cm}$ path lengths are insufficient to provide shear measurements, the transducers could be separated by longer acoustic paths. Equations (6-1) and (6-2) show that the acoustic path length is inversely proportional to the expected flow distortion errors. In addition, the differences in velocities created by shear would be greater over longer paths. However, the error created by not knowing the zero crossings precisely would increase with path length according to the following (Helstrom, 1975):

$$
\Delta t \sim \frac{\text { Voltage Noise }}{2 \Pi f *(\text { Signal Voltage })}
$$

due to the attenuation and spreading of the signal over longer path lengths.

If the $15.0 \mathrm{~cm}$ paths are sufficient to measure shear, a four-path axis would then be deployed for field tests. The horizontal acoustic paths would need to be aligned with the mean wind, and they would be used to measure shear. The measured difference between horizontal velocity in the top and bottom paths could be used in equation (2-3) to determine values of $\mathrm{u}_{*}$. These values could be compared to the $\mathrm{u}_{*}$ values generated by a 
sonic anemometer deployed nearby.

Eventually, a three-axis vorticity meter could be deployed. It could provide simultaneous direct measurements of shear and $\mathrm{u}_{*}$ in the same measurement volume. This would allow an improvement in the estimates of von Karman's constant. The three-axis vorticity meter could be deployed under various conditions to determine the most likely value for von Karman's constant. 


\section{References}

L. Bergmann, Ultrasonics: And Their Scientific and Technical Applications, John Wiley \&Sons, New York, 1938.

R. T. Beyer and S. V. Letcher, Physical Ultrasonics, Academic Press, New York, 1969.

N. L. Brown and K. D. Lawson, A High Precision Acoustic Current Sensor, Neil Brown Instrument Systems, Cataumet, MA.

A. Grelle and A. Lindroth, "Flow distortion by a solent sonic anemometer: wind tunnel calibration and its assessment for flux measurements over forest and field," J. Atmos. Oceanic Techn., 11, 1529-1542, 1994.

G. Hayward, A. Gachagan, R. Hamilton, D. A. Hutchins, and W. M. D. Wright, "Ceramic-epoxy composite transducers for non-contacting ultrasonic applications," in New Developments in Ultrasonic Transducers and Transducer Systems, Proceedings of the SPIE conference held 21-22 July 1992, Belingham, WA, pp.49-56.

K. F. Herzfeld, Absorption and Dispersion of Ultrasonic Waves, Academic Press, New York, 1959.

J. R. Holton, An Introduction to Dynamic Meteorology, Academic Press: International Geophysics Series, New York, 1979.

H. O. Kneser, "Molekulare schallabsorption in gasen", Z. Techn. Phys., 16, 213, 1935.

P. Schotanus, F. T. M. Nieuwstadt, and H. A. R. de Bruin, "Temperature measurement with a sonic anemometer and its application to heat and moisture fluxes", Bound.-Layer Meteor., 26, 81-93, 1983.

W. A. Smith, "New applications in ultrasonic transducers emerging from innovations in piezoelectric materials," in New Developments in Ultrasonic Transducers and Transducer Systems, Proceedings of the SPIE conference held 21-22 July 1992, Belingham, WA, pp.3-26.

Solent Research, Ultrasonic Anemometer, Product Spec., Needham, MA, Issue 4.1

R. B. Stull, An Introduction to Boundary Layer Meteorology, Kluwer Academic Pubs., Boston, MA, 1988.

H. Tennekes and J. L. Lumley, A First Course in Turbulence, MIT Press, Cambridge, 
MA, 1980.

F. T. Thwaites, Development of an Acoustic Vorticity Meter to Measure Shear in OceanBoundary Layers, P.H.D. Thesis, M.I.T.-W.H.O.I., 1995.

F. T. Thwaites, A. J. Williams 3rd, E. A. Terray, and J. H. Trowbridge, “A family of acoustic vorticity meters to measure ocean boundary layer shear," in the Fifth Working Conference on Current Measurement, Proceedings of the IEEE conference held 7-9 February 1995, St. Petersburg, FL, pp. 193-198.

D. A. Trivett, Diffuse Flow from Hydrothermal Vents, P.H.D. Thesis, M.I.T.-W.H.O.I., 1991.

A. J. Williams 3rd, J. S. Tochko, R. L. Koehler, W. D. Grant, T. F. Gross, and C. V. R. Dunn, "Measurement of turbulence in the oceanic bottom boundary layer with an acoustic current meter array,"J. Atmos.Oceanic Techn., 2, 312-327, 1987.

A. J. Williams 3rd, "Linearity and noise in differential travel time acoustic velocity measurement", in the Fifth Working Conference on Current Measurement, Proceedings of the IEEE conference held 7-9 February 1995, St. Petersburg, FL, pp. 216-219.

R. W. Wood, Supersonics: The Science of Inaudible Sounds, Brown University: Charles K. Colver Lectures (1937), Providence, RI, 1948.

J. C. Wyngaard, "The effects of probe-induced flow distortion on atmospheric turbulence measurements", J. App. Meteor., 20, 784-794, 1981. 


\section{APPENDIX A}

\section{Transducer Response Graphs}

A-1 Model using Thevenin equivalent circuit for receiving transducer

A-2 Direct measurements of transducer frequency response from HP4195A

A-3 Response of the transducer to an input signal using the direct measurements in A-2

The forms of ringing analysis that were not detailed in the text consisted of modeling one transducer and two transducer systems. The one transducer model of the frequency measurements from the HP4195A is shown in A-2 and A-3. The one transducer model produces more believable results than the one in the text, but its conditioning number is approximately $4.7 \times 10^{43}$ after digitization. The two transducer model consisted of a Thevinin equivalent circuit that was generated by modeling the piezoceramic resistor ringing into the silicon layer resistor and convolving the result. The Matlab programs that were used to generate the graphs immediately follow the graphs that they generated. The last two programs in this section show the Matlab routines used to create the graphs in the Ringing Analysis section of Chapter 3. 


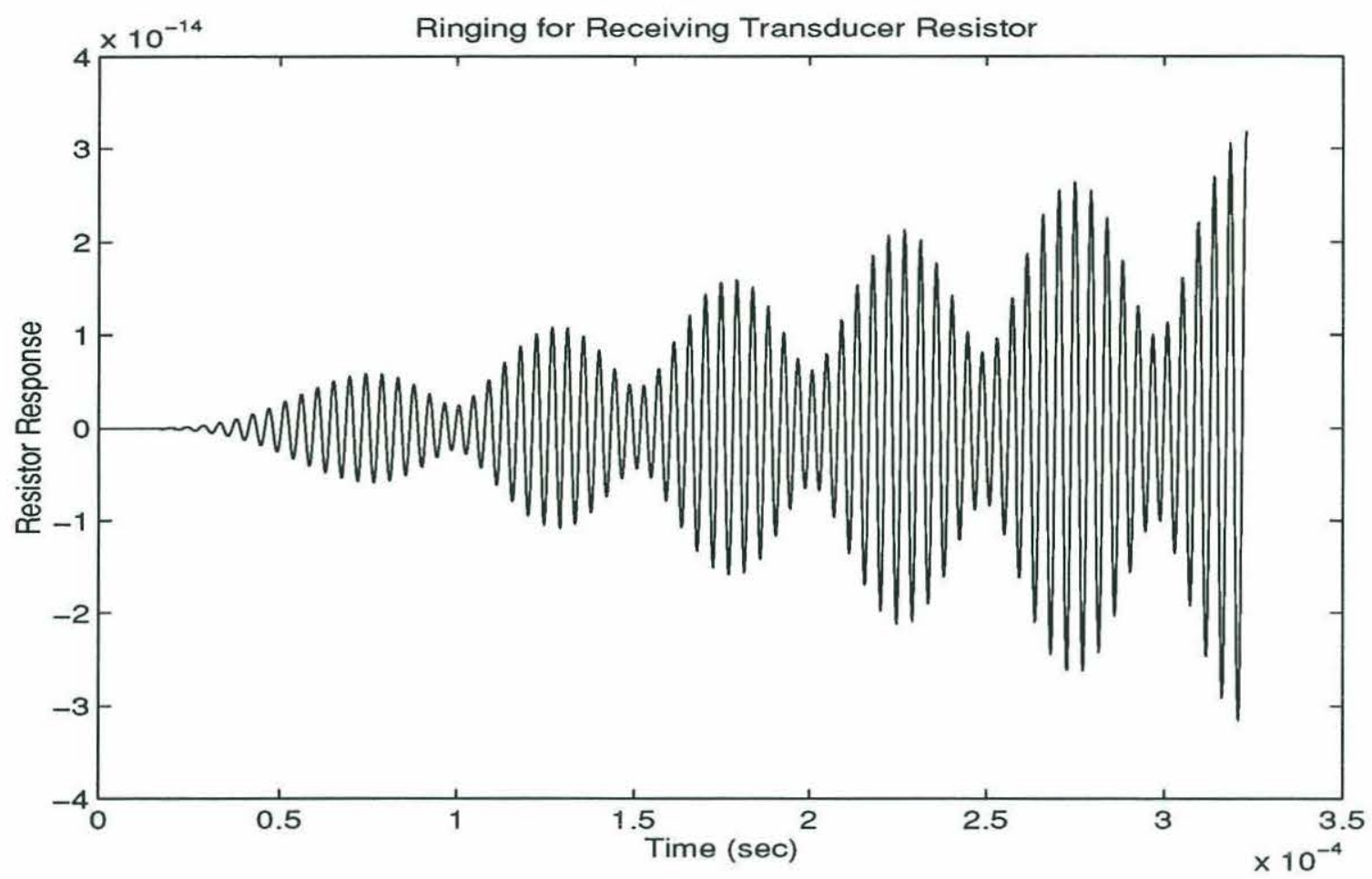

Figure A-1. Model using Thevinin equivalent circuit for receiving transducer

\%\%\%\%\%\%\%\%\%\%\%\%\%\%\%\%\%\%\%\%\%\%\%\%\%\%\%\%\%\%\%\%\%\%\%\%\%\%\%\%\%\%

$\%$ File saved as ring_eq.m that was used to generate the receiving transducer ringing plot clear

$\mathrm{L}=0.980964 \mathrm{e}-3$;

$\mathrm{L} 2=0.00084$;

$\mathrm{R}=45.5342$;

$\mathrm{R} 2=35$;

$\mathrm{C} 1=5.97691 \mathrm{e}-10$;

$\mathrm{C} 2=1.23217 \mathrm{e}-9$;

$\mathrm{C} 3=5.75 \mathrm{e}-10$;

$\mathrm{C} 4=2 \mathrm{e}-9$;

$\%$ Thevin equivalent about resistor for Silicon layer only

$\%$ num $=[10] ; \quad \% 1$ over 
$\%$ den $=[$ R2 $*$ L2 1 R2/C3]; \% $+1+1 / s$

$\%$ Thevin equivalent about resistor for piezoceramic only

$\%$ num $=\left[\begin{array}{lll}0 & 1 & 0\end{array}\right] ; \quad \% 1$ over

$\%$ den $=[\mathrm{R} * \mathrm{~L} 1 \mathrm{R} / \mathrm{C} 1] ; \quad \% \mathrm{~s}+1+1 / \mathrm{s}$

$\%$ Thevin Equivalent for transducer resistor coupling to Silicon layer

num $=\left[\begin{array}{lll}1 & 0 & 0\end{array}\right]$

den $=[\mathrm{R} * \mathrm{R} 2 * \mathrm{~L} * \mathrm{~L} 2 \mathrm{R} * \mathrm{~L}+\mathrm{R} 2 * \mathrm{~L} 2 \mathrm{R} * \mathrm{R} 2 * \mathrm{~L} / \mathrm{C} 3+\mathrm{R} * \mathrm{R} 2 * \mathrm{~L} 2 / \mathrm{C} 1+1 \mathrm{R} / \mathrm{C} 1+\mathrm{R} 2 / \mathrm{C} 3$

$\mathrm{R} * \mathrm{R} 2 /(\mathrm{C} 1 * \mathrm{C} 3)]$

fs $=4400000 ;$

parper $=1 / \mathrm{fs}$;

per $=1 / 220000$;

$\mathrm{I}=1$;

for $\mathrm{t}=0$ :parper: $14.2449 *$ per;

$$
\begin{aligned}
& \operatorname{wav}(\mathrm{I})=(1-\exp (-\mathrm{t} /(2 * \text { per }))) * \sin \left(\mathrm{t} / \operatorname{per}^{*} 2 * \mathrm{pi}\right) \\
& \operatorname{time}(\mathrm{I})=\mathrm{t} \\
& \quad \mathrm{I}=\mathrm{I}+1 ;
\end{aligned}
$$

end;

[numd,dend]= bilinear(num,den,fs,220000);

$\mathrm{x}=[$ wav zeros $(1,4 *$ length(time) $)]$

\% Receiving transducer represents a second set of coupling equivalents

numd $2=\operatorname{conv}$ (numd, numd);

dend $2=\operatorname{conv}($ dend,dend);

\% To see values unconvolved, simply replace numd $2 \&$ dend 2 w/ numd \& dend outy= filter(numd2, dend2,x); 
time $2=$ time $+\max ($ time $)+1 /$ fs;

time3 = time2 $+\max ($ time $)$;

time4= time $3+\max ($ time $)$;

time $5=$ time $4+\max ($ time $)$;

bigtime $=$ [time time 2 time 3 time 4 time5];

figure(1)

$\mathrm{W}=[100000: 100000: 10000000]$;

bode(num,den,w)

figure(2)

plot(bigtime,outy,'-');

title('Ringing for Receiving Transducer Resistor');

ylabel('Resistor Response');

xlabel('Time (sec)');

\%hold on

\%plot(bigtime, $\mathrm{x}$, ':' $^{\prime}$;

\%hold

\%\%\%\%\%\%\%\%\%\%\%\%\%\%\%\%\%\%\%\%\%\%\%\%\%\%\%\%\%\%\%\%\%\%\%\%\%\%\%\%\%\% 

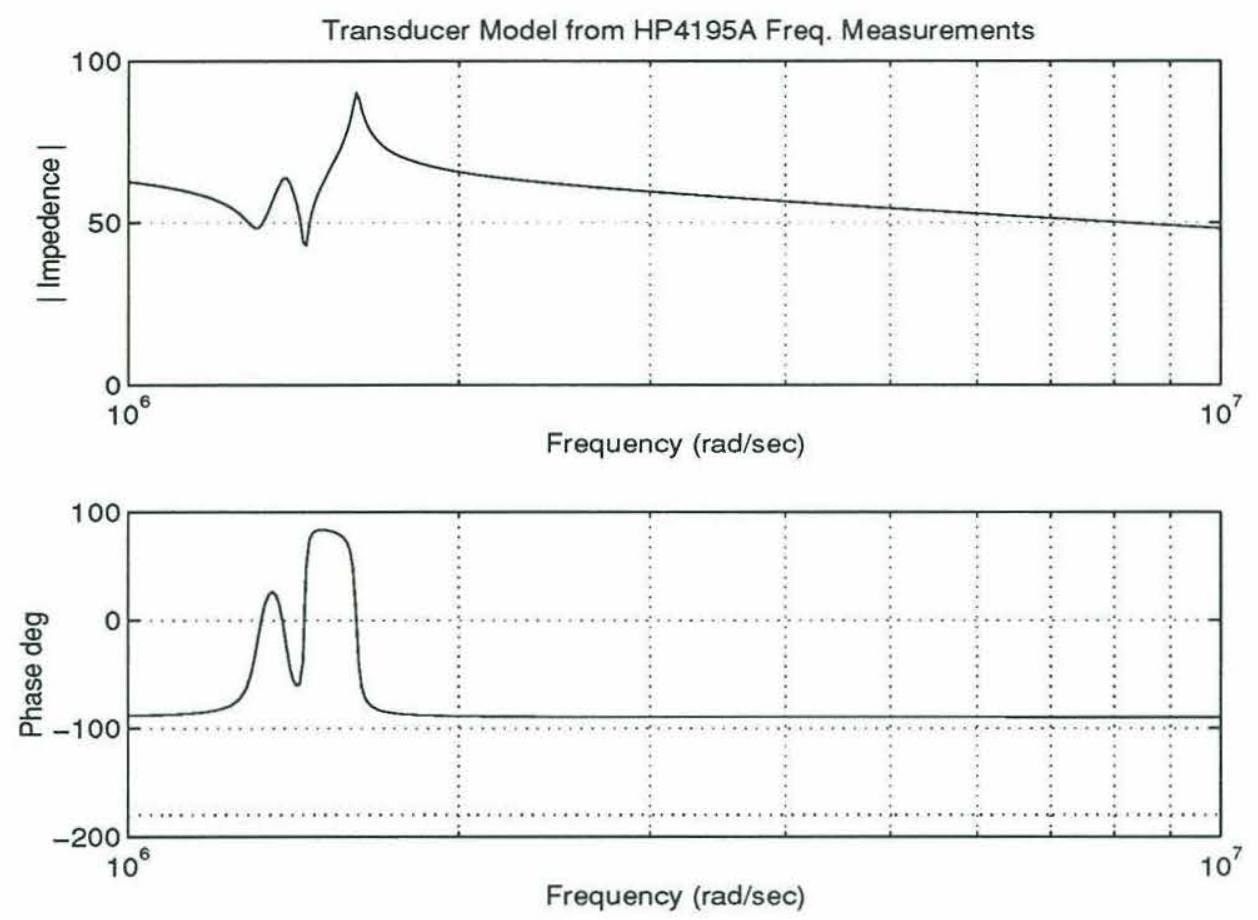

Figure A-2. Direct measurements of transducer frequency response using HP4195A

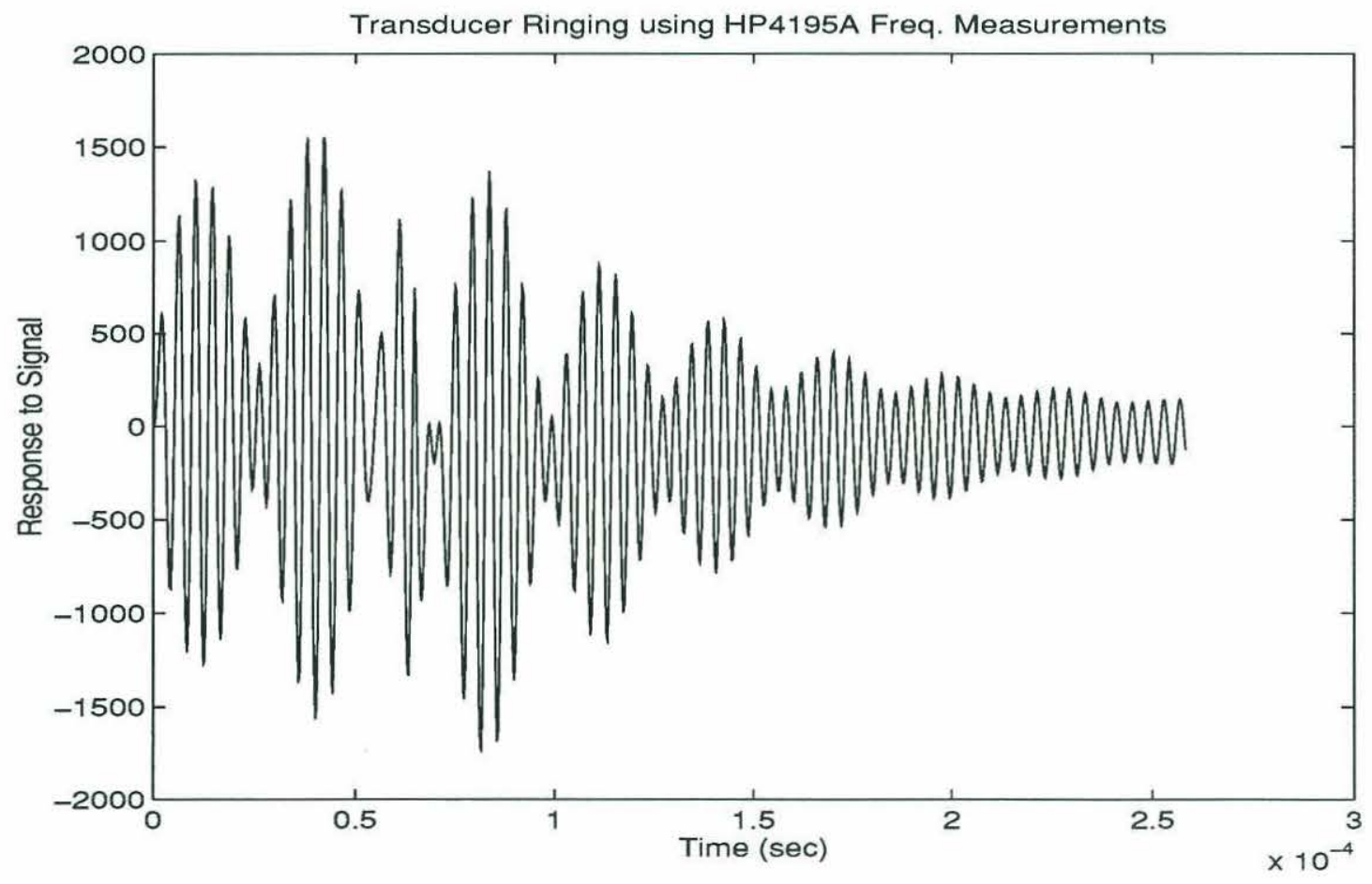

Fig. A-3. Model of response of transducer to input using A-2 
\%\%\%\%\%\%\%\%\%\%\%\%\%\%\%\%\%\%\%\%\%\%\%\%\%\%\%\%\%\%\%\%\%\%\%\%\%\%\%\%\%\%

$\%$ File saved as hp_ring.m that was used for Figures A-2 and A-3

clear

load hp4195a.txt

$\mathrm{f}=2 *$ pi*hp4195a(:,2);

MagImp $=1000 * \mathrm{hp} 4195 \mathrm{a}(:, 3) ; \quad \%$ Convert $\mathrm{k} \Omega$ to $\Omega$

PhaseA= hp4195a(:,4);

Rpart= MagImp.* ${ }^{*} \cos (\mathrm{pi} * \mathrm{PhaseA} / 180)$;

Ipart= MagImp. $* \sin (\mathrm{pi} * \mathrm{Phase} \mathrm{A} / 180)$;

h= Rpart + Ipart. $*$;

$\mathrm{nb}=4$;

na $=5$;

$\% \mathrm{H}$ is the Complex Freq., $\mathrm{f}$ is freq., $\mathrm{nb}$ is order of numerator,

$\%$ na is order of denominator, and $\mathrm{b}$ and a are real values for

$\%$ the numerator and denominator

$[\mathrm{b}, \mathrm{a}]=$ invfreqs $(\mathrm{h}, \mathrm{f}, \mathrm{nb}, \mathrm{na})$;

$\mathrm{w}=[1000000: 10000: 10000000] ;$

figure(1)

bode(b,a)

hold on

subplot(211)

title('Bode for hp_ring.m')

$\mathrm{fs}=4000000$

parper $=1 / \mathrm{fs}$;

per $=1 / 220000$;

$\mathrm{I}=1$;

for $\mathrm{t}=0$ :parper: $14.2449 *$ per; 


$$
\begin{aligned}
& \operatorname{wav}(\mathrm{I})=(1-\exp (-\mathrm{t} / \text { per })) * \sin \left(\mathrm{t} / \text { per }^{*} 2 * \mathrm{pi}\right) \\
& \operatorname{time}(\mathrm{I})=\mathrm{t} \\
& \quad \mathrm{I}=\mathrm{I}+1
\end{aligned}
$$

end;

$\%$ Transform descending powers of $\mathrm{s}$ to $\mathrm{z}$-transform coefficients

[bd,ad]= bilinear(b,a,fs);

$\mathrm{x}=[$ wav zeros $(1,3 *$ length(time $))]$;

$\%$ Convert Digital input into Digital Output through the

$\%$ Digital Filter of bd/ad

outy= filter $(\mathrm{bd}, \mathrm{ad}, \mathrm{x})$;

time $2=$ time $+\max ($ time $)+1 / f s$;

time $3=$ time $2+\max ($ time $)$;

time4= time $3+\max ($ time);

bigtime $=[$ time time 2 time 3 time4];

figure(2)

bode(b,a,w)

subplot(211)

ylabel('I Impedence l')

title('Transducer Model from HP4195A Freq. Measurements');

figure(3)

plot(bigtime,outy);

title('Transducer Ringing using HP4195A Freq. Measurements');

ylabel('Response to Signal');

xlabel('Time (sec)'); 


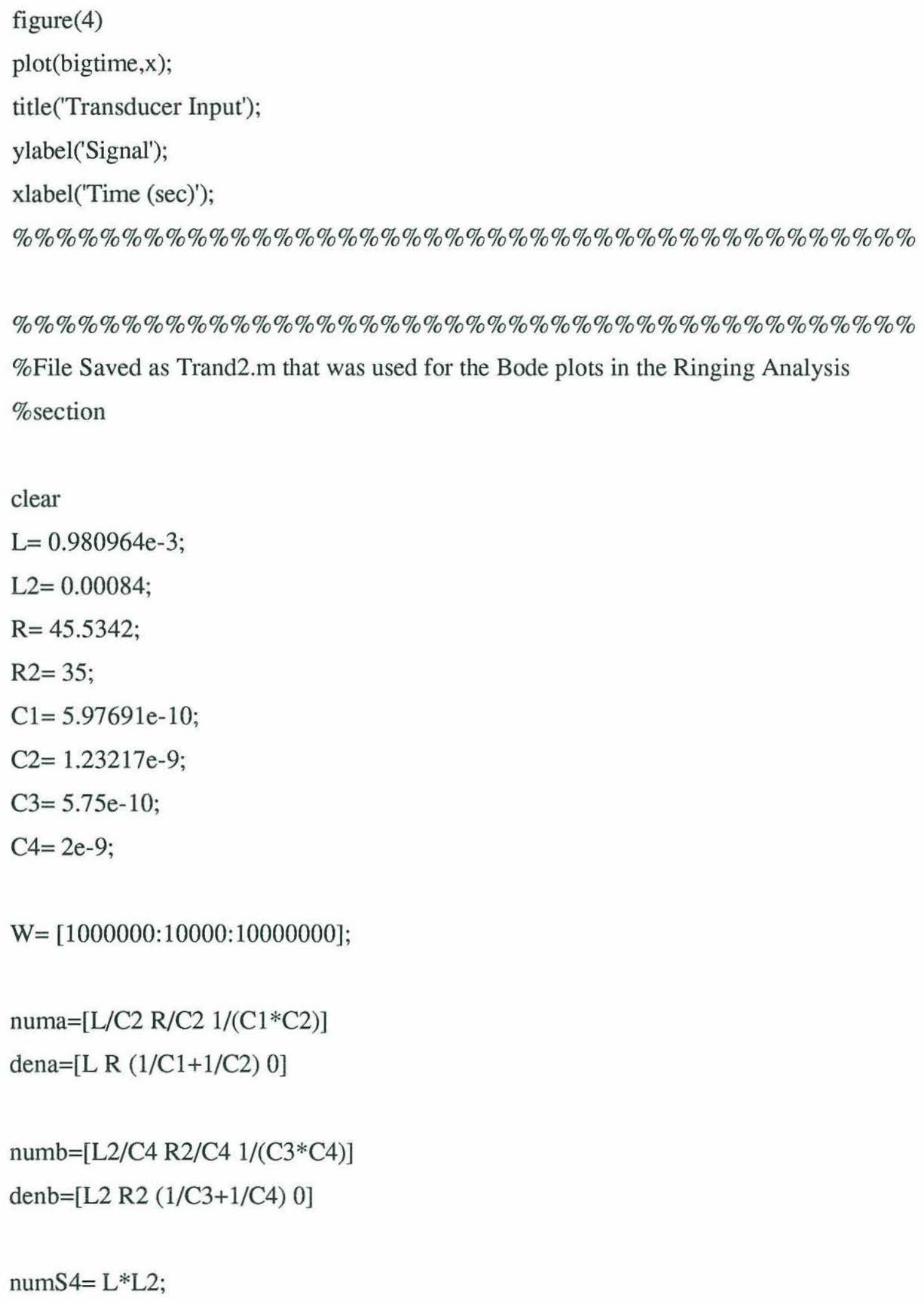




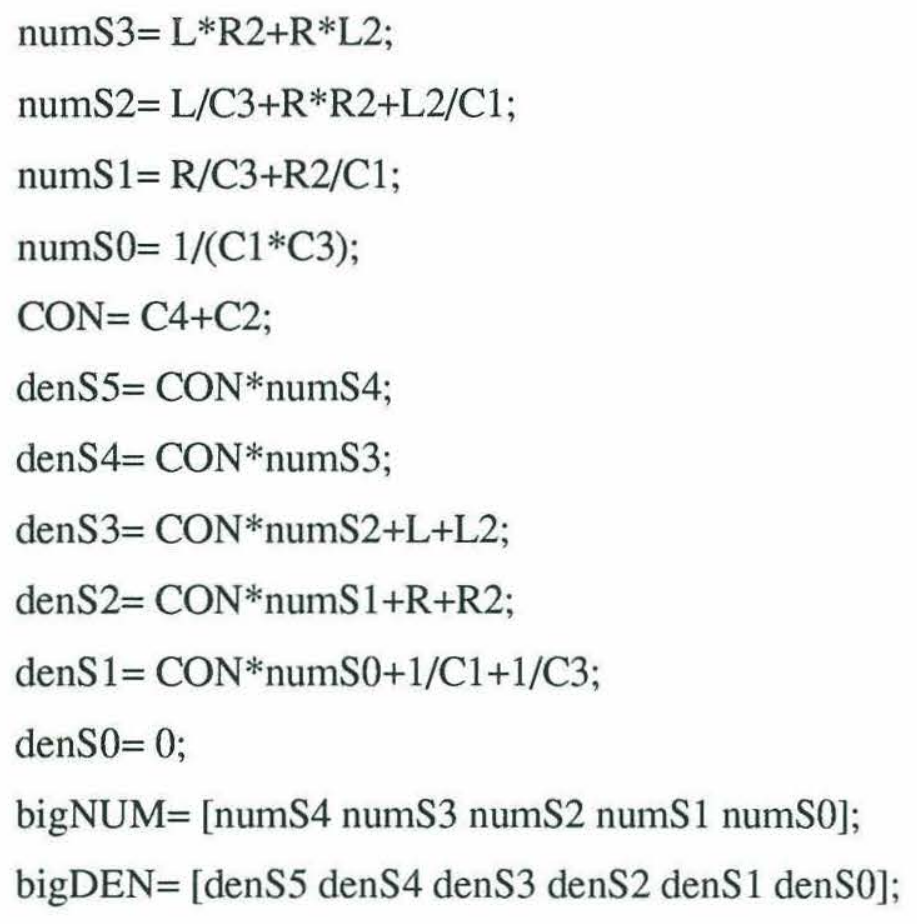


$\%$ Plot of the other half of the parallel circuit impedance and phase (alone)

figure(3)

bode(numb,denb,W)

hold on

$\operatorname{subplot}(211)$

ylabel('Mag. Impedance')

$\% \% \% \% \% \% \% \% \% \% \% \% \% \% \% \% \% \% \% \% \% \% \% \% \% \% \% \% \% \% \% \% \% \% \% \% \% \% \% \% \%$

\%\%\%\%\%\%\%\%\%\%\%\%\%\%\%\%\%\%\%\%\%\%\%\%\%\%\%\%\%\%\%\%\%\%\%\%\%\%\%\%\%\%

$\%$ File saved as ring.m that was used for the input signal and ringing analysis graphs

$\%$ presented in Chapter 3

clear

$\mathrm{fs}=4000000$;

parper $=1 / \mathrm{fs}$;

per $=1 / 220000$;

$\mathrm{I}=1$;

for $\mathrm{t}=0$ :parper: $14.2449 *$ per;

$$
\begin{aligned}
& \operatorname{wav}(\mathrm{I})=(1-\exp (-\mathrm{t} / \mathrm{per})) * \sin \left(\mathrm{t} / \operatorname{per}^{*} 2 * \text { pi }\right) \\
& \operatorname{time}(\mathrm{I})=\mathrm{t} ; \\
& \quad \mathrm{I}=\mathrm{I}+1 ;
\end{aligned}
$$

end;

figure(1)

plot(time,wav);

$\mathrm{L}=0.980964 \mathrm{e}-3$;

L2 $=0.00084$;

$\mathrm{R}=45.5342$;

$\mathrm{R} 2=35$;

$\mathrm{C} 1=5.97691 \mathrm{e}-10$; 


$$
\begin{aligned}
& C 2=1.23217 \mathrm{e}-9 ; \\
& C 3=5.75 \mathrm{e}-10 ; \\
& C 4=2 \mathrm{e}-9 ; \\
& \mathrm{w}=[1000000: 10000: 10000000] ;
\end{aligned}
$$

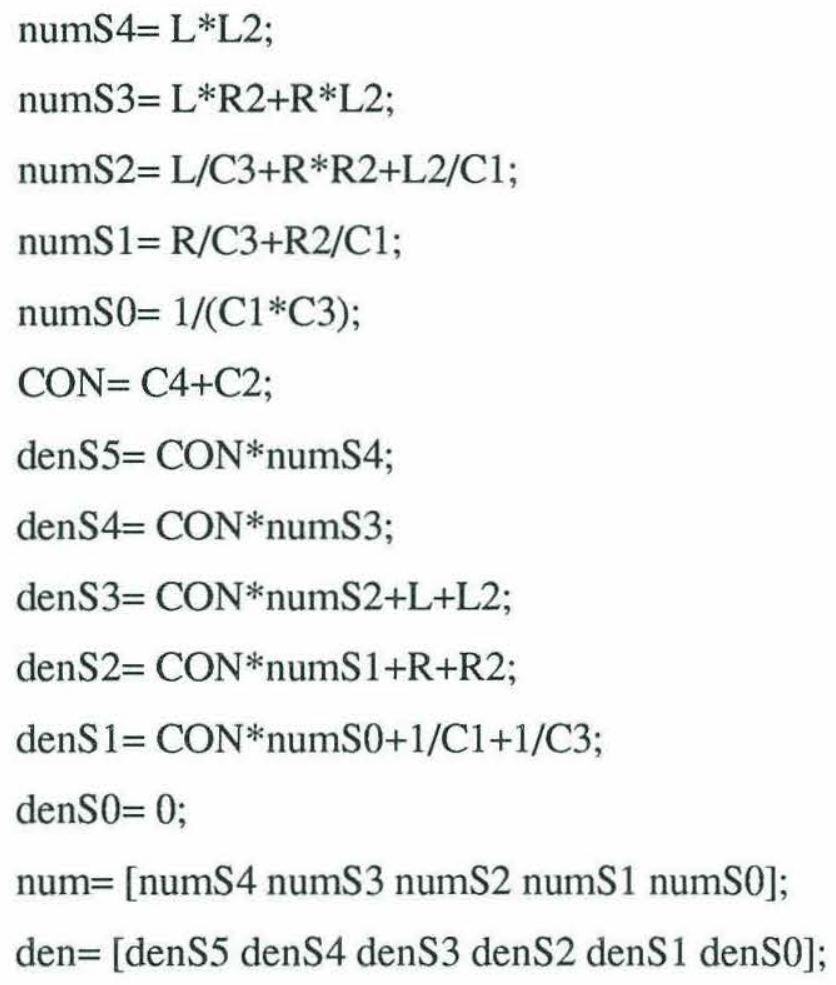


time4= time $3+\max ($ time $)$;

bigtime $=[$ time time 2 time 3 time 4$]$;

\author{
figure(2) \\ bode(num,den,w) \\ subplot(211) \\ ylabel('I Impedance l'); \\ title('Transducer Model');
}

figure(3)

plot(bigtime,outy);

title('Transducer Ringing');

ylabel('Response to Signal');

xlabel('Time (sec)');

\title{
figure(4)
}

plot(bigtime, $\mathrm{x}$ );

title('Transducer Input');

ylabel('Signal');

xlabel('Time (sec)');

$\% \% \% \% \% \% \% \% \% \% \% \% \% \% \% \% \% \% \% \% \% \% \% \% \% \% \% \% \% \% \% \% \% \% \% \% \% \% \% \% \% \%$ 


\section{APPENDIX B}

\section{Timing and Burst Generation Board}

B-1 Left half of timing and burst generator schematic

B-2 Right half of timing and burst generator schematic

The timing and burst generation board for an unmodified BASS is presented in this appendix. Because of the differences between air and water in group velocity and mean flow rate, it was necessary to make changes to the initial board. The major modifications to the board are detailed in Chapter 3 of the text. 


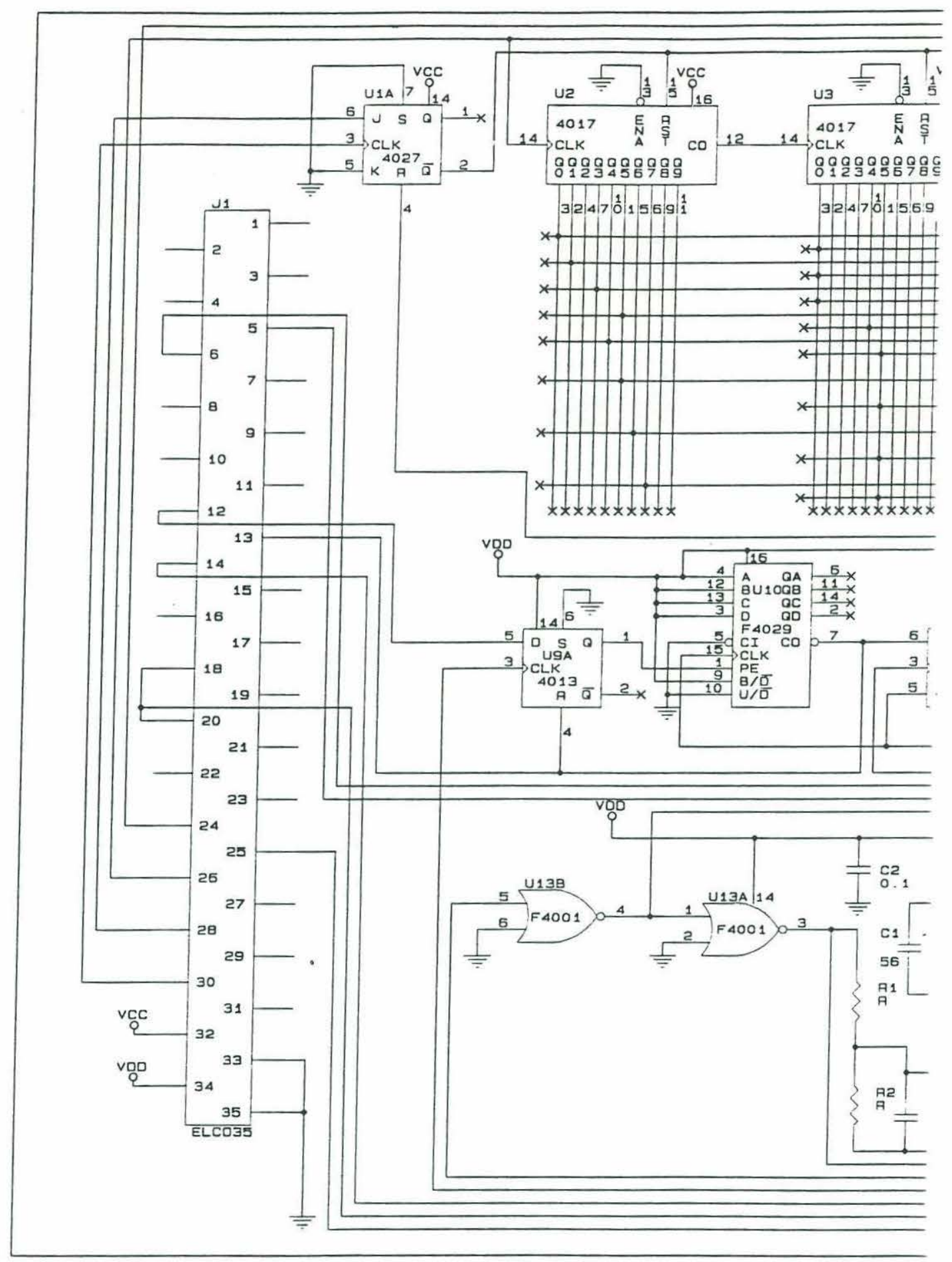

Figure B-1. Left half of timing and burst generator schematic 


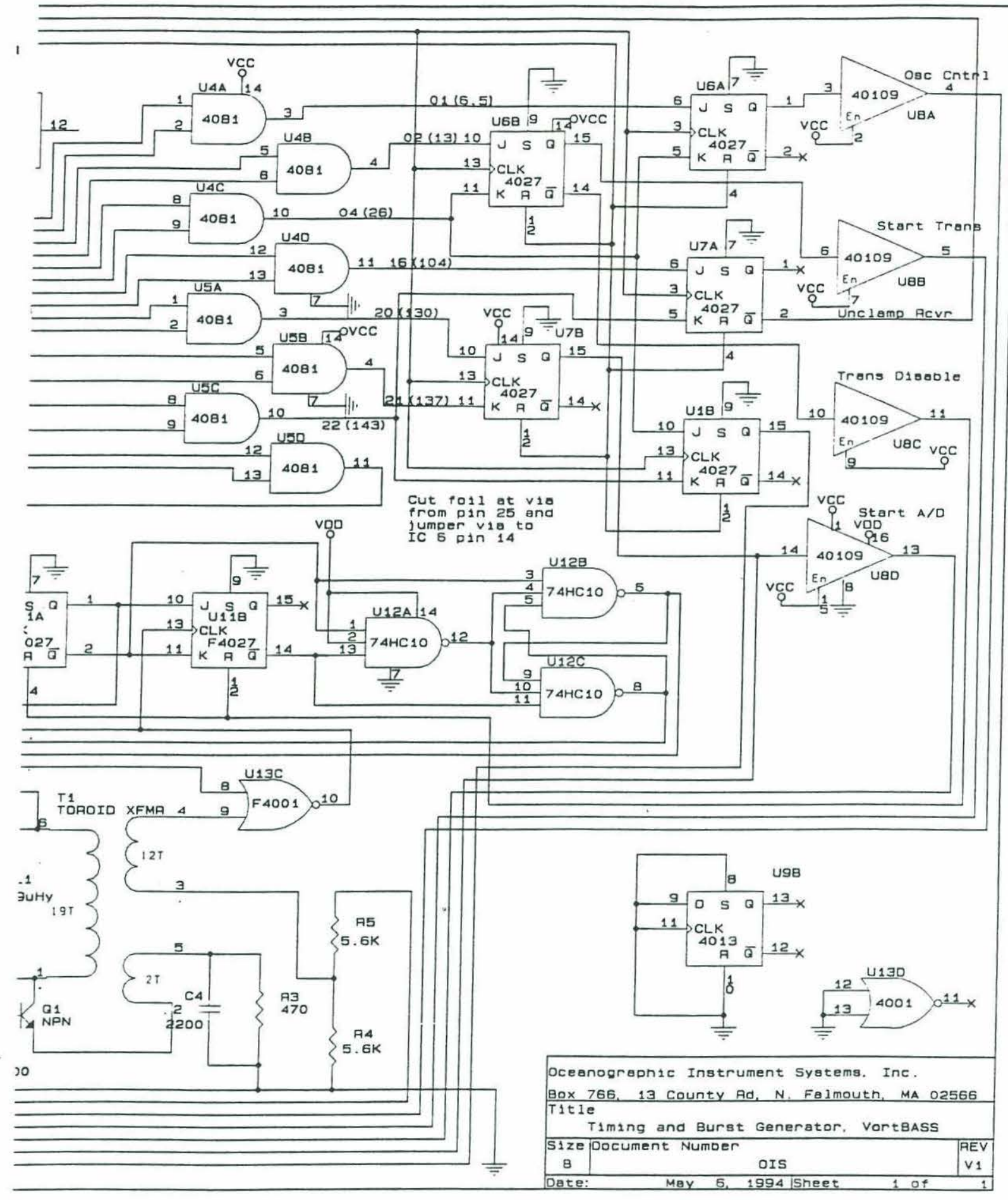

Figure B-2. Right half of timing and burst generator schematic 


\begin{abstract}
APPENDIX C
Windtunnel Programs

This appendix contains the programs used with the windtunnel and pitot tube. The most interesting result of this section was the difficulty in developing useable libraries in $\mathrm{C}$ for QBasic. If similar problems are encountered, the shell command of Qbasic coupled to a stand alone executable is an excellent solution. Using the programs below, a 286 computer was capable of taking several measurements per second. Since the response time of the pitot tube was 0.5 seconds, the processing speed requirements were exceeded. If faster measurements would have been required, a 386, 486, or Pentium could do the job.
\end{abstract}


'Qbat.bat - used to load A/D Board libraries so that other libraries could be loaded later ' inside Qbasic. This was not needed in the final version of Windshl.bas

cd c:lqb45

$\mathrm{qb} / \mathrm{l} \operatorname{cio} 8$

'Windshl.bas - version of Windtun.bas used to shell to C compiled executables after 'multiple library development attempts failed

DECLARE SUB PutBaro (NowBaro AS DOUBLE, AvBaro AS DOUBLE, VarBaro AS DOUBLE, SBaro AS DOUBLE, SquareBaro AS DOUBLE, J AS INTEGER) DECLARE SUB PutTemp (NowTemp AS DOUBLE, AvTemp AS DOUBLE, VarTemp AS DOUBLE, STemp AS DOUBLE, SquareTemp AS DOUBLE, J AS INTEGER) DECLARE SUB PutWind (NowSpd AS DOUBLE, Winds() AS DOUBLE, AvSpd AS DOUBLE, VarSpd AS DOUBLE, SSpd AS DOUBLE, SquareSpd AS DOUBLE, J AS INTEGER)

DECLARE SUB Temperature (C() AS INTEGER, NowTemp AS DOUBLE) DECLARE SUB Barometer (C) AS INTEGER, NowBaro AS DOUBLE) DECLARE SUB AtoD (DG() AS DOUBLE, D() AS INTEGER, C() AS INTEGER) DECLARE SUB Initboard (D) AS INTEGER) DECLARE SUB OutNow (NowBaro AS DOUBLE, AvBaro AS DOUBLE, VarBaro AS DOUBLE, NowTemp AS DOUBLE, AvTemp AS DOUBLE, VarTemp AS DOUBLE, NowSpd AS DOUBLE, AvSpd AS DOUBLE, VarSpd AS DOUBLE) DECLARE SUB SetScreen () DECLARE SUB WindSpd (NowBaro AS DOUBLE, NowTemp AS DOUBLE, NowSpd AS DOUBLE) 


\section{'PROGRAM WINDTUN.BAS}

' This program will include interaction between the subroutines

' called Temperature and Barometer and an A/D Board. It will

' reference a C program that makes use of the MKS Barotron/270

' Signal Conditioning Package. The A/D board will be use

' $+/-5$ volts for the counts routines.

' First, initialize all variables and arrays that will be used in your pro-

' gram including the following, which are used in the CALL routines.

DIM Directions(13) AS INTEGER 'Array for parameters used by

'CIO8 subroutine CALL.(13 is the

'maximum number of parameters

'used in any mode.)

COMMON SHARED Directions() AS INTEGER 'Allow subroutine access to

'this variable.

DECLARE SUB CIO8 (MD\%, BYVAL DUMMY\%, F\%) 'Declare subroutine and pass

'required parameters.

$\mathrm{F} \%=0$

'Set error flag to 0 .

ON KEY(2) GOSUB Stops

CONST ADchns $=4$

CONST SIZE $=\mathrm{ADchns}+1$

CONST SIZE $1=1200$

CONST VoltsToPU $=-9$

CONST bcoef $0=899.94$ 
CONST bcoef $1=.03663003 \#$

CONST $\operatorname{rcoef} 0=-242.8382$

CONST rcoef $1=2.275128$

CONST rcoef $2=.001879644 \#$

CONST rcoef $3=-.000004554426 \#$

CONST rcoef $4=.00000001132138 \#$

CONST rcoef5 $=-8.142306 \mathrm{D}-12$

TYPE INFO

DATESTART AS STRING * 10

Timestart AS STRING * 8

END TYPE

DIM J AS INTEGER

DIM L AS INTEGER

DIM COUNTS(1 TO 13) AS INTEGER

DIM Dataget(1 TO SIZE) AS DOUBLE

DIM NowTemp AS DOUBLE

DIM AvTemp AS DOUBLE

DIM VarTemp AS DOUBLE

DIM STemp AS DOUBLE

DIM SquareTemp AS DOUBLE

DIM NowBaro AS DOUBLE

DIM SBaro AS DOUBLE

DIM SquareBaro AS DOUBLE

DIM AvBaro AS DOUBLE

DIM VarBaro AS DOUBLE

DIM Winds(1 TO SIZE1) AS DOUBLE

DIM NowSpd AS DOUBLE

DIM SSpd AS DOUBLE 
DIM SquareSpd AS DOUBLE

DIM AvSpd AS DOUBLE

DIM VarSpd AS DOUBLE

DIM HellfreezesOver AS STRING * 5

$1 * * * * * * * * * * * * * *$ MAIN $* * * * * * * * * * * * * * * * * * * * * * * * * * * * * * * * * * * * * * * * *$

KEY(2) ON

$\mathrm{J}=0$

CLS

HellfreezesOver $=$ "False"

CALL Initboard(Directions())

CALL SetScreen

SHELL "mainmks.exe"

Timestart $=$ TIMER

LOCATE 21,2

PRINT "Getting first 10 seconds of data: "

DO

CALL AtoD(Dataget(), Directions(), COUNTS())

CALL Temperature(COUNTS(), NowTemp)

CALL Barometer(COUNTS(), NowBaro)

$\mathrm{J}=\mathrm{J}+1$

CALL PutBaro(NowBaro, AvBaro, VarBaro, SBaro, SquareBaro, J)

CALL PutTemp(NowTemp, AvTemp, VarTemp, STemp, SquareTemp, J)

Countup $=$ TIMER - Timestart

LOCATE 21, 35

PRINT STR\$(10 - Countup)

LOOP UNTIL Countup $>=10$ 
LOCATE 21,2

PRINT "

DO

SHELL "pitotram.exe"

CALL AtoD(Dataget(), Directions(), COUNTS())

CALL Temperature(COUNTS(), NowTemp)

CALL Barometer(COUNTS(), NowBaro)

$\mathrm{J}=\mathrm{J}+1$

$\mathrm{L}=\mathrm{L}+1$

CALL PutBaro(NowBaro, AvBaro, VarBaro, SBaro, SquareBaro, J)

CALL PutTemp(NowTemp, AvTemp, VarTemp, STemp, SquareTemp, J)

CALL WindSpd(AvBaro, AvTemp, NowSpd)

CALL PutWind(NowSpd, Winds(), AvSpd, VarSpd, SSpd, SquareSpd, L)

CALL OutNow(NowBaro, AvBaro, VarBaro, NowTemp, AvTemp, VarTemp, NowSpd, AvSpd, VarSpd)

LOOP UNTIL HellfreezesOver = "True"

\section{Stops:}

KEY(2) OFF

STOP

END 'Main

SUB AtoD (DG) AS DOUBLE, D() AS INTEGER, C() AS INTEGER)

$\mathrm{MD} \%=4$

FOR I\% $=1$ TO ADchns

CALL CIO8(MD\%, VARPTR(D(0)), F\%) 'Call the subroutine

$\mathrm{DG}(\mathrm{I} \%)=\mathrm{D}(0) / 2048 * 5$

$\mathrm{C}(\mathrm{I} \%)=\mathrm{D}(0)$

NEXT I\% 
SUB Barometer (C) AS INTEGER, NowBaro AS DOUBLE)

BCOUNTS $=\mathrm{C}(1)+2048$

IF BCOUNTS $<1$ THEN

BCOUNTS $=1$

ELSEIF BCOUNTS $>4095$ THEN

BCOUNTS $=4095$

END IF

'The counts values are converted to Barometric Pressure

NowBaro $=$ bcoef $0+$ bcoef $1 *$ BCOUNTS

END SUB 'Barometer

SUB Initboard (D() AS INTEGER)

' $\quad$ Initialize CIO-DAS08 using Mode 0

' Define the variables for MODE (MD\%), Base Address (D\%(0)) and Range

' (D\%(1)) selected for the CIO-DAS08 and the BUS speed (D\%(2)) of your PC.

' The Base Address is determined by the DIP switch on the CIO-DAS08.

' The Range is selected by another DIP switch on the CIO-DAS08.

' The BUS speed can be determined by using the program called PCLK.EXE that

' is included with these example programs.
$\mathrm{MD} \%=0$
'Set MODE to 0 (initialize CIO-DAS08)
$\mathrm{D}(0)=\& \mathrm{H} 330$
'Address as shipped from factory. 
'340 Hex (832 decimal)

$\mathrm{D}(1)=0$
$\mathrm{D}(2)=31$

'A/D range 0 to $10 \mathrm{VDC}$.

'Set the time constant for the PCLK

'31 is typical for an AT type computer

'(30 $=6 \mathrm{MHz}$ bus $)$.

'This variable is used by Mode 50

'and 51.

CALL CIO8(MD\%, VARPTR(D(0)), F\%) 'Call the subroutine

IF F\% $<>0$ THEN

PRINT "Initialization Error"

STOP

END IF

' The CIO-DAS08 is now initialized. Other modes may now be run.

' Set upper and lower scan limits of the CIO-DAS08 using Mode 1.

' Define the variables for MODE (MD\%), Lower Scan Limit (D\%(0)) and Upper

' Scan Limit (D\%(1)) that you wish to select for the CIO-DAS08. This

' example will scan all channels $(0-1)$.

$\mathrm{MD} \%=1$

'Set MODE to 1 (Mode to set MUX up)

$\mathrm{D}(0)=0$

'Lower scan limit

$\mathrm{D}(1)=\mathrm{ADchns}-1$

'Upper scan limit

'All channels will be read

CALL CIO8(MD\%, VARPTR(D(0)), F\%) 'Call the subroutine

IF F\% < 0 THEN

PRINT "Channel Initialization Error" 
STOP

END IF

END SUB 'Initboard

SUB OutNow (NowBaro AS DOUBLE, AvBaro AS DOUBLE, VarBaro AS DOUBLE, NowTemp AS DOUBLE, AvTemp AS DOUBLE, VarTemp AS DOUBLE, NowSpd AS

DOUBLE, AvSpd AS DOUBLE, VarSpd AS DOUBLE)

OPEN "WindOut.dat" FOR APPEND AS \#2

WRITE \#2, TIMER, NowSpd, NowBaro, NowTemp

CLOSE \#2

LOCATE 6, 65

PRINT USING "\ \"; TIME\$

LOCATE 8, 65

PRINT USING "\#\#.\#\#"; NowSpd

LOCATE 9, 65

PRINT USING "\#\#.\#\#"; AvSpd

LOCATE 10,65

PRINT USING "\#\#.\#\#"; VarSpd

LOCATE 12,65

PRINT USING "\#\#\#"; NowBaro

LOCATE 13,65

PRINT USING "\#\#\#"; AvBaro

LOCATE 14,65

PRINT USING "\#\#\#"; VarBaro

LOCATE 16, 65

PRINT USING "\#\#\#.\#\#"; NowTemp

LOCATE 17,65

PRINT USING "\#\#.\#\#"; AvTemp

LOCATE 18,65 
PRINT USING "\#\#.\#\#"; VarTemp

\section{END SUB 'OutNow}

SUB PutBaro (NowBaro AS DOUBLE, AvBaro AS DOUBLE, VarBaro AS DOUBLE, SBaro AS DOUBLE, SquareBaro AS DOUBLE, J AS INTEGER)

$$
\begin{aligned}
& \text { SBaro = SBaro + NowBaro } \\
& \text { SquareBaro = SquareBaro + NowBaro * NowBaro } \\
& \text { AvBaro = SBaro } / \mathrm{J} \\
& \text { VarBaro = }(\text { SquareBaro / J })-\text { AvBaro * AvBaro }
\end{aligned}
$$

END SUB 'PutBaro

SUB PutTemp (NowTemp AS DOUBLE, AvTemp AS DOUBLE, VarTemp AS

DOUBLE, STemp AS DOUBLE, SquareTemp AS DOUBLE, J AS INTEGER)

$$
\begin{aligned}
& \text { STemp }=\text { STemp }+ \text { NowTemp } \\
& \text { SquareTemp }=\text { SquareTemp }+ \text { NowTemp * NowTemp } \\
& \text { AvTemp }=\text { STemp } / \mathrm{J} \\
& \text { VarTemp }=(\text { SquareTemp } / \mathrm{J})-\text { AvTemp * AvTemp }
\end{aligned}
$$

END SUB 'PutTemp

SUB PutWind (NowSpd AS DOUBLE, Winds() AS DOUBLE, AvSpd AS DOUBLE, VarSpd AS DOUBLE, SSpd AS DOUBLE, SquareSpd AS DOUBLE, J AS INTEGER)

\footnotetext{
1. Winds $(J)=$ NowSpd

SSpd $=$ SSpd + NowSpd

SquareSpd $=$ SquareSpd + NowSpd $*$ NowSpd
} 
$\operatorname{AvSpd}=\operatorname{SSpd} / \mathrm{J}$

VarSpd $=($ SquareSpd $/ \mathrm{J})-$ AvSpd * AvSpd

END SUB 'PutWind

SUB SetScreen

LOCATE 4, 51

PRINT "DATE: "

LOCATE 4, 57

PRINT USING " $\backslash \backslash$ ।"; DATE\$

LOCATE 5,51

PRINT USING " Start: \ \"; TIME\$

LOCATE 6, 51

PRINT "Current Time: "

LOCATE 8, 51

PRINT "Wind Speed: $\quad \mathrm{m} / \mathrm{s}$ "

LOCATE 9, 51

PRINT "Running Mean: $\quad \mathrm{m} / \mathrm{s}$ "

LOCATE 10, 51

PRINT "Run Variance: $\quad \mathrm{m} / \mathrm{s} "$

LOCATE 12, 51

PRINT "Pressure: mBars"

LOCATE 13, 51

PRINT "Running Mean: mBars"

LOCATE 14, 51

PRINT "Run Variance: mBars"

LOCATE 16, 51

PRINT "Temperature: $\quad$ C"

LOCATE 17, 51

PRINT "Running Mean: C" 
LOCATE 18,51

PRINT "Run Variance: $\quad$ C"

END SUB 'SetScreen

SUB Temperature (C() AS INTEGER, NowTemp AS DOUBLE)

' $* * * * * * * * * * * * * * * * * *$ New Temperature Probe $* * * * * * * * * * * * * * * * * * * * * * * * * * * * * * * *$

- This Temperature Probe usually gives values between $2.7 \mathrm{~V}$ and $3.1 \mathrm{~V}$ to

' the $\mathrm{A} / \mathrm{D}$ Board. $2.7 \mathrm{~V}$ is 0 degrees $\mathrm{C} .3 .1 \mathrm{~V}$ is

NowTemp $=\mathrm{C}(2) / 2048 * 5 * 100.4-273.16$

END SUB 'Temperature

SUB WindSpd (NowBaro AS DOUBLE, NowTemp AS DOUBLE, NowSpd AS

DOUBLE)

DIM AirDens AS DOUBLE

DIM Diff AS DOUBLE

OPEN "D:Diff.tmp" FOR INPUT AS \#1

INPUT \#1, Diff

CLOSE \#1

AirDens $=.34838 *$ NowBaro $/($ NowTemp +273.15$)$

NowSpd $=16.306 *($ SQR $($ Diff $/$ AirDens $))$

END SUB 'WindSpeed 
/* MainMKS.C - version of MKSSet.CPP used to create the executable MainMKS.exe*/ /* which is used in the program Windshl.bas*/

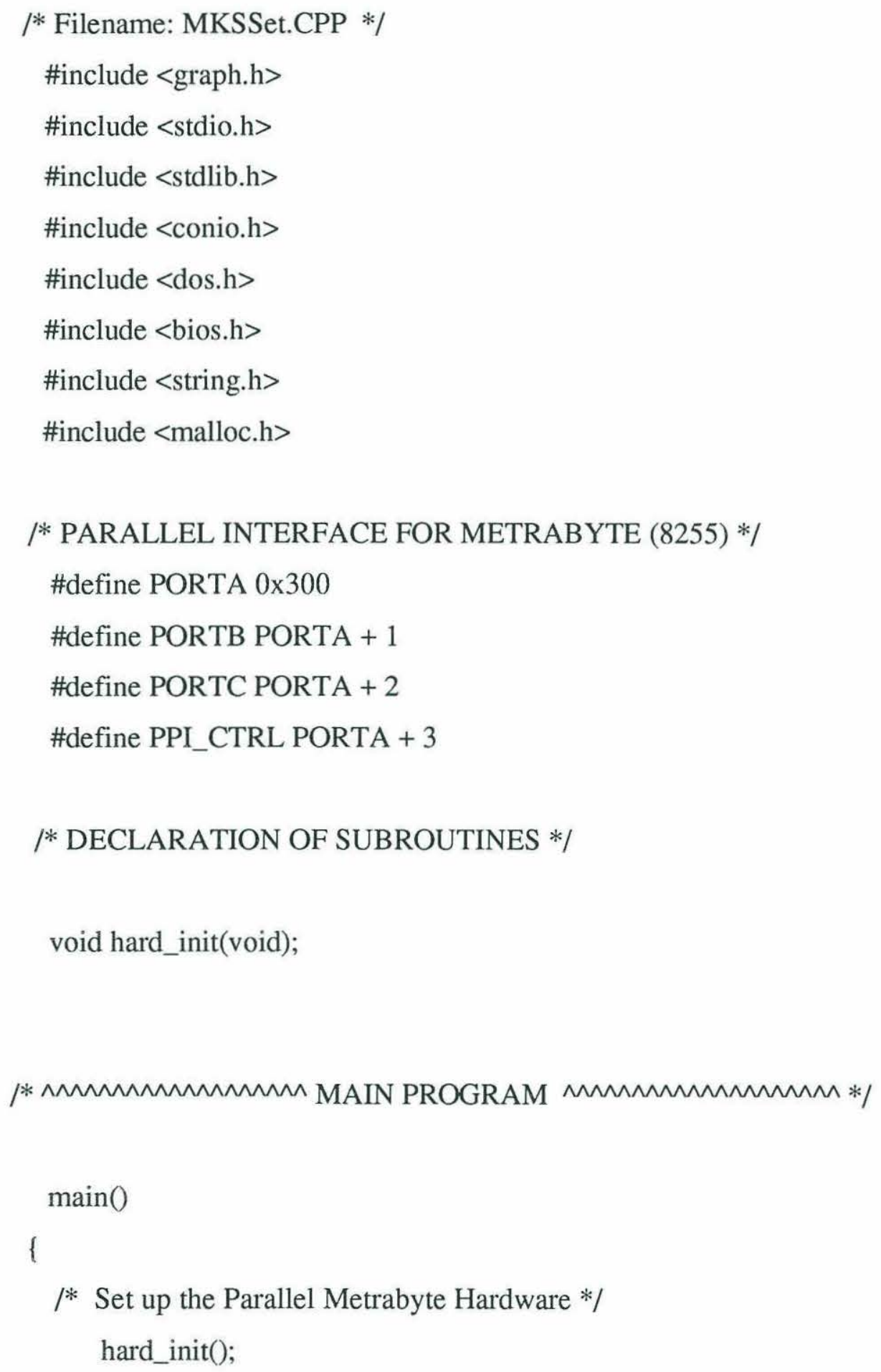


\} $\quad$ End of Main Program */

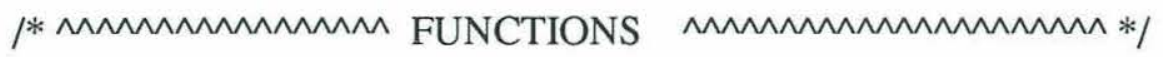

void hard_init(void)

\{

/* Set the PPI board for Port A, Port B, Port C-lower (INPUT)

and Port C-upper (OUTPUT). Control word \#11=0x93 */

outp(PPI_CTRL,0x93);

/* Release the HOLD $\backslash$ line with Port $\mathrm{C}$ bit set */

outp(PPI_CTRL,0x09);

/* Test DECIMAL OP\ line to insure MKS display unit is set right */

if (inp(PORTC) \& 0x04)

\{

/* Line is High (Decimal Point is WRONG) - warning */

printf(' $\mathrm{nDisplay}$ decimal point out of position - check MKS 270C setup. $\backslash n$ ");

/* Waits for Keystroke and then Clear Screen to Continue */

printf('vnHit Any Key When Ready`n");

getch $)$;

_clearscreen(_GCLEARSCREEN);

\}

\} $\quad I^{*}$ End of Function hard_init */

/* Pitotram.C - version of Pitot.cpp used to create the executable Pitotram.exe*/ 
/* which is used in the program Windshl.bas*/

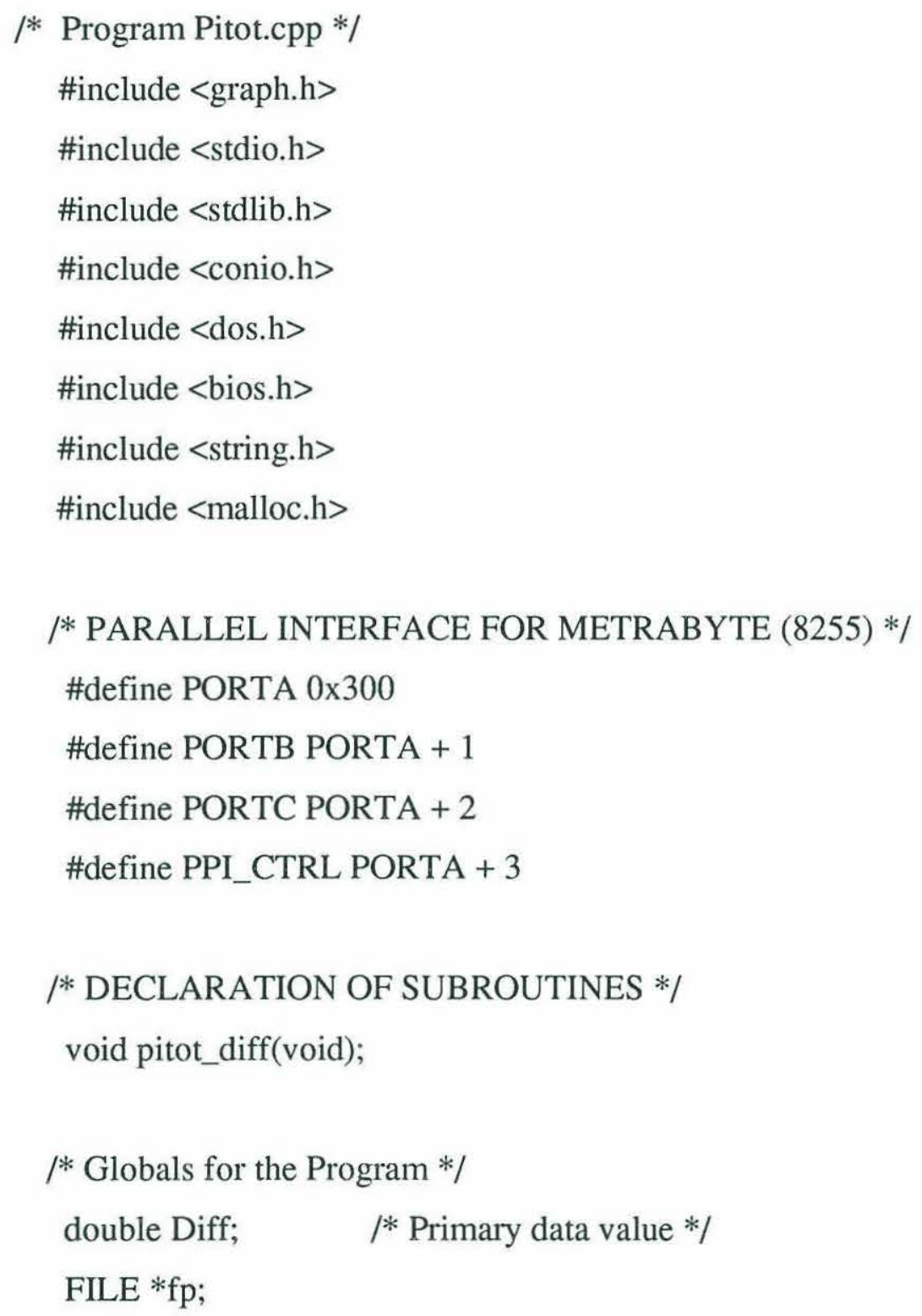


pitot_diff();

\} $/ *$ End of Main Program */

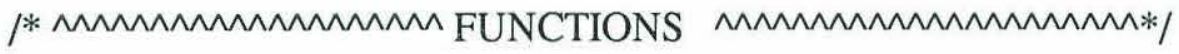

void pitot_diff(void)

\{

unsigned char msb,hi,lo;

fp= fopen("D:Wiff.tmp","w");

/* Activate the HOLD $\backslash$ line with Port $\mathrm{C}$ bit clear */

outp(PPI_CTRL,0x08);

/* Get the BCD reading from the Pitot Tube */

$\mathrm{msb}=\operatorname{inp}(\mathrm{PORTC}) \& 1$;

hi $=\operatorname{inp}(\mathrm{PORTB})$;

lo = inp(PORTA);

/* Release the HOLD $\backslash$ line with Port $\mathrm{C}$ bit set */

outp(PPI_CTRL,0x09);

Diff $=($ double $) \mathrm{msb}+($ double $) \mathrm{hi} / 100+($ double $) l \mathrm{o} / 10000$;

fprintf(fp,"\%lfn",Diff);

fclose(fp);

\} $\quad{ }^{*}$ End of Function pitot_diff */ 


\section{APPENDIX D}

TTBasic Program for BASS

The TTBasic program which follows has been modified from its usual format. The delay between measurements has been increased to two seconds by the command 'sleep $200^{\prime}$, and the program is set to read only one path of data. 
10 PRINT " Single Axis Air 7-18-95 from BigVRamC.TTB RAM" $20 \mathrm{Q}=\& H 4000 \quad$ :REM DATAFILE STARTS AT 4000 IN RAM '20 Q=\&H0143 :REM DATAFILE STARTS AT 0143 IN ROM

$100 \mathrm{X}=\& \mathrm{H} 112$

130 ASM X,JSR \&HFFE2 :REM FLUSH UART BUFFER

140 ASM X,CLR \&H11 :REM DISABLE UART

141 ASM X,LDAA \#5;STAA \&H10:REM BAUD RATE

142 ASM X,OIM \&H42,\&H1B :REM ENABLE INTS

143 ASM X,LDAA \#95;STAA \&H1C:REM GET $100 \mathrm{~Hz}$ RATE

144 ASM X,OIM \&H1B,\&H11 :REM RESTART UART

150 ASM X,RTS

160 CALL \&H112,0 :REM FLUSH UART BUFFER

200 ASM \&H9E,DB \&H00 :REM CONTROL DISABLE

202 SLEEP 0:PCLR 0,1,2,3,4,5,6,7,8,14,15:PSET 16:REM ESTABLISH DDRs

208 SLEEP 240:PCLR 16:REM LET A/D CALIBRATE FINISH IF STARTED.

210 PRINT " TYPE WAKE TO GET CONTROL $(5 \mathrm{sec}) "$

$212 \mathrm{X}=0$ : STORE $\mathrm{X}, \# 4, \& H 01010101: \mathrm{X}=0$ : ITEXT X,500

$214 \mathrm{X}=0$ : IF GET(X,\#4)<>\&H57414B45 GOTO 300

230 STOP

300 ONERR 100

' ASSEMBLY ROUTINES

$1010 \mathrm{X}=0: \mathrm{A}=0: \mathrm{B}=0: \mathrm{C}=0: \mathrm{D}=0: \mathrm{E}=0: \mathrm{F}=0: \mathrm{G}=0: \mathrm{H}=0: \mathrm{K}=0: \mathrm{L}=0: \mathrm{M}=0: \mathrm{N}=0$

1015 PRINT \#6H,A,B,C,D,E,F,G,H,K,L,M,X

1020 GOSUB 8000:REM FIRST PASS

1025 PRINT \#6H,A,B,C,D,E,F,G,H,K,L,M,X

1030 GOSUB 8000:REM SECOND PASS

1031 PRINT \#6H,A,B,C,D,E,F,G,H,K,L,M,X 
' CALIBRATE A/D

2050 SLEEP 0:PSET 15:SLEEP 600:PSET 16:REM PWR ON

2070 PCLR 15:SLEEP 240:REM A/D CALIBRATE;2,882,040 CYCLES AT 1.2288

$\mathrm{MHz}$

$2090 \mathrm{~N}=0$

3000 RTIME

$3040 \mathrm{X}=0$ :REM INITIALIZE DATAFILE

3050 STORE $X, \# 1, \&$ HEE:REM ESTABLISH STRAD AT ORIGIN

3055 STORE X,\#1,?(2):REM HOURS

3060 STORE X,\#1,?(1):REM MINUTES

3070 STORE $X, \# 1, ?(0):$ REM SECONDS

3075 STORE $X, \# 1, N$ :REM COUNT

3090 SLEEP 0

$3100 \mathrm{C}=\& \mathrm{H} 73000000+\mathrm{Q}+\mathrm{X}:$ REM MUX ADDRESS AND DATAFILE POINTER

' AB IS ADDRESS OF FLAGGED CONVERSIONS

3110 CALL A,C,X :REM CALL A/D ROUTINE,POWER LEFT ON AT END

$3111 \mathrm{X}=\mathrm{X} \%$ \&H10000-Q:REM GET BACK THE DATAFILE POINTER

' SUBTRACT ROUTINE (CALL B) EXPECTS FLAGGED DATA AT 6F38.

$3119 \mathrm{C}=\& \mathrm{H} 73000000+\mathrm{Q}+\mathrm{X}$ :REM DATAFILE LOCATION

3120 CALL B,C,X:REM CALL SUBTRACT AND TRANSFER

$3121 \mathrm{X}=\mathrm{X} \%$ \&H10000-Q:REM GET BACK THE BASIC DATAFILE POINTER

3195 SLEEP 200

$3200 \mathrm{~N}=\mathrm{N}+1$

$3210 \mathrm{X}=0$

3220 PRINT \#2H,GET(X,\#1)

3230 PRINT \#02,GET(X,\#1),":",GET(X,\#1),":",GET(X,\#1)," ";:REM HR:MM:SS

3240 PRINT \#02, GET(X,\#1)

3260 PRINT \#04H,GET(X,\#2) 
3270 PRINT

' 3280 PRINT $\{0,6\} ;:$ REM OUTPUT AS BINARY FOR SPEED

3300 GOTO 3000

$8000 \mathrm{X}=\& H 7300:$ REM MULTIPLEXOR LIST

8010 ASM X,DW \&H00FF;DW \&H01FF;DW \&HFFFF;DW \&HFFFF:REM ACM 1/A '8015 ASM X,DW \&H0888;DW \&H0989;DW \&H0A8A;DW \&H0B8B:REM ACM 1/A5-A8

'8020 ASM X,DW \&H20FF;DW \&H21FF;DW \&H22FF;DW \&H23FF:REM ACM 2 '8025 ASM X,DW \&H28FF;DW \&H29FF;DW \&H2AFF;DW \&H2BFF '8030 ASM X,DW \&H4000;DW \&H4100;DW \&H4200;DW \&H4300:REM ACM 3 '8035 ASM X,DW \&H4800;DW \&H4900;DW \&H4A00;DW \&H4B00 '8040 ASM X,DW \&H6000;DW \&H6100;DW \&H6200;DW \&H6300:REM ACM 4 '8045 ASM X,DW \&H6800;DW \&H6900;DW \&H6A00;DW \&H6B00 '8050 ASM X,DW \&H8000;DW \&H8100;DW \&H8200;DW \&H8300:REM ACM 5 '8060 ASM X,DW \&H8800;DW \&H8900;DW \&H8A00;DW \&H8B00 '8070 ASM X,DW \&HA000;DW \&HA100;DW \&HA200;DW \&HA300:REM ACM 6 '8080 ASM X,DW \&HA800;DW \&HA900;DW \&HAA00;DW \&HAB00 '8082 ASM X,DW \&HC000;DW \&HC100;DW \&HC200;DW \&HC300:REM ACM 7 '8084 ASM X,DW \&HC800;DW \&HC900;DW \&HCA00;DW \&HCB00 '8086 ASM X,DW \&HE000;DW \&HE100;DW \&HE200;DW \&HE300:REM ACM 8 '8088 ASM X,DW \&HE800;DW \&HE900;DW \&HEA00;DW \&HEB00 8090 ASM X,DW \&HFF00;DW \&HFF00:REM END OF LIST

$8100 \mathrm{X}=\& \mathrm{H} 3800: \mathrm{A}=\mathrm{X}: \mathrm{REM}$ A/D ROUTINE

' $\mathrm{X}$ IS POINTER TO AUX ARRAY, AB IS POINTER TO FLAGGED CONVERSION STORAGE

8105 ASM X,STD \&H7000:REM POINTER TO DATAFILE 8107 ASM X,LDD \#\&H6F38;STD \&H7002:REM POINTER TO FLAGGED CONVERSIONS 
8110 ASM X,OIM \&H04,\&H17;PSHX;LDX \#\&H0600:REM POWER ON, WAIT 5ms 8120 D=X:ASM X,DEX;BNE D;PULX:REM WAIT (4*.81us/LOOP)

8128 ASM X,SEI:REM DISABLE INTERRUPTS FOR TIMING 8150 ASM X,CLR \&H11;LDAA \#\&H10;STAA \&H10:REM DISABLE UART, SET SCI FOR

8160 ASM X,OIM 8,\&H11:REM INTERNALLY CLOCKED 8 BIT DATA RECEIVE ENABLE

'DUMMY PULSE SENT OUT TO INITIALIZE

8170 ASM X,OIM \&HAB,\&H15;AIM \&HBF,\&H15:REM DUMMY AUX LOCATION 8171 ASM X,OIM \&H80,\&H03;OIM \&H80,\&H03:REM START TIMING P27=1

8172 ASM X,AIM \&H7F,\&H03:REM REMOVE PULSE P27=0

8174 D=X:ASM X,LDAB \#\&H02;BITB \&H03;BEQ D:REM CHECK P21 FOR DONE 8179 C=X:ASM X,AIM \&H14,\&H15:REM ENTRY POINT FOR AUX,MASK PORT 5 8180 ASM X,LDAA \&H00,X;INX;INX:REM TOP OF MUX LIST,MOVE TO NEXT 8185 ASM X,ORAA \&H15;STAA \&H15:REM PUT MUX ON PORT 5 8200 ASM X,OIM \&H80,\&H03;OIM \&H80,\&H03:REM START TIMING P27=1 8210 ASM X,AIM \&H7F,\&H03:REM REMOVE PULSE P27=0

8220 D=X:ASM X,LDAB \#\&H02:REM TEST FOR DONE 8230 ASM X,BITB \&H03:REM CHECK P21 8240 ASM X,BEQ D

8250 ASM X,LDAA \&H00,X:REM GET NEXT MUX WORD 8260 ASM X,STAA \&H15:REM PUT MUX ON PORT 5 8270 ASM X,INX;INX:REM MOVE MUX POINTER TO NEXT WORD 8280 ASM X,OIM \&H80,\&H03;OIM \&H80,\&H03:REM START TIMING P27=1 8290 ASM X,AIM \&H7F,\&H03:REM REMOVE PULSE P27=0

8400 ASM X, CPX 0; CPX 0; CPX 0; CPX 0 8402 ASM X, CPX 0; CPX 0; CPX 0; CPX 0 
8403 ASM X, CPX 0; CPX 0; CPX 0; CPX 0

8404 ASM X, CPX 0; CPX 0; CPX 0; CPX 0

8410 ASM X,LDAA \&H11; LDAB \&H12:REM TRIGGER A READ

8420 ASM X, CPX 0; CPX 0; CPX 0; CPX 0:REM 16ECLOCK

8430 ASM $X$, LDAA \&H11;LDAB \&H12:REM HIGH BYTE IN B AND READ NEXT

8440 ASM X, CPX 0; CPX 0; CPX 0; CPX 0:REM 16ECLOCK

8450 ASM X, LDAA \&H12:REM LOW BYTE IN A DON'T READ NEXT

'REM FLIP THE BITS OF THE WORDS

8451 ASM X, ROLA;RORB;ROLA;RORB;ROLA;RORB;ROLA;RORB

8452 ASM X, ROLA;RORB;ROLA;RORB;ROLA;RORB;ROLA;RORB;ROLA

8480 ASM X,TIM \&H20,\&H03:REM TEST BOTH RECEIVED

8485 ASM X,BEQ G:REM BRANCH IF RECEIVED

8490 ASM X,CLRA;CLRB:REM IF NOT RECEIVED,CLEAR

$8505 \mathrm{G}=\mathrm{X}$

'PUT AWAYTO@(50) ARRAY THE FLAGGED VALUES

8510 ASM X, PSHX; LDX \&H7002; STD 0,X; INX; INX; STX \&H7002; PULX

8520 ASM X,LDAB \#\&HFF

8530 ASM X,EORB \&H00,X:REM CHECK FOR END OF LIST

'8540 ASM X,BNE D:REM LOOP IF NOT DONE

8540 ASM X, BEQ L;JMP D : L=X

8550 ASM X,LDAB \#\&H02:REM TEST FOR HOLD PULSE

$8555 \mathrm{D}=\mathrm{X}$

8560 ASM X,BITB \&H03:REM CHECK P21

8570 ASM X,BEQ D

8572 ASM X, CPX 0; CPX 0; CPX 0; CPX 0 
8573 ASM X, CPX 0; CPX 0; CPX 0; CPX 0 8574 ASM X, CPX 0; CPX 0; CPX 0; CPX 0 8575 ASM X, CPX 0; CPX 0; CPX 0; CPX 0 8580 ASM X,LDAA \&H11; LDAB \&H12:REM TRIGGER A READ 8590 ASM X, CPX 0; CPX 0; CPX 0; CPX 0:REM 16ECLOCK 8600 ASM $X$, LDAA \&H11;LDAB \&H12:REM HIGH BYTE IN B AND READ NEXT 8610 ASM X, CPX 0; CPX 0; CPX 0; CPX 0:REM 16ECLOCK 8620 ASM X, LDAA \&H12:REM LOW BYTE IN A DON'T READ NEXT 'REM FLIP THE BITS OF THE WORDS PUTS HIGH BYTE IN A, LOW BYTE IN B 8621 ASM X, ROLA;RORB;ROLA;RORB;ROLA;RORB;ROLA;RORB 8622 ASM X, ROLA;RORB;ROLA;RORB;ROLA;RORB;ROLA;RORB;ROLA

8630 ASM X,TIM \&H20,\&H03:REM TEST BOTH RECEIVED 8635 ASM X,BEQ H:REM BRANCH IF RECEIVED 8645 ASM X, CLRA;CLRB:REM IF NOT RECEIVED,CLEAR $8655 \mathrm{H}=\mathrm{X}$

' FINISH PUT AWAY TO @(50) ARRAY THE FLAGGED VALUES 8680 ASM X, PSHX; LDX \&H7002; STD 0,X; INX; INX; STX \&H7002; PULX

8705 ASM X,CLR \&H11:REM DISABLE SCI 8710 ASM X,LDAA \#5;STAA \&H10:REM BAUD RATE FROM TIMER1 (\#5 GIVES 9600)

8720 ASM X,OIM \&H42,\&H1B:REM ENABLE TIMER2 INTS AND E/128 8730 ASM X,LDAA \#95;STAA \&H1C:REM TIMER COUNT TO GET $100 \mathrm{~Hz}$ 8740 ASM X,OIM \&H02,\&H11:REM 02 RESTART UART NO RECEIVE ' reconf uart, ENABLE IT, power off (PHYSICALLY ENABLE IT) 8748 ASM X,CLI:REM CLEAR INTERRUPT MASK 
8750 ASM X,AIM \&H14,\&H15:REM PUT MULTIPLEXORS ON PARK 8760 ASM X,AIM \&HFA,\&H17:REM P60,P62=0,AUX \& POWER OFF 8775 ASM X,LDD \&H7000:REM NO AUX VALUES STORED 8780 ASM X,RTS

$9100 \mathrm{~B}=\mathrm{X}$ :REM SUBTRACT AND TRANSFER SUBROUTINE USING STRMEM ' POINTERS: $m(7000)=$ DATA ARRAY POINTER $($ NOT UPDATED WITH STRMEM)

1 $\mathrm{m}(7002)=$ FLAGGED AXIS PAIRS STORAGE

' $\quad 6$ F38 IS @(50) IN RAM MUST BE SAME AS A/D ROUTINE

' $\mathrm{m}(\mathrm{X})=$ AUX LIST FOR END OF LIST CHECKING. PASSED IN $\mathrm{X}$

'9110 ASM X, STD \&H7000

9115 ASM X, LDD \#\&H6F38; STD \&H7002

$9120 \mathrm{~K}=\mathrm{X}$ : ASM X,PSHX;LDX \&H7002;LDD 0,X;INX;INX:REM GET WORD

9140 ASM X,BEQ F:REM TEST FLAG ON NORMAL MEAS

9150 ASM X,SUBD 0,X:REM DOUBLE SUBTRACT

9152 ASM X,RORA;RORB:REM SHIFT RIGHT WITH CARRY = DIVIDE BY TWO

9160 ASM X,TST 0,X:REM TEST FLAG ON REVERSED MEAS

9170 ASM X,BEQ F

9200 D=X:ASM X,INX;INX;STX \&H7002;PULX:REM MOVE ON TO NEXT PAIR

9203 REM ' SAVE RESULT TO DATAFILE WITH STRMEM

'9205 ASM X,PSHX;LDX \&H7000;STD 0,X;INX;INX;STX \&H7000;PULX

9205 ASM X,PSHB;JSR \&HFFD3;PULA;JSR \&HFFD3 
' CHECK FOR END OF LIST. AUX LIST= FOUR BYTES / AXIS

9240 ASM X,INX;INX;INX;INX

9250 ASM X,LDAB \#\&HFF:REM CHECK FOR END OF LIST

9255 ASM X,EORB \&H00,X

9260 ASM X,BNE K:REM LOOP IF NOT DONE

'9265 ASM X,LDD \&H7000:REM LOAD DATAFILE POINTER FOR RETURN

9270 ASM X,RTS:REM EXIT

$9275 \mathrm{~F}=\mathrm{X}$

'REM FLAG MISSED

9280 ASM X,LDD \#\&H8000

9290 ASM X,BRA D

9900 RETURN

9999 END 


\section{APPENDIX E}

Specifications of Manufacturer for E-188/220

This appendix contains the manufacture's specifications for the E-188/220 transducer produced by Massa Products. The agreement that was produced between these specifications and the results from the HP4195A spectrum analyzer was outstanding. The measurements of four different E-188/220 transducers using the HP4195A produced good agreement between the transducers and the specifications. 


\section{Model E-188}

\section{Specifications}

\section{Frequencyat}

Receiving

Sensitivity

Bandwidth

(Transmitting)

Transmitting

Sensitivity

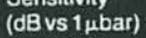

pervoltat.

1 foot)

Receiving

Sensitivity

(dBvs 1 volt/ubar)

Driving Voltage

( $10 \%$ duty cycle)

Nominal Impedence

TotalBeam Angle

$(-3 \mathrm{~dB})$ Conical

Operating

Temperature

Humidity

Weight
E-188/215 E-188/220

$215 \mathrm{kHz} \quad 220 \mathrm{kHz}$ $\pm 2.5 \mathrm{kHz} \quad=2.5 \mathrm{kHz}$

$25 \mathrm{kHz} \quad 25 \mathrm{kHz}$

$+20$

$+20$

$-77$

$50 \mathrm{Vp}-\mathrm{p}$

$-77$

50 V $p-p \quad 50 \vee p-p$

$1000 \Omega 2 \quad 1000 \Omega$

$10^{\circ}$

$10^{\circ}$

$0.70^{\circ} \mathrm{C} \quad 0.70^{\circ} \mathrm{C}$

$0-90 \%$ Non-condensing

10 grams 10 grams

\section{时划}

Massa Praducts

Corporation

280 Lincoln Street

Hingham, Massachusetts 02043

Tel: $617-749-4800$

TWX: 710-348-6932

\section{OUTLINE DIMENSIONS}

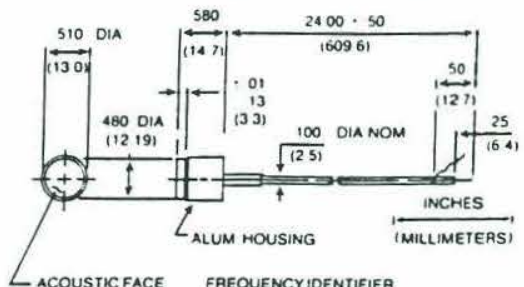

ENCYIDENTIFIER

WHITE DOT $215 \mathrm{kHz} \cdot 2 \mathrm{kHz}$
BAOWNDOT $220 \mathrm{kHz} \cdot 2 \mathrm{kHz}$

TRANSMITTING RESPONSE

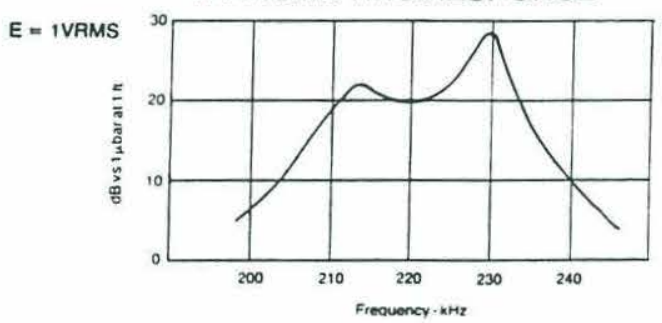

RECEIVING RESPONSE

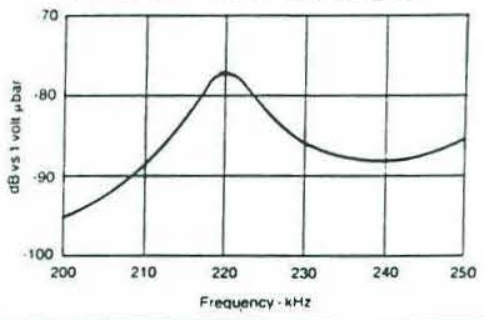

IMPEDANCE

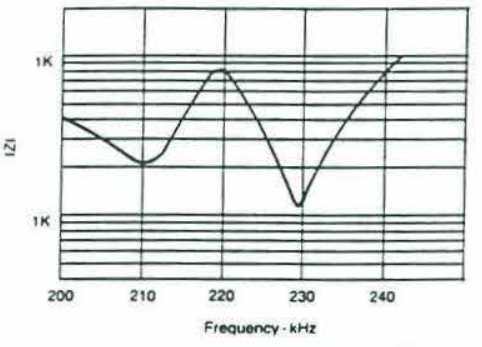

DIRECTIONAL RESPONSE

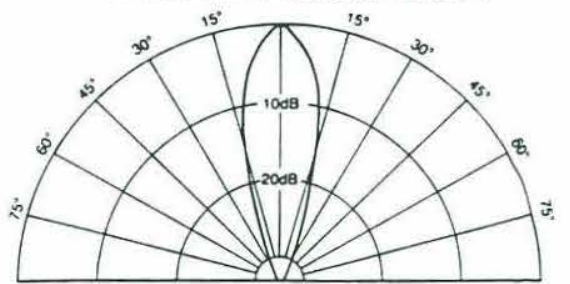

Figure E-1. Massa Products' specifications for E-188/220 